\title{
A Sustainable Approach for Optimal Steel Sheet Pile Structure Assessment, Maintenance, and Rehabilitation
}

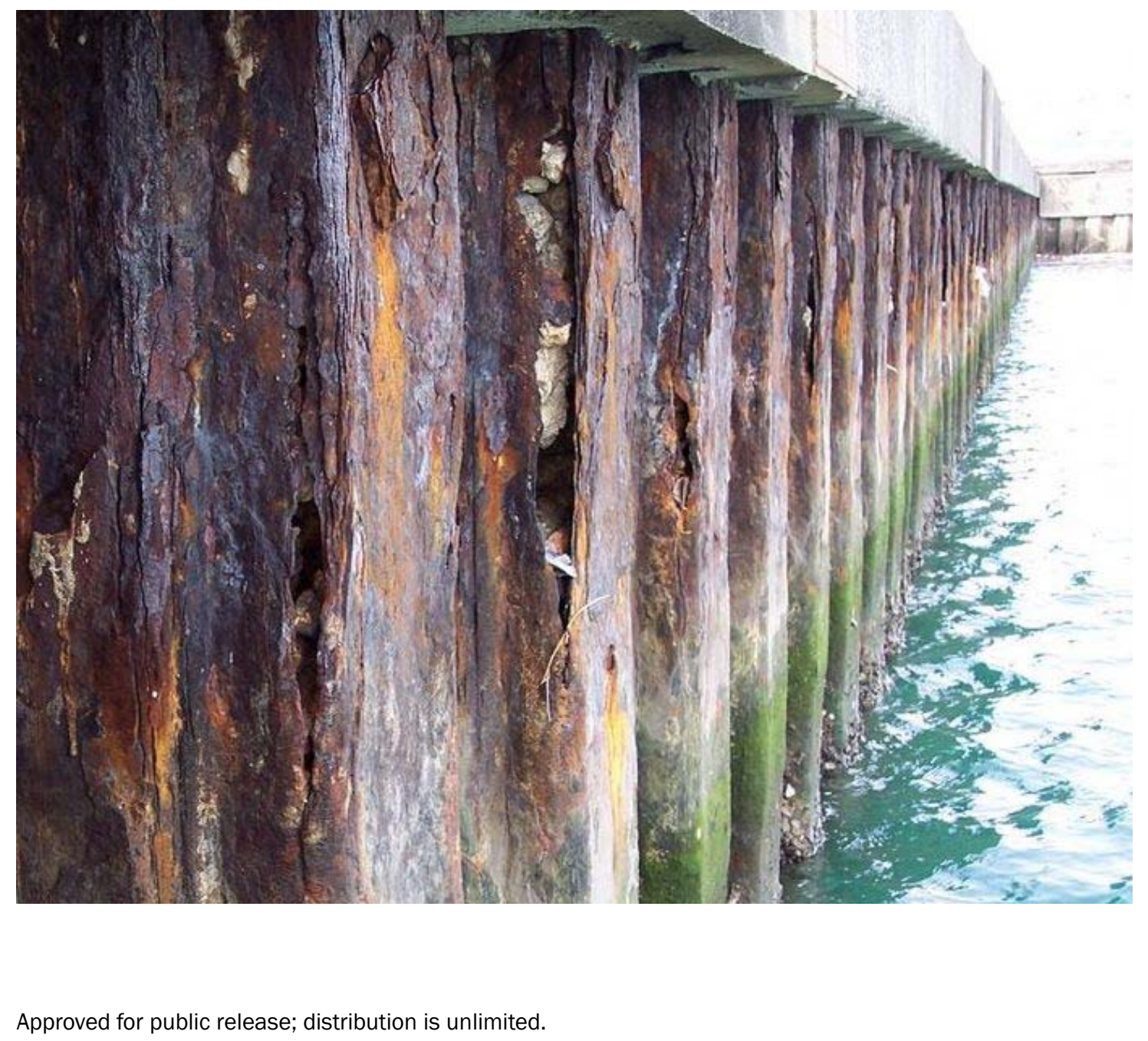





\title{
A Sustainable Approach for Optimal Steel Sheet Pile Structure Assessment, Maintenance, and Rehabilitation
}

\author{
Kevin L. Rens, Ph.D., P.E. \\ Rens Engineering \\ 585 St. Andrews Lane \\ Louisville, CO 80027 \\ Rui Liu, Ph.D. \\ Department of Civil Engineering \\ University of Colorado Denver \\ PO Box 173364 \\ Denver, CO 80217 \\ Stuart Foltz \\ Construction Engineering Research Laboratory \\ U.S. Army Engineer Research and Development Center \\ 2902 Newmark Drive \\ Champaign, IL 61822
}

Final report

Approved for public release; distribution is unlimited.

\author{
Prepared for Headquarters \\ U.S. Army Corps of Engineers \\ 441 G Street NW \\ Washington, DC 20314-1000
}




\section{Abstract}

The U.S. Army Corps of Engineers (USACE) has constructed a wide variety of civil works structures. Due to age and other factors, many of these structures have deteriorated to a point that they need varying levels of maintenance and repair (M\&R). Steel sheet pile (SSP) structures are part of the USACE civilian projects such as lock and dam and other navigation facilities. Failure of a SSP wall or cell can significantly affect the operations of a lock and dam or general river navigation. An improved SSP inspection procedure is proposed, to couple previously developed field inspection condition index (CI) methodology with reliability assessments and to quantify the life-cycle costs and environmental impacts associated with various M\&R scenarios. M\&R strategies over the analysis period are determined through reliability assessment for structures with relatively low CI (structures in CI Zone 2 and Zone 3). The level of failure would then be determined by the life cycle cost analysis (LCCA) and environmental life cycle assessment (LCA) of M\&R alternatives. Using these methodologies, specific USACE districts will gain improved capabilities to monitor the current conditions of SSP infrastructure and to identify the prioritized structures requiring sustainable M\&R.

DISCLAIMER: The contents of this report are not to be used for advertising, publication, or promotional purposes. Citation of trade names does not constitute an official endorsement or approval of the use of such commercial products. All product names and trademarks cited are the property of their respective owners. The findings of this report are not to be construed as an official Department of the Army position unless so designated by other authorized documents. 


\section{Table of Contents}

Abstract .............................................................................................................................. if

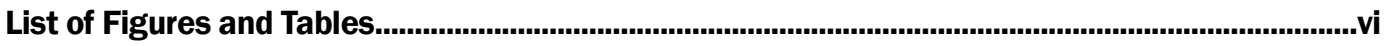

Preface ....................................................................................................................................... viii

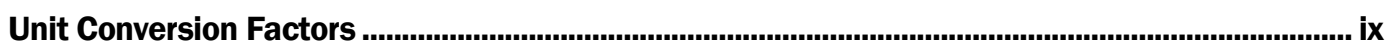

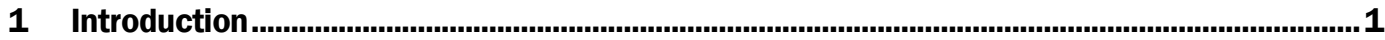

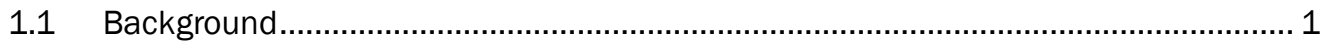

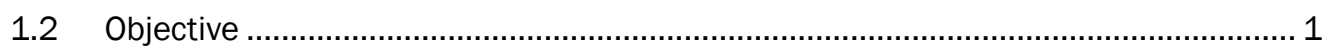

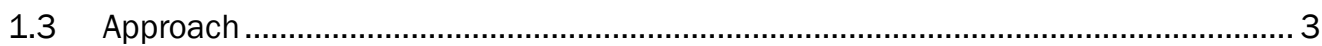

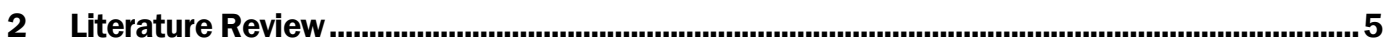

2.1 Infrastructure management............................................................................. 5

2.2 System for inspection and rating..................................................................... 7

2.3 Development of the condition index.................................................................... 8

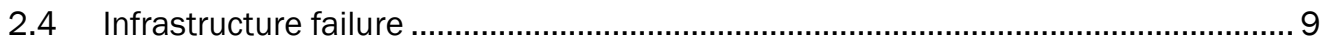

3 Condition Index Methodology ....................................................................................12

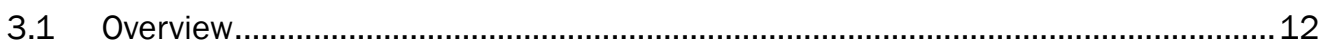

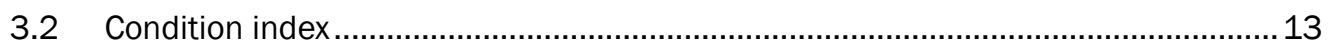

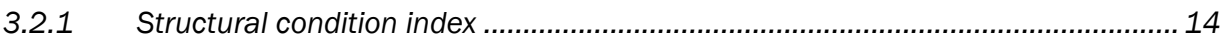

3.2.2 Functional condition index ............................................................................. 15

3.3 Principles and methods of life-cycle cost analysis ................................................ 17

3.4 LCCA of USACE's public works ............................................................................ 19

3.5 Applications of LCCA to other infrastructures ................................................... 19

3.5.1 Pavement construction.................................................................................... 19

3.5.2 Water and sewer mains ..................................................................................... 21

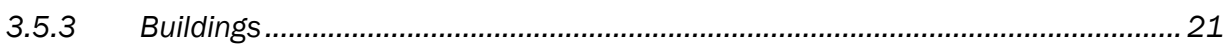

3.5.4 Summary of LCCA applications ..................................................................... 21

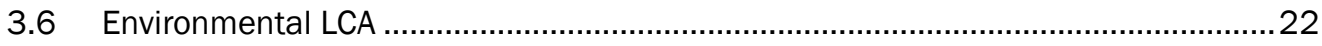

4 Sustainable M\&R Procedure for SSP Structures ..............................................................24

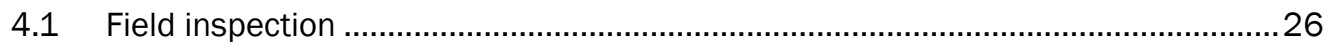

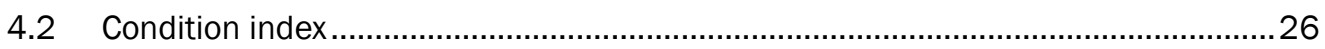

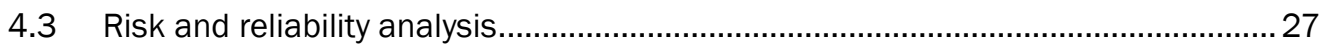




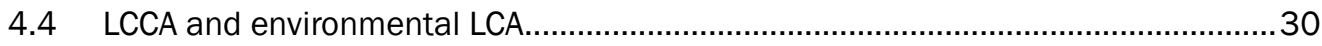

5 Risk and Reliability Assessment of Steel Sheet Pile .........................................................32

5.1 Reliability index of SSP structures................................................................. 32

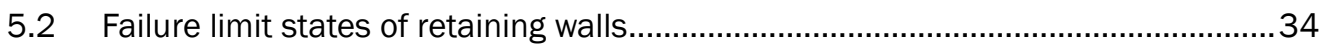

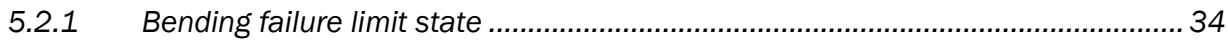

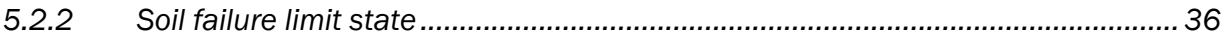

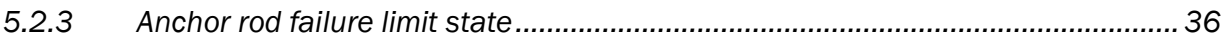

5.3 Failure limit states of cellular structures............................................................. 37

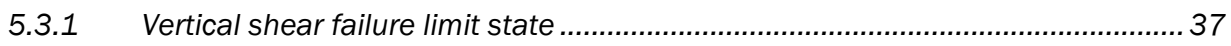

5.3.2 Sliding on foundation failure limit state............................................................. 39

5.3.3 Bursting of cells failure limit state ...................................................................... 39

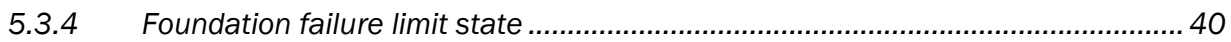

5.4 Hasofer-Lind reliability index............................................................................. 40

5.4.1 Linear limit state functions............................................................................. 40

5.4.2 Nonlinear limit state functions ...................................................................... 41

5.5 Updating the reliability of SSP structures using visual inspection

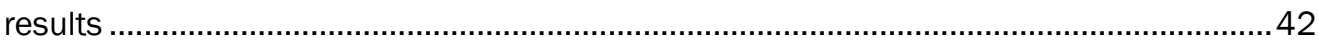

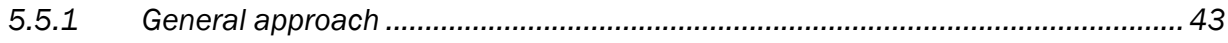

5.5.2 Condition state definition for corrosion updating ............................................... 43

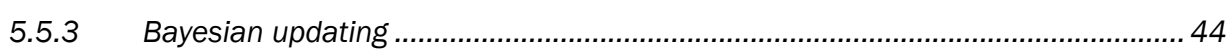

5.6 Time-dependent reliability index profile ........................................................... 45

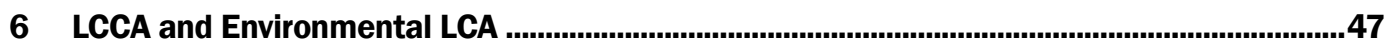

6.1 Principles and methods of LCCA for SSP structures .......................................... 47

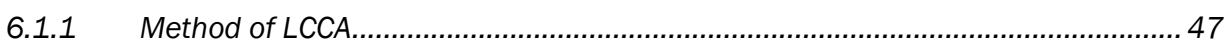

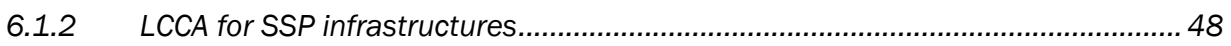

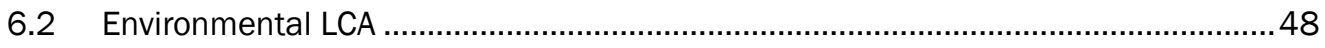

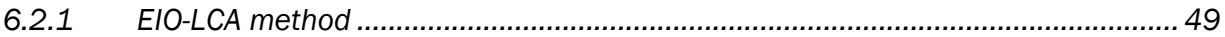

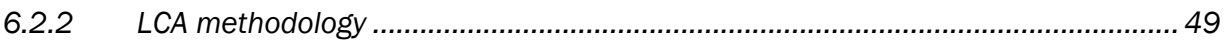

7 Case Study Examples

7.1 Example SSP retaining wall (modified from Asker 1988; Greimann et al. 1990b) . .54

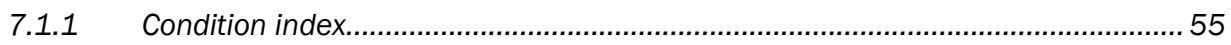

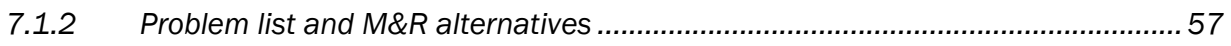

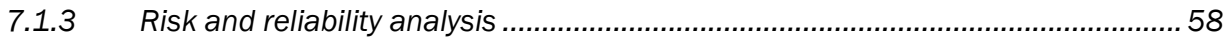

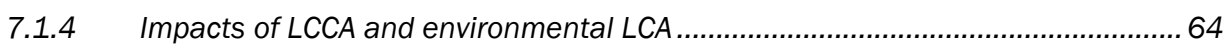

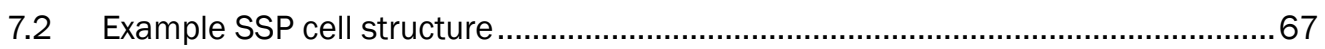




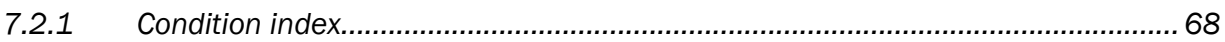

7.2.2 Problem list and M\&R alternatives .................................................................. 71

7.2.3 Risk and reliability analysis ................................................................................ 72

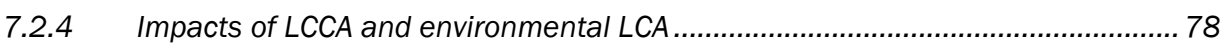

8 Conclusion and Recommendations for Further Study .......................................................81

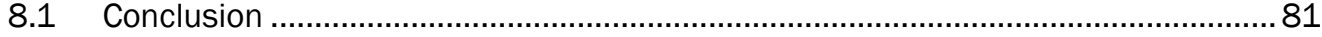

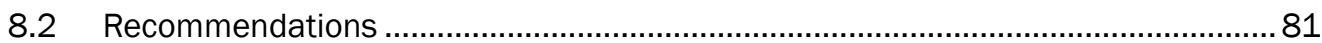

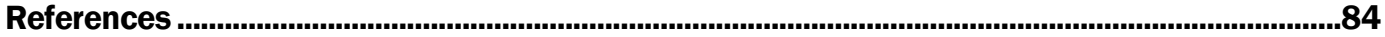

Appendix A: Proposal for Uncertainties Development for Time-Dependent

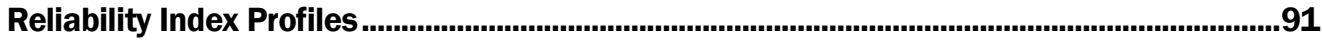

Report Documentation Page .....................................................................................................96 


\section{List of Figures and Tables}

\section{Figures}

Figure 1. Schematic of historic inspection, maintenance, and repair analysis of steel sheet pile.

Figure 2. Proposed inspection, maintenance, and repair procedure for SSP

structures.

Figure 3. Failure modes for retaining walls (adapted from Asker 1988).

Figure 4. Failure modes for cellular structures (adapted from Asker 1988)

Figure 5. Reliability index profile of an infrastructure with M\&R (adapted from

Frangopol et al. 2001). .46

Figure 6. Cantilever wall in cohesive soil (adapted from Asker 1988).

Figure 7. Time-dependent reliability index profiles.

Figure 8. Single cell on rock foundation: (a) plan; (b) cross section

Figure 9. Time-dependent reliability index profiles.

\section{Tables}

Table 1. 2009 report card for America's infrastructure (ASCE 2009).

Table 2. Condition index scale.

Table 3. Distresses in steel sheet pile structures (Greimann and Stecker 1990b)..........................27

Table 4. Reliability index and probability of failure.

Table 5. Conditions state definitions for corrosion levels (adapted from Estes et al.

2003)

Table 6. SSP structure flow.

Table 7. Cradle-to-cradle LCA Model for SSP structures...................................................................51

Table 8. Cl data example distresses for SSP wall example. .

Table 9. Conditions state definitions for corrosion levels (adapted from Estes et al. 2003)

Table 10. Uncertainties for the time-dependent reliability index profile.

Table 11. Cost comparison of the three alternatives.

Table 12. Cradle-to-cradle LCA model for SSP structures. ...............................................................66

Table 13. Environmental impacts of the three alternatives. ............................................................66

Table 14.Ranking of the three wall alternatives.............................................................................66

Table 15. Cl data example distresses for SSP cell example...........................................................68 
Table 16. Conditions state definitions for corrosion levels (adapted from Estes et al.

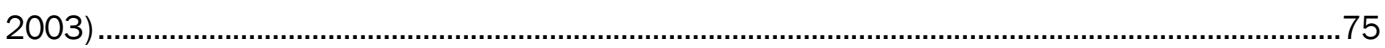

Table 17. Uncertainties for the time-dependent reliability index profile. ........................................... 77

Table 18. Cost comparison of the three alternatives. ......................................................................

Table 19 Cradle-to-cradle LCA Model for SSP structures....................................................................79

Table 20. Environmental impacts of the three alternatives. ...............................................................79

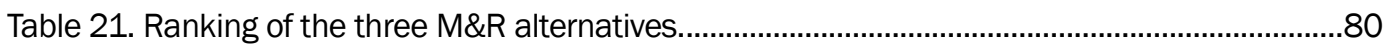




\section{Preface}

This study was conducted for Headquarters, US Army Corps of Engineers (USACE) under Project W9132T-10-P-0082. The technical monitor was Elliot Ng, Chief, Asset Management.

The work was performed under the direction of the Materials and Structures Branch (CF-M) of the Facilities Division (CF), U.S. Army Engineer Research and Development Center - Construction Engineering Research Laboratory (ERDC-CERL). At the time of publication, Vicki Van Blaricum was Chief, CEERD-CF-M; Michael Golish was Chief, CEERD-CF; and Martin J. Savoie was the Technical Director for Installations. The Deputy Director of ERDC-CERL was Dr. Kirankumar Topudurti, and the Director was Dr. Ilker Adiguzel.

COL Kevin J. Wilson was the Commander and Executive Director of ERDC, and Dr. J effery P. Holland was the Director. 


\section{Unit Conversion Factors}

\begin{tabular}{|c|c|c|}
\hline Multiply & By & To Obtain \\
\hline cubic feet & 0.02831685 & cubic meters \\
\hline cubic inches & $1.6387064 \mathrm{E}-05$ & cubic meters \\
\hline cubic yards & 0.7645549 & cubic meters \\
\hline feet & 0.3048 & meters \\
\hline foot-pounds force & 1.355818 & joules \\
\hline inches & 0.0254 & meters \\
\hline inch-pounds (force) & 0.1129848 & newton meters \\
\hline miles (U.S. statute) & $1,609.347$ & meters \\
\hline miles per hour & 0.44704 & meters per second \\
\hline mils & 0.0254 & millimeters \\
\hline pounds (force) & 4.448222 & newtons \\
\hline pounds (force) per foot & 14.59390 & newtons per meter \\
\hline pounds (force) per inch & 175.1268 & newtons per meter \\
\hline pounds (force) per square foot & 47.88026 & pascals \\
\hline pounds (force) per square inch & 6.894757 & kilopascals \\
\hline pounds (mass) & 0.45359237 & kilograms \\
\hline pounds (mass) per cubic foot & 16.01846 & kilograms per cubic meter \\
\hline pounds (mass) per cubic inch & $2.757990 \mathrm{E}+04$ & kilograms per cubic meter \\
\hline pounds (mass) per square foot & 4.882428 & kilograms per square meter \\
\hline pounds (mass) per square yard & 0.542492 & kilograms per square meter \\
\hline square feet & 0.09290304 & square meters \\
\hline square inches & $6.4516 \mathrm{E}-04$ & square meters \\
\hline square miles & $2.589998 \mathrm{E}+06$ & square meters \\
\hline square yards & 0.8361274 & square meters \\
\hline tons (force) & $8,896.443$ & newtons \\
\hline tons (force) per square foot & 95.76052 & kilopascals \\
\hline tons (long) per cubic yard & $1,328.939$ & kilograms per cubic meter \\
\hline tons ( 2,000 pounds, mass) & 907.1847 & kilograms \\
\hline tons ( 2,000 pounds, mass) per square foot & $9,764.856$ & kilograms per square meter \\
\hline yards & 0.9144 & meters \\
\hline
\end{tabular}




\section{Introduction}

\subsection{Background}

The US Army Corps of Engineers (USACE) has constructed a wide variety of civil works structures. Many of these structures have deteriorated to a point that they need varying levels of maintenance and repair (M\&R). Steel sheet pile (SSP) structures are part of the USACE civil works projects that include locks and dams, and other navigation facilities. Failure of an SSP wall or cell can significantly affect the operations of any lock and dam facility or general river navigation. The inspection and rating procedure for SSP structures has had sufficient development (Greimann and Stecker 1990a; McKay et al. 1999). However, the condition index (CI) methodology is subjective due to the selection of safety factor and some limiting geometric or numerical quantities $\left(\mathrm{X}_{\max }\right)$. The three $\mathrm{CI}$ zones were defined subjectively too. Therefore, the rating procedure needs to be modified to more accurately reflect the real condition of a deteriorated structure. A historical or classical life-cycle cost analysis (LCCA) involves comparing both the large one-time repairs and the associated greater costs to the smaller, more frequent repairs, and then analyzing the benefits and consequences. An annualized cost was calculated using LCCA in the original inspection and rating procedure. However, it was later determined that the LCCA model was too simple to be able to meaningfully compare the economic benefits of various repair options (McKay et al. 1999). Also, it is becoming increasingly common to evaluate the environmental and sustainable impacts of these decisions in addition to the classical analysis. Therefore, a methodology is also presented to estimate the life-cycle environmental impacts of SSP structures under each M\&R scenario.

\subsection{Objective}

The objective of this project is to investigate a potential methodology for evaluating the optimum M\&R* of SSP infrastructure according to its current conditions. The work was performed at a scoping level with some portions more developed than others. Where the method is developed and de-

* The focus in this report is primarily on repair and rehabilitation. 
scribed in the most detail, existing content was used from other sources. The content is primarily focused on the following:

1. Condition Evaluation: Develop an improved assessment model for USACE Districts and other owners to identify the current condition and reliability of SSP infrastructures.

2. Guideline Developments: Combine the condition information with concepts of life-cycle costs and optimal M\&R scenarios. The optimal M\&R scenario also can be selected by combination of the condition information with environmental life-cycle assessment (LCA).

3. Examples and Recommendation: Optimization of the M\&R scenarios for SSP example structures according to the LCCA and environmental LCA under various M\&Rs. Recommendations for further work are also presented.

Ideally, prioritization of M\&R expenditures should be based on minimization of risk (event probabilities and event consequences). As a scopinglevel study, this report develops event probabilities for a point in time. While it addresses current physical condition as part of a probabilistic comparison of loads and capacities, it does not develop any methods for using this information to estimate annual probabilities that would be used in a risk calculation. This is discussed further in the recommendations for further study section. Analysis of event consequences was not a part of the scope of this report.

The methods and calculations covered within this report have a level of detail that is greater than would typically be used to determine and prioritize SSP maintenance and repair needs. As such, these methods may never be implemented or used as presented. Regardless, it is important to illustrate the level of detail that can be applied to the relatively simple problem of determining optimal M\&R for SSP. Indeed, it could be made far more detailed than shown. Realistically, prioritization schemes applied across the wide variety of infrastructure within multiple business areas will almost certainly need to be significantly easier and quicker to use while maintaining enough precision to remain meaningful. Simpler schemes necessarily lack details but it is important that the value of each detail be carefully considered before it is removed from the process. In order to do this most effectively, all the details of a robust calculation should be explicitly considered. This report is a first step toward recognizing those details, for just one type of infrastructure. Much more work could be done to com- 
plete this methodology for SSP, simplify it, and then complete similar methods for other types of infrastructure.

\subsection{Approach}

The innovation in this research study is to recommend the optimal M\&R scenario for SSP infrastructure by coupling the field inspection methodology with reliability assessments to quantify life-cycle cost and environmental impacts of various M\&R consequences.

A literature review was completed as described in Chapter 2 . The inspection and rating procedure for wall and cell SSP infrastructure was reviewed including the historic CI methodology and M\&R analysis. In addition, literature in the areas of bridge, pavement, and other types of infrastructure assessment and management was also reviewed.

The field inspection CI methodology developed in Chapter 3 is coupled with reliability assessments to propose an improved SSP inspection procedure in Chapter 4, which is then used to quantify the life-cycle costs and environmental impacts associated with various M\&R scenarios. The same historical structural and functional $\mathrm{CI}$ and associated inspection procedure are employed in this proposed procedure. The $\mathrm{CI}$ is used to alert engineers to the current condition of the structure. Although the CI number is not used directly in the reliability analysis, the CI follows naturally and automatically from the field inspection and it does provide a problem list which is useful for the associated M\&R alternative consequences needed for the reliability analysis. M\&R strategies over the analysis period (from present to the end of the structure's lifetime) are determined through reliability assessment for structures with relatively low CI. It is more important to do the reliability analysis for these structures. The level of failure (i.e., level of maintenance activity) is then to be determined by the LCCA and environmental LCA of M\&R alternatives.

The failure limit states of SSP structures and the principles to assess the reliability are proposed in Chapter 5. With steel deterioration corrosion models, the condition of in-situ structures is able to be approximated and evaluated. Because the corrosion models were developed theoretically, the reliability of SSP structures is updated using visual condition index inspections. The time-dependent reliability index profile is then developed to determine the M\&R strategies over the analysis period of the structure. 
An LCA model is developed in Chapter 6 for evaluating the life-cycle costs and environmental impacts of various M\&R alternatives. The processes evaluated in this LCA include: material manufacturing, transport, construction, M\&R, and end-of-life. The optimal M\&R alternative is the one with the least cost and minimum environmental impacts. While USACE does not typically complete an environmental LCA, there may be an increased need to do so in the future (HR Wallingford 2011).

The modernized SSP structure inspection and analysis procedure is demonstrated in Chapter 7 by two example problems consisting of a wall and a cell structure. The best M\&R option was selected based on the LCA results for the economic and environmental impacts. Conclusion and recommendations are included in Chapter 8.

A future study using historical and archived SSP data is proposed in Appendix A. The M\&R procedure utilized in this report for SSP infrastructure is able to reflect, in the best possible way, the estimated condition of a deteriorated structure. The selection of the optimal M\&R alternative depends on the time-dependent reliability index profile. To construct the reliability curve depicting condition levels versus time, statistical uncertainties need to be developed by using historical and archived inspection data and M\&R records for SSP or similar hydraulic steel structures. It is proposed that the new, improved SSP M\&R procedure be applied to deteriorated SSP structures within one or several USACE districts, to test the system and to identify optimal M\&R alternatives. 


\section{Literature Review}

\subsection{Infrastructure management}

Hudson et al. (1997) defined infrastructure as the physical facilities that provide essential public service for the services listed below.

- transportation (e.g., roads, bridges, highways, rail systems, locks, waterways, ports)

- water and waste water (e.g., water supply systems, sanitary and storm sewers, sewage treatment plants)

- solid waste management (e.g., waste disposal, landfills)

- energy production and distribution (e.g., power production plants, electrical transmission network, pipelines)

- public buildings (e.g., schools, hospitals, post offices, police stations, fire houses, court houses)

- recreation (parks, sport complexes)

- communication (internet, telephone network, etc.)

Infrastructure also has been defined in many other ways:

Those physical facilities that are sometimes called public works. Public works are physical structures and facilities that.... . provide water, power, waste disposal, transportation, and similar services to facilitate the achievement of common social and economic objectives. (Grigg 1988)

Infrastructure is the basic physical and organizational structures needed for the operation of a society or enterprise, or the services and facilities necessary for an economy to function. The term typically refers to the technical structures that support a society, such as roads, water supply, sewers, power grids, telecommunications, and so forth. (Wikipedia 2010: "Infrastructure") 
The nation's infrastructure is its system of public facilities, both publicly and privately funded, which provide for the delivery of essential services and a sustained standard of living. This interdependent, yet self-contained, set of structures provides for mobility, shelter, services, and utilities. (AGCA 1982)

A society that neglects its infrastructure loses the ability to transport people and food, provide clean air and water, control disease, and connect commerce (NSF 1994).

The U.S. infrastructure construction boom during the 1950s, 1960s, and 1970s resulted in numerous projects along with advances in planning and design practices. Until the1980s, however, much of the infrastructure development did not consider maintenance, future rehabilitation/ renovation, and replacement activities in overall planning and costing. Consequently, the quality of service drops because of aging. In some cases, the resulting drop can cause structural failure and associated loss of life. This result supports the need for life-cycle analysis and ongoing, planned monitoring throughout the life cycle (Hudson et al. 1997).

Many papers and reports have been written during the past 25 years that documented the need for infrastructure maintenance and rehabilitation. A good overall summary was given by the American Society of Civil Engineers (ASCE). Table 1 shows the ASCE report card for 2009, which gives America's infrastructure an overall GPA of " $\mathrm{D}$ " and recommends a 5-year investment of $\$ 2.2$ trillion to remedy this problem (ASCE 2009).

Table 1. 2009 report card for America's infrastructure (ASCE 2009).

\begin{tabular}{|l|l|l|}
\hline Infrastructure & Grade & Note \\
\hline Aviation & D & \\
\hline Bridges & C & \\
\hline Dams & D & \\
\hline Drinking Water & D- & A = Exceptional \\
\hline Energy & D+ & B = Good \\
\hline Hazardous Waste & D & C = Mediocre \\
\hline Inland Waterways & D- & D = Poor \\
\hline Levees & D- & F = Failing \\
\hline
\end{tabular}




\begin{tabular}{|l|l|l|}
\hline Infrastructure & Grade & Note \\
\hline Public Parks and Recreation & C- & \\
\hline Rail & C- & \\
\hline Roads & D- & \\
\hline Schools & D & \\
\hline Solid Waste & C+ & \\
\hline Transit & D & \\
\hline Wastewater & D- & \\
\hline G.P.A & D & \\
\hline
\end{tabular}

\subsection{System for inspection and rating}

A procedure for inspection and rating was needed to keep engineers and operations and maintenance (O\&M) personnel in touch with the infrastructure to discover dangerous distresses that ordinarily would go unnoticed and unmeasured. The potential for structure failures often is not visible to the naked eye, but simple routinely executed measurements will point directly at a set of likely or readily identifiable causes. More often than not, such abnormalities can be addressed through routine in-house repair or readjustment, but could develop into much more serious and problematic situations if ignored (Foltz et al. 2001). Inspection history provides information for future reference and comparison. Comparisons can be made with previous inspections at the same site and with inspections and performance at other sites with similar condition. Based on a set of inspections and rating history, the rate of deterioration can be estimated, which has many potential uses in the prediction of failure for the infrastructure, M\&R planning, and the budgeting process.

One pioneering concept of performance in terms of the present serviceability index was developed in the 1960s by the American Association of State Highway and Transportation Officials (AASHTO) Road Test involving highway pavements (HRB 1962). That was followed by appraisal methods and condition rating procedures for bridges, developed in the early 1970s after the collapse of several structures: Silver Bridge in West Virginia, 1967; Buckman Bridge near J acksonville in Florida, 1970; and Chesapeake Bay Bridge in Annapolis, 1970. The concept of M\&R during the service life of pavement assets was developed in the mid-1970s (Haas et al. 1994). 
Beginning in the late 1970s, infrastructure caught the attention of the media and the public; attention grew with publication of the book America in Ruins: The Decaying Infrastructure (Choate and Walter 1981). Such attention showed that better management and financing approaches were needed. It became apparent that it was essential for available funds to be spent in a cost-effective and timely way. This funding concern led to the Intermodal Surface Transportation Efficiency Act (ISTEA) of 1991, which included six management systems for use by state-level departments of transportation: pavement, bridge, safety, congestion, transit, and intermodal. In addition, the Federal Highway Administration (FHWA) became active in supporting efforts to improve bridge management concepts by developing the National Bridge Inventory (NBI) coding guidelines (Hudson 1987; Golabi 1992).

\subsection{Development of the condition index}

At the direction of the USACE Headquarters-Civil Works Directorate, another type of infrastructure management guideline, the CI, was used to develop condition rating procedures for many components of USACE Civil Works infrastructure; its development was part of the Operations Management Problem Area of the Repair, Evaluation, Maintenance, and Rehabilitation (REMR) research program (Foltz et al. 2001). Successful operation and maintenance management systems were subsequently developed for pavement (PAVER) (Shahin and Kohn 1981), roofing (ROOFER) (Shahin et al. 1987), and others (such as RAILER and BUILDER) which then motivated the development of similar systems for a variety of Civil Works structures. The REMR research program was initiated in 1984 and completed in 1998. The primary goal of REMR was to develop affordable and simple technology that would extend the service life of the aging USACE infrastructure. Technology developed under REMR focused on concrete and steel materials, along with geotechnical, hydraulic, electrical and mechanical, environmental, and coastal types of infrastructure; it also addressed the CIs developed under operations management (Rens 1989; Greimann and Stecker 1990a, 1990b; Greimann et al. 1990a, 1990b, 1991, 1993, 1994, 1996, 1997; Stecker et al. 1993, 1997; Rens et al. 1993, 1994).

The development of CIs focused primarily on creating the inspection procedures necessary to collect the information needed for quantifying a structure's condition (Foltz et al. 2001). CI ratings are based primarily on physical deterioration as determined by distresses that can be seen or 
measured. Although the CIs can vary somewhat, they generally include: (1) an inspection procedure (all CIs except embankment dams); (2) simple measurements and visual observations (all CIs), or slightly more involved measurements (gates); and (3) a quantification of condition (all CIs) (Foltz et al. 2001; Foltz and McKay 2008).

CIs also assist in the prioritization of nonrecurring maintenance work packages in the annual USACE O\&M budget and help in defending that budget. In addition, there are a number of other current and potential benefits to the use of CIs. These benefits include (Foltz et al. 2001):

- quantification of condition for infrastructure

- identification of specific problems

- investigation of concerns

- creation of a condition history

- supporting documentation for presentation of decisions and prioritization of work

- information source for contracting scopes of work

- quantification of condition for a project or a system

- source for training tool

- data source for detailed risk analysis

- simplified estimate of reliability

\subsection{Infrastructure failure}

Failure refers to "the state or condition of not meeting a desirable or intended objective, and may be viewed as the opposite of success" (Wikipedia 2010, "Failure"). Failure of infrastructure has also been defined in many other ways, as given below.

- Some failures are "catastrophic, resulting in losses of human lives and property." (Hudson et al. 1997). Examples include bridge collapses, off-shore oil-rig disasters, foundation failures, failures of dams and dikes, corrosion-related failures, and earthquake damages.

- Leonards (1982) defined failures as "an unacceptable difference be tween expected and observed performance."

- Delatte (2009) proposed a simplified, two-part definition of design:

"1) Figure out everything that can possibly go wrong; 2) make sure it doesn't happen." Delatte calls this "failure literacy." 
- Feld and Carper (1997) defined structural engineering as "the art and science of molding materials we do not fully understand, into shapes we cannot precisely analyze, to resist forces we cannot accurately predict - all in such a way that the society at large is given no reason to suspect the extent of our ignorance." The authors quote Mencken (1949) as saying "there is always an easy solution to every human problem - neat, plausible, and wrong. Failures are complex problems; the clear, simple, and obvious answer may be incomplete or incorrect."

- Nowak and Collins (2000) said that the reliability of a structure "is often understood to equal the probability that a structure will not fail to perform its intended function." They indicate "the term failure does not necessarily mean catastrophic failure but is used to indicate that the structure does not perform as desired."

- The REMR program uses a CI to describe the conditions of USACE's civil works structures. The CI is a number between 0 and 100 that is a gauge of the physical or functional deterioration of a structure. Arbitrary ranges were assigned to identify recommended actions. A structure with a CI ranging between 0- 39 is flagged for further evaluation of needed repair, rehabilitation, or reconstruction. A structure no longer functions when its CI ranges between 0 9 (McKay et al. 1999). However, these statements of conditions and failures are defined subjectively. Because the CI is based on a combination of failure modes, it may not accurately reflect the need for M\&R or the structure's relative reliability.

The work that is the subject of this report defines failure as when the infrastructure cannot provide adequate service due to one or more of these reasons:

- The structure is structurally unsafe.

- The structure is functionally obsolete.

- The structure causes delay and inconvenience to the users due to overuse and overdemand.

- The structure has become costly to maintain and preserve.

- The structure's maintenance and repair causes excessive greenhouse gas (GHG) emission and energy consumption.

In other words, if the unsafe or functionally obsolete structure is too costly to repair or the M\&R alternatives emit too much GHG or consume too 
much energy, this structure should be replaced - i.e., the structure has failed (even though the CI of the structure might be higher than 9). A lifecycle analysis model was developed and employed in this study to compare life-cycle cost and environmental impacts of M\&R alternatives with replacement of the SSP structure.

The remaining sections of this report focus on the inspection and rating of SSP structures and also discuss the methodologies of applying LCCA and environmental LCA in the areas of bridge, pavement, and other types of infrastructure assessment and management. 


\section{Condition Index Methodology}

\subsection{Overview}

SSP structures can be categorized into several types: anchored walls, cantilevered walls, single cell walls, and multiple-cell walls. Greimann and Stecker (1989, 1990b) developed the original methodology for inspection and rating of SSP structures. This maintenance and repair analysis procedure is shown schematically in Figure 1. The physical attributes were obtained through a field inspection of the SSP structure. All data would be collected by a tape measure, a level, a string line, a camera, subjective observation (poor, average, good, excellent, etc.) and the like in the field inspection. A DOS-based computer program was developed to calculate a CI for the structure based on the inspection data. An annualized cost also was calculated using LCCA if the user provided cost and lifetime information about each solution. However, it was later determined that the LCCA model was too simple to meaningfully compare the economic benefits of various repair options (McKay et al. 1999).

In this project, the field inspection methodology developed in the early CI work is used as a reasonable procedure to obtain in-situ data. The functional CI and structural CI follow directly based on the field data obtained. In addition, CI formulates an organized distress list that is essential for the modern risk and reliability analysis proposed in this current work. 


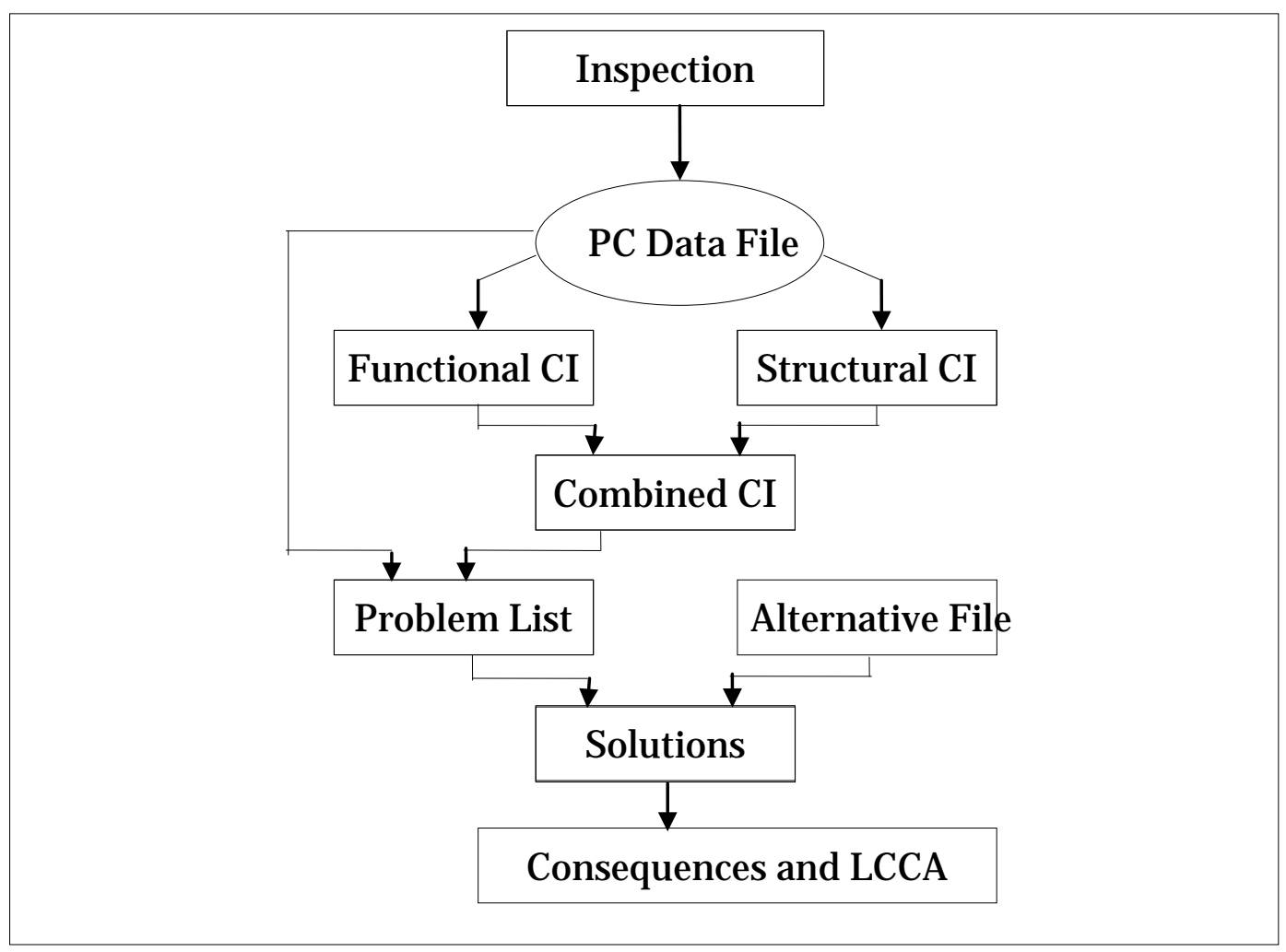

Figure 1. Schematic of historic inspection, maintenance, and repair analysis of steel sheet pile.

\subsection{Condition index}

Safety and serviceability are two general criteria for evaluating the condition of structures. The CI is a numerical scale from $0-100$, indicating a relative need to perform maintenance and/ or repair because of structural or functional deterioration of the SSP structures (Table 2). The overall CI is the minimum of structural index and functional index. If the $\mathrm{CI}$ is $70-$ 100 , immediate action is not required; if the $\mathrm{CI}$ is $40-69$, economic analysis of repair alternatives are recommended for determining appropriate maintenance action; if the $\mathrm{CI}$ is $0-39$, detailed evaluation is required to determine the need for repair, rehabilitation, or reconstruction and safety evaluation. These ranges are divided in three condition index zones, 1- 3 (Table 2). In the earlier REMR work, structures in Zone 3 were flagged and prioritized for maintenance. Accordingly, a structure no longer functions when its CI ranges between 0- 9 (McKay et al. 1999). 
Table 2. Condition index scale.

\begin{tabular}{|l|l|l|}
\hline Zone & $\begin{array}{l}\text { Condition } \\
\text { Index }\end{array}$ & Condition description \\
\hline \multirow{2}{*}{1} & $85-100$ & Excellent: No noticeable defects. Some aging or wear may be visible \\
\cline { 2 - 3 } & $70-84$ & Good: Only minor deterioration or defects are evident \\
\hline \multirow{2}{*}{2} & $55-69$ & Fair: Some deterioration or defects are evident, function not impaired \\
\cline { 2 - 3 } & $40-54$ & Marginal: Moderate deterioration. Function is still adequate \\
\hline \multirow{3}{*}{3} & $25-39$ & $\begin{array}{l}\text { Poor: Serious deterioration in at least some portions of the structure. } \\
\text { Function is inadequate. }\end{array}$ \\
\cline { 2 - 3 } & $10-24$ & Very poor: Extensive deterioration. Barely functional. \\
\cline { 2 - 3 } & $0-9$ & $\begin{array}{l}\text { Failed: No longer functions. General failure or complete failure of a major } \\
\text { structural component. }\end{array}$ \\
\hline
\end{tabular}

\subsubsection{Structural condition index}

The structural CI is to measure the safety of the structure or risk of failure of the structure. It is based on the factor of safety calculated for the structure subjected to current and extreme loading.

For anchored walls and cantilever walls, three failure modes were analyzed: pile sheet bending, anchor tension (anchored walls only), and soil failure at the toe. Three factors of safety were computed based on the equivalent beam method and vertical cantilever beam for the anchored walls and cantilever walls respectively. For the cellular structures, three different factors of safety associated with three different failure modes were considered: vertical shear on cell centerline, sliding on foundation, and bursting. The foundation failure factor of safety was also considered for cellular structures founded on consolidating clay. Asker (1988) provides a detailed analysis method for each structure type. These failures modes are reviewed in Chapter 5 for the failure limit states analyses.

The structural CI and the factor of safety were related by the following two equations:

$$
\begin{gathered}
C I=40 * F S, F S \leq 1 \\
C I=40+60\left(\frac{F S-1}{F S_{d}-1}\right), F S \geq 1
\end{gathered}
$$


where:

$\mathrm{CI}=$ condition index;

$\mathrm{FS}=$ factor of safety; and

$\mathrm{FSd}=$ design factor of safety.

The structural CI for the wall section was given by Equation 3-3, after several factors of safety were calculated for the multiple failure modes.

$$
\text { Structural } C I=100\left(\frac{C I_{1}}{100}\right)\left(\frac{C I_{2}}{100}\right)\left(\frac{C I_{3}}{100}\right) \ldots \ldots
$$

\subsubsection{Functional condition index}

Eight distresses were identified for SSP structures: misalignment, corrosion, settlement, cavity formation, interlock separation, holes, dents, and cracks. Each distress was measured by some geometric or numerical quantity (X). The functional condition index was defined by:

$$
\text { Functional } C I=100(0.4)^{X / X_{\max }}
$$

where:

$\mathrm{Xmax}=$ some limiting value of $\mathrm{X}$.

The point at which the functional $\mathrm{CI}$ is 40 was defined as $\mathrm{X}_{\max }$. Values $\mathrm{X}_{\max }$ for the eight distresses were presented in the project report (Greimann and Stecker 1990b).

When several types of distress occur, the condition indexes were combined into a single value using normalized weighting factors:

$$
W_{i}=\frac{w_{i}}{\Sigma w_{i}}(100)
$$


where:

wi $=$ the weight factor for each distress, reflecting the importance of the various distresses.

The weighting factors were presented in the project report (Greimann and Stecker 1990b).

The combined functional CI was given by:

$$
\text { Functional } C I=W_{1} C I_{1}+W_{2} C I_{2}+\ldots+W_{8} C I_{8}
$$

During field testing, it was determined that the distress's relative importance was amplified as it became more severe; a variable adjustment factor was introduced to account for this. The adjustment factor had a maximum value of 8 if a distress had a condition index less than 40 . The weighting factor of the severe distress was increased as its functional condition index approaches Zone 3. The calculation for the adjustment factor is shown below.

$$
\text { adjustment factor }= \begin{cases}8 & 0 \leq \mathrm{CI} \leq 39 \\ 8-7 \times(\mathrm{CI}-40) / 30 & 40 \leq \mathrm{CI} \leq 69 \\ 1 & 70 \leq \mathrm{CI} \leq 100\end{cases}
$$

Jiang and Rens (2010a, 2010b) adopted the CI amplification factor for the bridge health index for the City and County of Denver.

The inspection and rating procedure for SSP structures has had sufficient development. However, the CI methodology is subjective, due to the selection of safety factor and $\mathrm{X}_{\max }$. The three CI zones were defined subjectively, too. Therefore, the inspection procedure needs to be modified to reflect the real condition of a deteriorated structure. As both reliability analyses and systematic inspection programs for the world's infrastructure gain increased usage and prominence (Padula et al. 1994; USACE 1997, 2002; McAllister and Ellingwood 2000, 2002), an improved SSP inspection procedure is proposed in the following chapters. The proposed procedure couples CI field inspection methodology with risk and reliability 
assessment to quantify the LCCA and environmental LCA impacts of various M\&R scenarios. The principles and methods of LCCA and environmental LCA are reviewed next.

\subsection{Principles and methods of life-cycle cost analysis}

A modern infrastructure management system recognizes the importance of service-life analysis, including agency costs as well as non-agency costs. The LCCA can explore the possibility for more efficient investments and it is a vital component of any infrastructure management system (US Army 1986; DOI 1983; TRB 1985).

The agency costs include the following items (Hudson et al 1997;

Frangopol and Furuta 2001; NCHRP 2003).

- initial capital costs of construction

- future costs of maintenance, rehabilitation, renovation, and reconstruction

- residual value at the end of the period (based on the remaining life)

- disposal cost

- engineering and administration

- costs of borrowing (if projects are not financed from current revenue)

Non-agency costs involve the user of the infrastructure or facility, or costs that are incurred by non-users (ibid.).

- User costs include the following items.

o occupancy time in or on the facility

o operating costs (vehicles, ships, planes etc.)

0 accidents

o time delays due to maintenance, rehabilitation and repair activities 
o time delays due to under capacity

- Nonuser costs include the following items.

o environmental pollution (emissions, noise, visual, etc.)

o neighborhood disruptions

The principles of LCCA applicable to infrastructure management include the following points (Hudson 1997; Frangopol and Furuta 2001; NCHRP 2003).

- The level at which the analysis is to be made must be clearly identified.

- The economic analysis provides support for a management decision but does not alone represent a decision.

- Criteria, rules, or guides for such decisions must be separately formulated prior to the economic analysis even though such criteria may be straightforward and simple.

- The economic analysis itself has no relationship to the financing of a project.

- An economic analysis should consider as many feasible alternatives as possible within the constraints of time and other resources.

- All alternatives should be compared over the same life-cycle or time period.

- The economic analysis of infrastructure projects should include agency costs, user costs, and benefits if possible.

Methods of economic analysis can be categorized using the following methods (ibid.).

- equivalent uniform annual cost method or simply the annual cost method

- present worth method for (1) cost, (2) benefits, or (3) benefits minus costs- usually termed "the net present value method"

- rate-of-return method

- benefit-cost-ratio method

- cost-effectiveness method 
There are several basic considerations in selecting the most appropriate method for economic evaluation of alternatives. These considerations are given in the questions below (ibid.).

- How important is the initial capital expenditure in comparison to future expected expenditures?

- What method of analysis is most understandable to the decision maker?

- What method suits the requirements of the particular agency involved?

- Are measures of benefits or effectiveness to be included in the analysis?

For the current work, costs of professional and technical services, initial construction, M\&R, and salvage were chosen for agency costs. GHG emission and energy consumption were chosen as non-agency cost for environmental LCA, discussed in Section 1.7. Present worth method for cost was chosen for the economic analysis because it is straightforward and easy to understand.

\subsection{LCCA of USACE's public works}

As risk and reliability assessments gained increased usage, they have been incorporated into the LCCA for several types of infrastructure (Mori and Ellingwood 1993; Lounis and Mirza 2001; Kong and Frangopol 2004; Liu and Frangopol 2006; Petcherdchoo et al. 2008). Estes et al. (2003) updated the reliability of steel miter gates on locks and dams for USACE by using quantified visual inspection results. The time-dependent reliability function can be provided to the economists who use a probability tree of likely failure events and a cost-benefit analysis to determine if the major rehabilitation is economically justified. This procedure has not been implemented with USACE. The current research employs the reliability assessments to quantify the life-cycle costs of various M\&R alternatives, which is illustrated in the following sections and chapters.

\subsection{Applications of LCCA to other infrastructures}

\subsubsection{Pavement construction}

The concept of LCCA in pavement construction was first discussed by American Association of State Highway and Transportation Officials 
(AASHTO) "Red Book" in the 1960s (Wilde et al. 2001), but it did not appear in the federal legislation until the ISTEA of 1991. The FHWA and the World Bank have developed vehicle-operating-cost models applicable to pavement life-cycle analysis (Zaniewski 1982; Watanatada et al. 1987; Uddin 1993; Paterson 1992). The National Highway System Designation Act of 1995 further imposed a new requirement making LCCA compulsory for National Highway System (NHS) projects costing more than \$25 million. The requirement was annulled under the Transportation Equity Act (TEA) for the 21st Century in 1998, but the FHWA and AASHTO remain active in assisting the states in developing their own LCCA procedures (GPO 2001).

Petcherdchoo et al. (2008) state that the LCCA is an important part of any infrastructure management system, which is able to "assist decision makers in the process of selecting the minimum expected life-cycle cost solution, maintaining the desired levels of reliability, and serviceability of existing highways and bridges. In this manner, the limited available budgets can be put to the best possible use."

The FHWA does not prescribe specific forms for LCCA, but provides guidance to states such as publishing the "Life-Cycle Cost Analysis in Pavement Design" interim technical bulletin (FHWA 1998), the "Life-Cycle Cost Analysis Primer" (FHWA 2002), the "Economic Analysis Primer" (FHWA 2003), and by organizing workshops. The FHWA also provides the "RealCost" LCCA software with a user manual, but use of this software is at the discretion of each state. Accordingly, states apply LCCA at various levels and often use state-developed methods and tools.

Over $80 \%$ of the states complete LCCA during the pavement selection process of various projects. While all states consider initial construction and future rehabilitation costs, only $40 \%$ incorporate user costs associated with road construction activities (e.g., delay at work zone). Nonuser social costs such as environmental damage are not considered (Chan et al. 2008). State DOTs use slightly different analysis periods, pavement maintenance strategies, and discount rates as well (Wilde et al. 2001; Ozbay et al. 2004).

ERES Consultants (2003) and Ozbay et al. (2004) reported that most states do not have well-established procedures-they offer only brief instructional guidelines. The authors added that gaps exist between 
theoretical and actual LCCA applications. For example, sophisticated models to estimate user costs have been developed (Carr 2000; NJ DOT 1999), but many state DOTs use simple tabular data to estimate user costs. Uncertainty in LCCA parameters can be incorporated into LCCA by using probabilistic models (Gerke et al. 1998; FHWA 1998; Wilde et al. 2001), yet deterministic models (i.e., those that do not model risk and variability) are mostly adopted by state DOTs. Models are available that quantify and monetize the social impact of road construction including health impacts of pollutants emissions, noise, etc. (Delucchi and McCubbin 1996; Wilde et al. 2001). Nonuser social costs are seldom considered by state DOTs.

LCCA is also recognized in bridge management system development (Hudson 1987; Frangopol et al. 1997, 2001; Frangopol and Das 1999; Das 2000; Frangopol et al. 2001; Kong and Frangopol 2004; Liu and Frangopol 2006).

\subsubsection{Water and sewer mains}

Economic analysis to compare repair versus replacement M\&R alternatives for water and sewer mains has been used by agencies in many cities, such as New York City, Dallas, Texas, Washington DC, and Seattle (O'Day 1984; Steinthal 1984; Thomasson 1982). In general, replacement alternatives are more favorable when mains have deteriorated structurally and compiled a consistent record of frequent breaks.

\subsubsection{Buildings}

The National Institute of Standards and Technology (NIST) has also developed a computer program, Building Life-Cycle Cost (BLCC), and is currently involved in an international effort to standardize service life-cycle analysis procedures (AIJ 1993; BS 1992; CSA 1994; Frohnsdorff 1996). The Building Maintenance, Repair, and Replacement Database (BMDB) computer program offered by the American Society for Testing and Materials (ASTM) can be used to estimate data for building life-cycle cost analysis (ASTM 1990).

\subsubsection{Summary of LCCA applications}

LCCA is an essential part of infrastructure management. As discussed in the application of LCCA to highway and bridges, gaps exist between theoretical and actual LCCA applications. Non-agency costs (e.g., user cost; en- 
vironmental pollution) may not be omitted if good results are expected from the infrastructure management system.

\subsection{Environmental LCA}

The damage to the environment, including GHG emission, has not been considered in the M\&R for infrastructure. If the environmental impact of rehabilitation is more severe than the replacement of the structure, this indicates that one aspect of the structure does not perform as desired.

LCA is able to quantify environmental and ecosystem impacts associated with a product over its entire life cycle. The LCA approach considers all stages of a product, which include raw material acquisition, production manufacturing, transportation, installation, operation and maintenance, and ultimately, disposal, recycling and/ or waste management. If the product is disposed of in the landfill at the end of life, the LCA is "cradle-tograve". And if the product is recycled into new materials at the end of life, the LCA is "cradle-to-cradle" (Liu 2010).

LCA includes three models: process-sum LCA models, economy-wide LCA models and a hybrid LCA.

- Process-sum LCA models - Track material and energy flows, including toxics, in all stages of a product. The primary limitation of process-sum models are limits on the number of upstream processes than can be included-- thus only approximate potential environmental impacts are addressed (Reiner 2007).

- Economy-wide LCA models - These models do not require arbitrary boundaries. One model is the Economic Input-Output (EIO) model (Carnegie 2010). Input into the EIO-LCA model is economic only and the cost models are based on producer prices for the products in terms of 1997 US dollars (USD). Economic data is then linked to energy use and toxic releases associated with each industrial sector. But this model cannot evaluate individual processes, e.g., the difference on the environmental impact between the wet or dry kilning processes in cement production cannot be discerned from the overall impacts associated with concrete production. The LCA model developed for this present study will incorporate the EIO-LCA. The primary materials evaluated in this LCA include structural steel, painting, and coating used for M\&R. The processes evaluated in this type of LCA include: material 
manufacturing, transport, construction, M\&R, and end-of-life. The GHG emission and energy consumption of wall and cell SSP structures, with various M\&R scenarios over the analysis period, will also be compared.

- Hybrid LCA - The hybrid LCA combines a process-sum model for specific manufacturing processes where detailed inputs are known and economy-wide model for outputs of associated processes (e.g., transport of materials) to provide for an approximation of product impact.

There are four goals adhered to by the LCA methodology (ISO 2006).

1. Goal and scope: outlines the purpose of the study and its breadth and depth; identifies the functional unit for the study.

2. Inventory analysis: identifies and quantifies the environmental inputs and outputs associated with a product over its entire life cycle.

3. Impact assessment: characterizes inventory flows (inputs and outputs) in relation to a set of environmental and health impacts.

4. Interpretation step: combines the environmental impacts with the goals of the LCA study.

An environmental cradle-to-cradle model was created as part of this work to evaluate the GHG emission and energy consumption from the SSP structures under different M\&R strategies. The environmental impact acts as an optional criterion for the selection of the optimal M\&R alternative. 


\section{Sustainable M\&R Procedure for SSP Structures}

The overall, proposed, modernized M\&R identification and optimization procedure for SSP structures is shown in Figure 2. There are five steps in this improved approach:

Step 1: field inspection

Step 2: condition index (optional)

Step 3: risk and reliability assessment

Step 4: LCCA and environmental LCA (environmental LCA is optional) Step 5: solution

It is recommended to employ the CI methodology and especially the field inspection routine developed by Greimann and Stecker (1989, 1990b). The physical attributes can be obtained through a field inspection of the SSP structure. All data would be collected by a tape measure, a level, a string line, a camera, subjective observation (poor, average, good, excellent, etc.) and similar techniques in the field inspection. Once the field inspection is complete and the inspection data is available, the CI of the structure can be calculated automatically based on prior work (Greimann and Stecker 1990b). The field inspection and CI calculation also provide the distress list and M\&R alternatives needed for the risk and reliability analysis. The $\mathrm{CI}$ is used to inform engineers of the structures' current condition. Then, the M\&R strategies for the structures in Zone 2 and Zone 3 are to be determined through reliability assessment. The reliability analysis is based on the failure mode of the structure, which is determined by the field inspection. The reliability of the structure or the probability of failure is to be determined by the governing failure limit state function. For example, misalignment and corrosion are two identified stresses of a deteriorated structure. The misalignment and corrosion distresses are most likely related to the bending failure limit state. The reliability of the structure or the probability of failure is to be determined by the bending failure limit state function. 


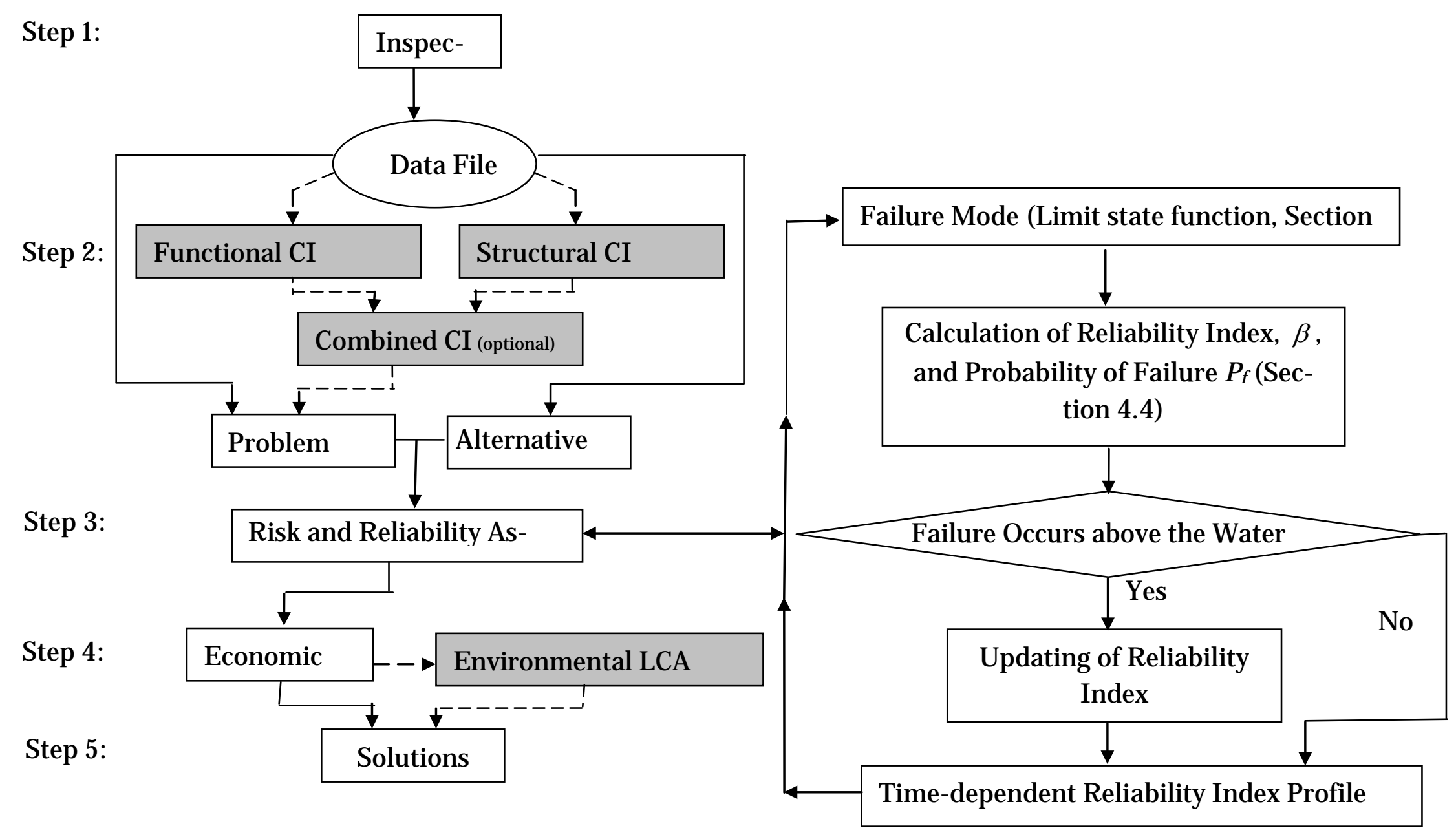

Figure 2. Proposed inspection, maintenance, and repair procedure for SSP structures. 
The reliability of a structure is usually evaluated by using the reliability index. To estimate the time-based condition of a deteriorated structure, the reliability index is calculated by incorporating a steel corrosion model. Because the model was developed experimentally, it should be updated using visual inspection results if the governing failure mode occurs above the water level. This reliability index is used to develop time-dependent reliability index profiles for various M\&R alternatives with the uncertainties calculated from historical inspection data and M\&R records. The optimal M\&R activity is then to be determined by LCCA and environmental LCA of M\&R alternatives. The five steps in Figure 2 are elaborated in the following sections and chapters.

\subsection{Field inspection}

Greimann and Stecker (1990b) developed the process of the field inspection. The inspection forms, including comment sheets, consist of 26 pages. The first two pages record the data such as the location of the structure, inspection history, historic water level, and maintenance history. Page 3A, 3B, and 3C are used to describe some of the structural details (e.g., crosssection type, soil information, and anchor configuration). Alternate pages exist for anchored or cantilever walls, single cells, and multiple cells. The loading data behind the wall and the dredge depth adjacent to the structure are recorded on Pages 4 and 5. Page 6 is used to describe distresses (e.g., corrosion, cracks, and dents) that have occurred to the structure during its lifetime. Comments on the historical information, structural components, loading and dredge lines, and distress profiles are included in the inspection forms. Pages 4, 5, and 6 also have notes on how to measure and record critical data. Finally, all pages include multiple fields of general comment sections.

\subsection{Condition index}

The rating process consists of an algorithm developed by Greimann and Stecker (1990b) and Asker (1988) to calculate the CI for the structure, based on the field inspection. Two general structural criteria for evaluating the CI are available: safety and serviceability. The minimum structural index and functional index make up the overall CI of the structure. (The CI methodology was introduced and summarized in Chapter 3.)

The CI procedure is aimed at assessing the current condition of the structure. Table 3 shows the number of distresses that may be identified for 
each structure. Greimann and Stecker (1990b) stated that each distress may have one or more causes. For example, misalignment may be caused by the sheet bending, anchor failure, or toe failure. To repair the distress, it is often desirable to know the cause. An in-depth field inspection with excavation, diving, or ultrasonic inspections may be required to accurately identify the cause.

Table 3. Distresses in steel sheet pile structures (Greimann and Stecker 1990b).

\begin{tabular}{|l|l|}
\hline Distress & Brief Description \\
\hline Misalignment & Horizontal or vertical deviation from the design alignment \\
\hline Corrosion & Loss of steel due to interaction with environment \\
\hline Settlement & Vertical movement of material behind sheet pile \\
\hline Cavity formation & Loss of fill material behind or within sheet pile \\
\hline Interlock separation & Failure of sheet interlocks \\
\hline Holes & Broad opening in sheet \\
\hline Dents & Depression in sheet without rupture \\
\hline Cracks & Narrow break in sheet \\
\hline
\end{tabular}

There is a set of possible maintenance and repair alternatives for each distress identified in Table 3. The appropriate maintenance and repair alternative depends on the cause of the problem (Greimann and Stecker 1990b). For example, to fix a misalignment problem, sections of wall could be replaced, the anchor system repaired, or the dredge line brought back to design levels and protected. To fix the corrosion distress, sections of wall could be replaced or the protective coating could be added. Several alternatives may be possible-ranging from inexpensive but short-term to complete replacement of the wall - each of which would provide various levels of remedial action for each of the distresses. Some alternatives may fix only one distress; others may fix several. A set of alternatives is collected together to form one M\&R solution. The optimum solution is the one with the least life-cycle cost and environmental impact.

\subsection{Risk and reliability analysis}

M\&R strategies for the structures with relatively low CIs over the analysis period are then to be determined through reliability assessment. Immediate actions are not required for structures with relatively high CIs. The reliability analysis is based on the failure mode of the structure, which is determined by the field inspection. The reliability of the structure or the probability of failure is to be determined by the governing failure limit 
state function. For example, consider that misalignment, corrosion, and cracks are identified as distresses of a deteriorated SSP structure. A possible cause of misalignment may be by the sheet bending. Corrosion and cracking lead to a reduced moment of inertia. Therefore the three distresses are likely related to the bending failure limit state. The reliability of the structure or the probability of failure is to be determined by the bending failure limit state function. This analysis identifies the current condition of the structure, and it can be used to develop time-dependent reliability index profile which predicts future performance of the structure over several decades and is the basis for optimum life-cycle inspection and repair planning.

Several failure modes are analyzed to calculate the structural CI (Asker 1988). The reliability analysis is based on these failure limit states. Two types of SSP structures are considered: SSP retaining walls and cellular structures. Retaining walls include cantilever walls and anchored walls. Cellular structures have cellular walls and single cells. For anchored walls and cantilever walls, three failure limit states are considered as illustrated in Figure 3: pile sheet bending, anchor tension (anchored walls only), and soil failure at toe. For the cellular structures, three failure limit states are considered as illustrated in Figure 4: vertical shear on cell centerline, sliding on foundation, and bursting. The foundation failure mode (Figure 4d) is investigated for cellular structures resting on clay.

The mechanics to complete the risk and reliability assessment are proposed in Chapter 5. The basic concept of reliability index is introduced in Section 5.1. The failure mode of the structure is determined from the field inspection data. The limit-state functions are given in Section 5.2 for retaining walls and in Section 5.3 for cellular structures. These functions are used to calculate the reliability index using the method introduced in Section 5.4. The reliability index is calculated for a deteriorated structure by incorporating a steel corrosion model. Because the model was developed experimentally, it should be updated using visual inspection results by the Bayesian technique (Section 5.5.3) if the governing failure limit state occurs above the water level. This reliability index is used to develop timedependent reliability index profiles for various M\&R alternatives with the uncertainties calculated from historical inspection data and M\&R records (Section 5.5). The optimal M\&R activity is then to be determined by LCCA and environmental LCA of M\&R alternatives (Chapter 6). 


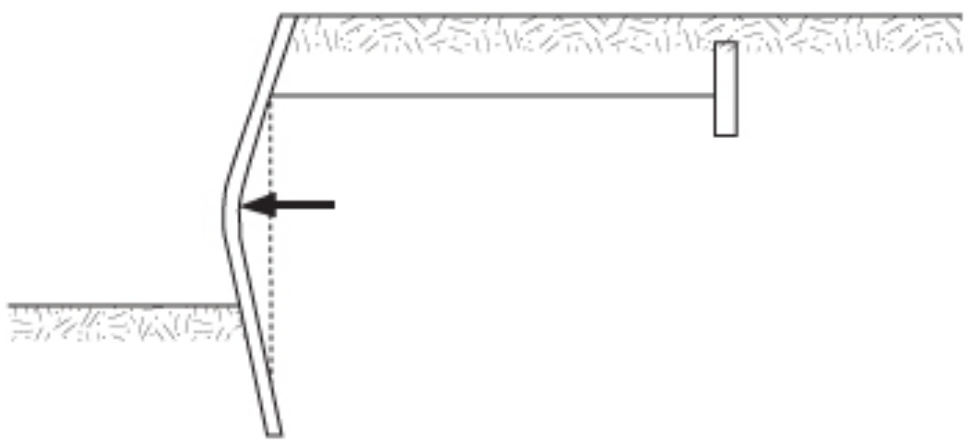

(a) Failure of piling in bending

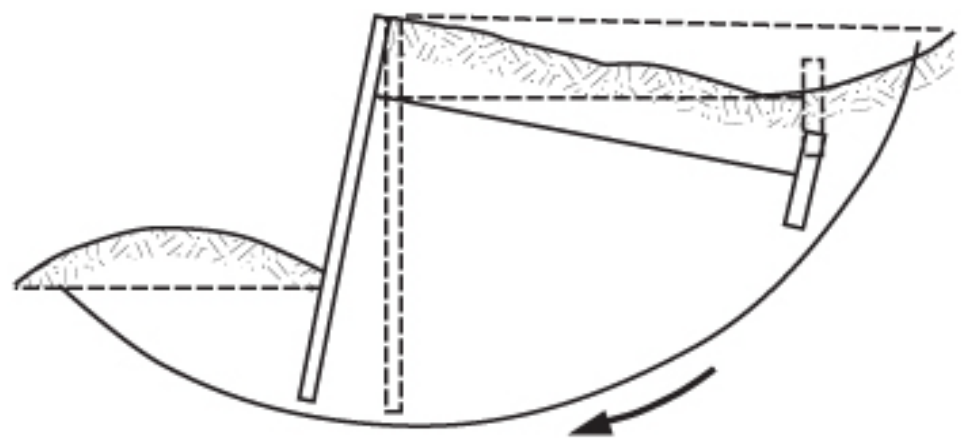

(b) Soil failure

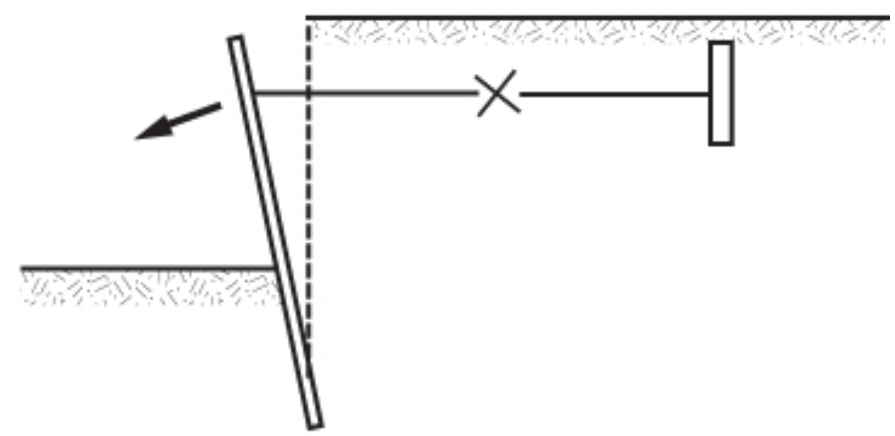

(c) Failure of anchor rod (anchored walls only)

Figure 3. Failure modes for retaining walls (adapted from Asker 1988). 


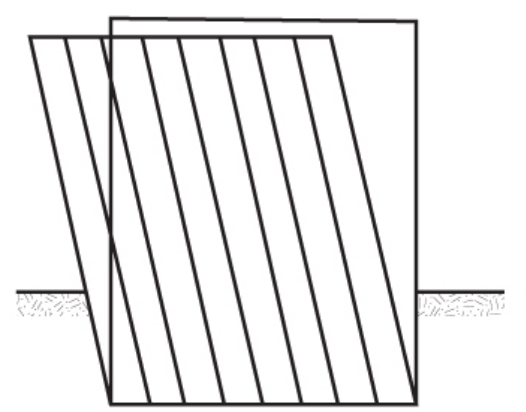

(a) Vertical shear

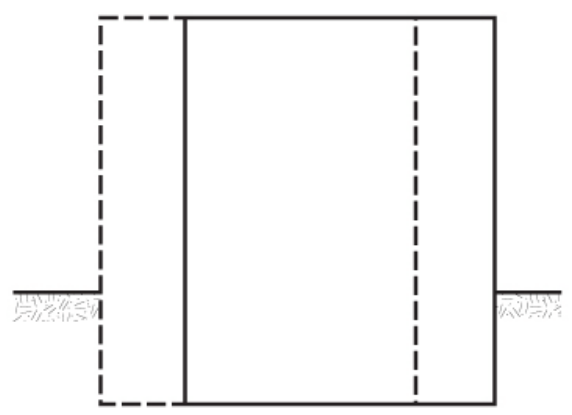

(b) Sliding on foundation

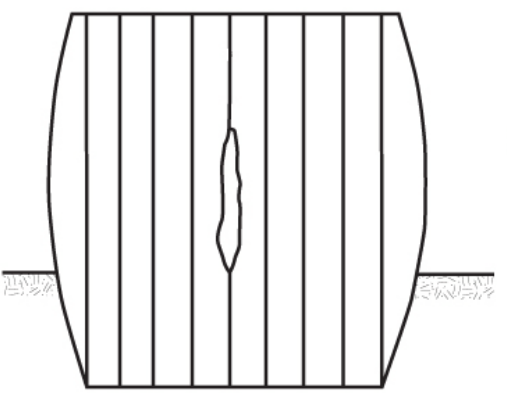

(c) Bursting of cells

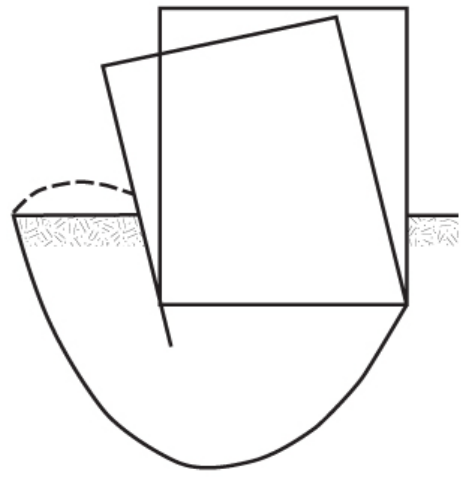

(d) Foundation failure (clay)

Figure 4. Failure modes for cellular structures (adapted from Asker 1988).

\subsection{LCCA and environmental LCA}

After the M\&R strategies for alternatives are determined, an LCA model proposed in this study is employed for the analysis of life-cycle costs and environmental impacts of different alternatives. The life cycle costs, GHG emission, and energy consumption of different M\&R alternatives can be calculated. The optimal alternative is the one with least cost, least GHG emission, and least energy consumption.

The GHG analysis is an optional separate analysis. One can select the optimal alternative based on cost comparisons only. However, sustainability has become a global topic which current and future generations are facing. It is becoming critical to produce green materials (e.g., high performance green concrete) and to apply intelligent design (e.g., sustainable M\&R strategies) to maintain environmental and economic sustainability during infrastructure development and rehabilitation. Many local governments in 
Colorado (e.g., City and County of Denver) have corresponding policies (e.g., Denver Greenprint) to reduce GHG emissions and energy consumption. In Denver, a Greenhouse Gas Reduction Plan (GGRP) has been developed. The GGRP monitors the emissions impacts of the city's work over time, including adoption of high-performance building practices, reducing materials use and waste production (e.g., incorporating fly ash into concrete to replace $20 \%$ of cement), supports for growth patterns that deemphasize reliance on cars, and development of more renewable energy sources for the city. Therefore, it is recommended to include the environmental LCA in the improved approach for the optimal SSP structure M\&R.

The remaining sections in this report introduce the principles needed to assess the reliability of the SSP structures (Chapter 5), the proposed LCA and LCCA models for evaluating the economic and environmental impacts of various M\&R alternatives (Chapter 6), a wall and a cell example (Chapter 7), and conclusion and recommendations for further work (Chapter 8). 


\section{Risk and Reliability Assessment of Steel Sheet Pile}

\subsection{Reliability index of SSP structures}

The first step to assess the reliability of a SSP structure is to determine its failure mode. The failure mode is determined by the field inspection. For example, misalignment and corrosion are two identified stresses of a deteriorated structure. The misalignment and corrosion distresses are most likely related to the bending failure mode. Various failure modes of SSP structures were reviewed in Chapter 4 . The reliability analysis is based on the failure limit states of a SSP structure. The failure modes of a retaining wall and a cellular structure were shown in Figure 3 and Figure 4 respectively (Asker 1988).

A limit state function can be defined for one of the failure modes as

$$
g(R, Q)=R-Q
$$

where:

$\mathrm{R}=$ the resistance; and

$\mathrm{Q}=$ the load effect.

The state of the SSP structure can be described using various parameters $\mathrm{X}_{1}, \mathrm{X}_{2}, \ldots, \mathrm{X}_{\mathrm{n}}$, which are load and resistance parameters including dead load, live load, SSP structure dimension, compressive strength, yield strength, and moment of inertia (Nowak and Collins 2000). A limit state function is a function $g\left(X_{1}, X_{2}, \ldots X_{n}\right)$ such that:

For a safe structure

$$
g\left(X_{1}, X_{2}, \ldots, X_{n}\right)>0
$$

Border or boundary between safe and unsafe

$$
g\left(X_{1}, X_{2}, \ldots, X_{n}\right)=0
$$


For failure

$$
g\left(X_{1}, X_{2}, \ldots, X_{n}\right)<0
$$

The SSP structure reliability is defined as the probability (Pr) that the structure survives,

$$
\operatorname{Pr}(g \geq 0)=1-\operatorname{Pr}(g<0)
$$

The probability of $g\left(X_{1}, X_{2}, \ldots, X_{n}\right)<0$ is defined as the probability of failure, $\mathrm{P}_{\mathrm{f}}$. However the probability of failure is often very difficult to evaluate. In practice, it is calculated indirectly using the concept of the reliability index, $\beta$.

Hasofer and Lind (1974) define the reliability index as the shortest distance from the origin of reduced variables to the line defined by Eq. 5-6.

$$
g\left(Z_{R}, Z_{Q}\right)=0
$$

The reduced variables $\mathrm{Z}_{\mathrm{R}}$ and $\mathrm{Z}_{\mathrm{Q}}$ are defined as:

$$
\begin{gathered}
Z_{R}=\frac{R-\mu_{R}}{\sigma_{R}} \\
Z_{Q}=\frac{Q-\mu_{Q}}{\sigma_{Q}}
\end{gathered}
$$

where:

$\mu_{R}=$ the mean value of the resistance;

$\sigma_{R}=$ the standard deviation of the resistance;

$\mu_{Q}=$ the mean value of the load effect; and

$\sigma_{Q}=$ the standard deviation of the load effect.

The reliability index can be then calculated from the following formula:

$$
\beta=\frac{\mu_{R}-\mu_{Q}}{\sqrt{\sigma_{R}^{2}+\sigma_{Q}^{2}}}
$$


For normally distributed random variables $\mathrm{R}$ and $\mathrm{Q}$, it can be shown that the reliability index is related to the probability of failure by

$$
\beta=-\Phi^{-1}\left(P_{f}\right) \text { or } P_{f}=\Phi(-\beta)
$$

Table 4 provides an indication of how $\beta$ varies with $P_{f}$ and vice versa based on Eq. 5-10.

The Hasofer-Lind reliability index will be used to evaluate the reliability of SSP structures. The procedure is introduced in Section 5.4.

Table 4. Reliability index and probability of failure.

\begin{tabular}{|c|c|}
\hline $\mathrm{P}_{\mathrm{f}}$ & $\beta$ \\
\hline $10^{-1}$ & 1.28 \\
\hline $10^{-2}$ & 2.33 \\
\hline $10^{-3}$ & 3.09 \\
\hline $10^{-4}$ & 3.71 \\
\hline $10^{-5}$ & 4.26 \\
\hline $10^{-6}$ & 4.75 \\
\hline $10^{-7}$ & 5.19 \\
\hline $10^{-8}$ & 5.62 \\
\hline $10^{-9}$ & 5.99 \\
\hline
\end{tabular}

\subsection{Failure limit states of retaining walls}

\subsubsection{Bending failure limit state}

The elastic bending stress equation is used to determine the actual stress in a SSP retaining wall:

$$
F_{a c t}=\frac{M_{\max } k}{S}
$$

where:

$\mathrm{M}_{\max }=$ the maximum bending moment which occurs at the point of zero shear;

$\mathrm{S}=$ the elastic section modulus; and

$\mathrm{k}=$ stress uncertainty factor. 
The methods to calculate $\mathrm{M}_{\max }$ for cantilever walls and anchored walls are detailed in Asker (1988). It is a random variable depending on the water elevation, top to dredge distance, soil properties, and surcharge load at the section of a SSP retaining wall being evaluated. Based on the inventory data, the distribution of $\mathrm{M}_{\max }$ can be determined. To simplify the calculation, $\mathrm{M}_{\max }$ is assumed to be a deterministic variable in this study.

The elastic section modulus $S$ is a random variable but assumed to be a deterministic variable in this study. The values of various SSP cross sections are available at United States Steel Corporation Steel Sheet Piling Handbook (1979). Corrosion deterioration is considered in this study. It occurs at the splash and atmospheric zones of the SSP retaining walls. Based on results from laboratory corrosion tests (USACE 1939; Albrecht and Naeemi 1984), the following deterioration models were derived for the atmospheric and splash zones respectively (Padula et al. 1994):

$$
\begin{array}{r}
\log C=\log 23.4+0.65 \log t+\varepsilon_{c} \\
\log C=\log 148.5+0.903 \log t+\varepsilon_{c}
\end{array}
$$

where:

$\mathrm{C}=$ the thickness loss (micrometers);

$\mathrm{t}=$ time (years), and

$\varepsilon_{c}=$ an uncertainty factor

The uncertainty factor $\varepsilon_{c}$ has a mean of 0 and standard deviations of 0.219 and 0.099 for the atmospheric and splash zones, respectively (Padula et al. 1994). The random stress uncertainty factor $\mathrm{k}$ is assumed lognormally distributed with a mean value of 0.96 and a standard deviation of 0.12 (Padula et al. 1994). This value was determined by calculating the ratio of actual strain gage data and the theoretical strains following the design model assumptions from various hydraulic steel structures.

The bending failure limit state function is defined as

$$
g\left(F_{y}, k\right)=F_{y}-\frac{M_{\max } k}{S}
$$


where:

$F_{y}$ is the yield stress of the steel, which is a random variable with a normal distribution.

The reliability index of this limit state function is time-dependent due to the corrosion deterioration. The time-dependent reliability index profile can be depicted to evaluate the future performance of the SSP retaining wall.

\subsubsection{Soil failure limit state}

Asker (1988) provided the method to calculate the soil factor of safety using trial and error. The factor of safety is determined when the values $\mathrm{D}$ equals $\mathrm{D}^{\prime}$, where $\mathrm{D}$ is the penetration of the piles required for equilibrium and $\mathrm{D}^{\prime}$ is the actual penetration of the pile. In design, $\mathrm{D}^{\prime}$ is selected as $20 \%$ to $40 \%$ larger than D to provide a factor of safety. Based on this, the soil failure limit state function is :

$$
g(D)=D^{\prime}-D
$$

The pile penetration depth, $\mathrm{D}$, is a random variable and it depends on the water elevation, top to dredge distance, soil properties, and surcharge load at the section of a SSP retaining wall being evaluated.

\subsubsection{Anchor rod failure limit state}

This limit state only exists for anchored retaining walls. The failure limit state function is defined as:

$$
g\left(k, F_{y}, A\right)=F_{y}-\frac{T d k^{\prime}}{A}
$$

where

$\mathrm{F}_{\mathrm{y}}=$ the yield stress of the steel;

$\mathrm{T}=$ the anchor force per unit length of wall;

$\mathrm{d}=$ the distance between anchor rods;

$\mathrm{A}=$ the cross-sectional area of the rod; and

$\mathrm{k}^{\prime}=$ the random stress uncertainty factor. 
The yield stress $\left(\mathrm{F}_{\mathrm{y}}\right)$ is a random variable with a normal distribution. The anchor force $\left(\mathrm{T}^{\prime}\right)$ depends on the water elevation, top-to-dredge distance, soil properties, and surcharge load at the section of the SSP retaining wall being evaluated. The distribution of $\mathrm{T}$ can be determined if the inventory data are available. The variable $d$ is a deterministic variable. The cross section area (A) is a random variable, the distribution of which should be provided in the anchor rod product information. If there is no data available, it is assumed to be a deterministic variable. Like $\mathrm{k}$ in the bending failure limit state, $\mathrm{k}^{\prime}$ is determined by calculating the ratio of actual strain gage data and the theoretical strains following the design model assumptions from various anchored retaining walls. It is assumed to have the same distribution as $\mathrm{k}$. The reliability analysis for the anchor rod failure limit state requires an assumption about the anchor rod corrosion deterioration model. It is conservatively assumed to be one-half the thickness loss of due to corrosion of the retaining wall in the atmospheric area:

$$
\log 2 C=\log 23.4+0.65 \log t+\varepsilon_{c}
$$

where:

$\mathrm{C}=$ the thickness loss (micrometers) due to corrosion underground;

$\mathrm{t}=$ time (years); and

$\varepsilon_{c}=$ an uncertainty factor with a mean of 0 and standard deviations of

0.219 .

\subsection{Failure limit states of cellular structures}

\subsubsection{Vertical shear failure limit state}

For this mode, failure is assumed to occur along the centerline of the cell when the maximum shearing resistance of the cell fill and the interlocks is reached. The total shearing force on the centerline of the cell can be calculated as (Asker 1988):

$$
Q=\frac{3 M}{2 B}
$$

where:

$\mathrm{Q}=$ total shearing force per unit length of cell;

$\mathrm{M}=$ net overturning moment or resisting moment per unit length of cell; 
$\mathrm{B}=$ equivalent width of cellular structure.

The limit state function is defined as:

$$
g\left(M_{r}, M_{0}\right)=M_{r}-M_{0}
$$

where:

$\mathrm{M}_{\mathrm{r}}$ = the resisting moment per unit length of cell;

$\mathrm{M}_{\mathrm{o}}=$ net overturning moment per unit length of cell.

The general equation for the net overturning moment per unit length of cell can be written as:

$$
M_{o}=M_{a}+M_{w}+F H
$$

where:

$\mathrm{M}_{\mathrm{a}}=$ moment about the base due to the active earth pressure acting to the right of the cell;

$\mathrm{M}_{\mathrm{w}}=$ moment due to the water elevation difference on both sides of the cellular wall;

$\mathrm{F}=$ horizontal force applied at the top of single cells per unit length of cell;

$\mathrm{H}=$ height of cellular structure.

$\mathrm{M}_{\mathrm{o}}$ is a random variable depending on the soil properties, the water elevation difference on both sides of the cellular wall, etc.

For soils other than soft and medium clay, the resisting moment is (Asker 1988):

$$
M_{r}=\frac{2}{3} S_{t} B+M_{P}
$$

where:

$\mathrm{M}_{\mathrm{p}}=$ moment about the base due to the passive resistance of the soil acting to the left of the cell;

$\mathrm{S}_{\mathrm{t}}=$ the interlock friction; and

$\mathrm{B}=$ equivalent width of cellular structure. 
For soft soil and medium clay, the resisting moment is:

$$
M_{r}=F_{t} R f\left(\frac{B}{L}\right)\left(\frac{L+0.25 B}{L+0.5 B}\right)+M_{P}
$$

where:

$\mathrm{F}_{\mathrm{t}}=$ interlock tension;

$\mathrm{R}=$ radius of cell;

$\mathrm{f}=$ coefficient of interlock friction, which is assumed to be 0.3 ;

$\mathrm{B}=$ equivalent width of cell; and

$\mathrm{L}=$ length of cell.

\subsubsection{Sliding on foundation failure limit state}

The limit state function for sliding on foundation failure limit state is:

$$
g\left(F_{P}, F_{f}, F_{a}, F_{w}, F\right)=F_{P}+F_{f}-F_{a}-F_{w}-F
$$

where:

$\mathrm{F}_{\mathrm{P}}=$ force resulting from passive earth pressure;

$F_{\mathrm{f}}=$ the frictional resistance per unit length of cell;

$\mathrm{F}_{\mathrm{a}}=$ force resulting from active earth pressure;

$\mathrm{F}_{\mathrm{w}}=$ force due to water elevation difference on both sides of cellular walls; and

$\mathrm{F}=$ force applied near the top of single cell structures.

The calculations of these random variables are shown in Asker (1988).

\subsubsection{Bursting of cells failure limit state}

The limit state function is:

$$
g\left(t, \sigma_{t}\right)=\frac{T_{u} t}{t_{0}}-\sigma_{t} R
$$


where:

$\mathrm{T}_{\mathrm{u}}=$ the minimum ultimate interlock strength per unit length for straight web sections;

$\mathrm{t}=$ the thickness of the SSP cell;

$\mathrm{t}_{0}=$ original thickness of the SSP cell;

$\sigma_{t}=$ the maximum interlock pressure in the main cell; and

$\mathrm{R}=$ the cell radius.

\subsubsection{Foundation failure limit state}

Foundation failure is investigated for cellular structures founded on clay. The limit state function is:

$$
g(C, \gamma, H)=5.7 C-\gamma H
$$

where:

$\mathrm{C}=$ unit cohesion of foundation;

$\gamma=$ unit weight of fill; and

$\mathrm{H}=$ height of cellular structure above ground level.

\subsection{Hasofer-Lind reliability index}

After the failure mode is determined, the reliability index is to be calculated using the failure limit state function. Hasofer and Lind (1974) proposed a method to evaluate the limit state function at a "design point" which is on the failure surface $g=0$. An iteration technique must be used for nonlinear limit state functions to solve for the reliability index since the design point is generally not known. The following sections detail the basics of Hasofer-Lind reliability index.

\subsubsection{Linear limit state functions}

Consider a linear limit function of the form:

$$
g\left(X_{1}, X_{2}, \ldots, X_{n}\right)=a_{0}+a_{1} X_{1}+a_{2} X_{2}+\cdots+a_{n} X_{n}=a_{0}+\sum_{i=1}^{n} a_{i} X_{i}
$$


where:

$\mathrm{a}_{\mathrm{i}}=$ constants, and

$\mathrm{X}_{\mathrm{i}}=$ uncorrelated random variables.

The reliability index can be calculated as:

$$
\beta=\frac{a_{0}+\sum_{i=1}^{n} a_{i} u_{x i}}{\sqrt{\sum_{i=1}^{n}\left(a_{i} \sigma_{x i}\right)^{2}}}
$$

where:

$u_{x i}=$ means of the random variables; and

$\sigma_{x i}=$ standard deviations of the random variables.

\subsubsection{Nonlinear limit state functions}

There are two alternative iterative procedures to calculate the reliability index for nonlinear limit state functions: the matrix procedure and the simultaneous equation procedure. Nowak and Collins (2000) detail the Rackwitz-Fiessler matrix procedure, which is not used in this study. The simultaneous equation procedure is given as the following eight steps:

1. Formulate the limit state function and appropriate parameters for all random variables involved.

2. Express the limit state function in terms of reduced variables $\mathrm{Z}_{\mathrm{i}}$.

$$
Z_{i}^{*}=\frac{X_{i}-\mu_{x i}}{\sigma_{x i}}
$$

3. Express the limit state function in terms of $\beta$ and $\alpha_{i}$.

$$
Z_{i}=\beta \alpha_{i}
$$

4. Calculate the $\mathrm{n} \alpha_{i}$ values. Use equation 5-30 to express each $\alpha_{i}$ as a function of all $\alpha_{i}$ as a function of all $\alpha_{i}$ and $\beta$. 


$$
\alpha_{i}=\frac{-\frac{\partial g}{\partial Z_{i}}}{\sqrt{\sum_{k=1}^{n}\left(\frac{\partial g}{\partial Z_{k}}\right)^{2}}}
$$

5. Complete the initial cycle: Assume numerical values of $\beta$ and all $\alpha_{i}$, noting that the $\alpha_{i}$ values must satisfy:

$$
\sum_{i=1}^{n}\left(\alpha_{i}\right)^{2}=1
$$

6. Use the numerical values of $\beta$ and $\alpha_{i}$ on the right-hand sides of the equations formed in Steps 3 and 4 above.

7. Solve the $\mathrm{n}+1$ simultaneous equations in Step 6 for $\beta$ and $\alpha_{i}$.

8. Go back to Step 6 and repeat. Iterate until the $\beta$ and $\alpha_{i}$ values converge.

A spreadsheet or a section of short computer code is needed to easily calculate the reliability index for a nonlinear limit state function. The simultaneous equation procedure and the matrix procedure just use information on the means and standard deviations of the random variables. Detailed information on the type of distribution for each random variable is not needed. If the distributions of the random variables are available, the Rackwitz-Fiessler matrix procedure can be employed for calculating reliability indexes (Nowak and Collins 2000).

\subsection{Updating the reliability of SSP structures using visual inspection results}

The reliability index calculations for several failure limit states employ steel deterioration models. These models are usually derived theoretically. To be effective, they must be updated over time to revise the maintenance strategy based on how a structure actually behaves (Estes et al. 2003). Non-destructive evaluations taken at optimum time intervals provide the best sources of data. However they are often expensive and the data are not available for every structure. It becomes more important to use the information from routine visual CI inspections to update lifetime reliability assessments. But the updating can only be employed when the failure 
mode occurs above the water level. The distresses are able to be recorded by visual inspection.

\subsubsection{General approach}

Estes et al (2003) proposed a general approach for using visual inspection information to update the reliability of any type of structure. This approach has been employed to update reliability of steel miter gates on locks and dams (ibid.). To be effective, it needs to be applied to each relevant failure mode or distress, not at the component CI level. To use the visual inspection information to update a reliability analysis, one must do the following.

- Ensure that classification is sufficiently described in quantifiable terms such as section loss, percentage of spalls, etc. Revise the condition state definition if necessary.

- Define the condition state in probabilistic terms. Some conservative assumptions may be needed to achieve this.

- Relate what the inspector is observing to the specific deterioration being updated. This is easy if the defect is being observed directly and more difficult if the defect cannot be seen.

- Update the deterioration model based on the new information. Because there can be a high degree of uncertainty associated with both the prior deterioration and the visual inspection results, a Bayesian approach to updating is necessary.

- Update the reliability of the structure. (Estes et al. 2003)

\subsubsection{Condition state definition for corrosion updating}

As discussed before, the corrosion models were derived theoretically and these models must be updated over time based on the visual inspection results. If failure occurs above the water level, the reliability of the structure will be updated.

A CI methodology has been used by the USACE since the early 1980's to help prioritize maintenance of existing civil works structures. The data from a CI inspection can be conservatively utilized for updating the relia- 
bility of a structure in corrosion deterioration with some minor modifications. The condition state for corrosion updating is quantified in terms of the relative section loss as shown in Table 5 . The method was proposed by Estes et al (2003) and used to update the reliability of miter gates.

Table 5. Conditions state definitions for corrosion levels (adapted from Estes et al. 2003).

\begin{tabular}{|l|l|l|l|l|}
\hline \multirow{2}{*}{ Rating } & \multirow{2}{*}{ Description } & \multicolumn{3}{|l|}{ Thickness loss per side } \\
\cline { 3 - 5 } & & mils & $\mu \mathrm{m}$ & Distribution $(\mu \mathrm{m})$ \\
\hline 0 & New condition & 0 & 0 & - \\
\hline 1 & $\begin{array}{l}\text { Minor surface scale or widely scattered } \\
\text { small pits }\end{array}$ & $0-8$ & $0-200$ & $\mathrm{LN}[100,51]$ \\
\hline 2 & $\begin{array}{l}\text { Considerable surface scale and / or } \\
\text { moderate pitting }\end{array}$ & $0-20$ & $0-500$ & $\mathrm{LN}[250,128]$ \\
\hline 3 & $\begin{array}{l}\text { Severe pitting in dense pattern, } \\
\text { thickness reduction in local areas }\end{array}$ & $0-40$ & $0-1000$ & $\mathrm{LN}[500,255]$ \\
\hline 4 & Obvious uniform thickness reduction & $40-120$ & $1000-3000$ & $\mathrm{~N}[2000,510]$ \\
\hline 5 & $\begin{array}{l}\text { Holes due to thickness reduction and } \\
\text { general thickness reduction }\end{array}$ & $>120$ & $>3000$ & $\mathrm{~N}[4500,1531]$ \\
\hline
\end{tabular}

Estes et al. (2003) state:

It is assumed that condition state deterioration over time is linear and the deterioration intensity is normally or lognormally distributed. To ensure the model is conservative, it is also assumed that a structural element is initially at the half-way point of a specific condition state and progressively shifts over time. The standard deviation of the distribution is determined by the quality of the inspection program. The inspectors are categorized as very experienced, experienced, and inexperienced and the correct condition state ratings could be expected $95 \%, 85 \%$, and $75 \%$ of the time, respectively.

The distributions of corrosion levels in Table 5 are based on a very experienced inspector.

\subsubsection{Bayesian updating}

Estes et al (2003) state "bayesian updating uses both the prior information and new inspection information to account for the relative uncertainty associated with these types of information". For the case where both prior 
and new probability density functions are normally distributed, the posterior function is also normally distributed and has the mean value and standard deviation, respectively, as

$$
\begin{gathered}
\mu^{\prime \prime}=\frac{\mu\left(\sigma^{\prime}\right)^{2}+\mu^{\prime}(\sigma)^{2}}{\left(\sigma^{\prime}\right)^{2}+(\sigma)^{2}} \\
\sigma^{\prime \prime}=\sqrt{\frac{\left(\sigma^{\prime}\right)^{2}(\sigma)^{2}}{\left(\sigma^{\prime}\right)^{2}+(\sigma)^{2}}}
\end{gathered}
$$

where:

$\mu, \mu^{\prime}$ and $\mu^{\prime \prime}$ represent the mean values of the inspection results, the prior distribution, and the posterior distribution respectively; and

$\sigma, \sigma^{\prime}$, and $\sigma^{\prime \prime}$ represent the standard deviations of those same distributions.

The posterior mean value and standard deviations of the thickness loss are used to calculate the reliability index reflecting how the structure actually behaves. This reliability index is used to develop time-dependent reliability index profiles for various M\&R alternatives with the uncertainties calculated from historical inspection data and M\&R records. The profiles predict the performance of the structure under various M\&R alternatives in the future.

\subsection{Time-dependent reliability index profile}

The reliability profile $\beta(t)$ is defined as the variation of the reliability index with time (Thoft-Christensen 1996; Estes and Frangopol 1996; Nowak et al. 1998). Frangopol et al (2001) proposed a reliability-based life-cycle management strategy for highway bridges. The objective of the future bridge management is to allocate and use the limited resources to balance lifetime reliability and life-cycle cost in an optimal manner. The same idea is adopted in this study. The method to develop a time dependent reliability index profile is illustrated using the ideas of Frangopol et al (2001).

Uncertainties during the whole life process of an infrastructure in the time-dependent reliability index profile are shown in Figure 5. The notations for the probability density functions shown in Figure 5 are as follows: 
(a) =initial reliability level; (b) = time of damage initiation; (c) = reliability deterioration rate without maintenance; $(\mathrm{d})=$ first rehabilitation time [i.e., age at which the minimum acceptable reliability level is reached for the first time]; (e) =improvement in reliability due to essential/ corrective maintenance; (f) = time of damage initiation after essential/ corrective maintenance has been done; $(\mathrm{g})=$ reliability deterioration rate after essential/ corrective maintenance has been done; and $(\mathrm{h})=$ second rehabilitate time.

(Frangopol 2001).

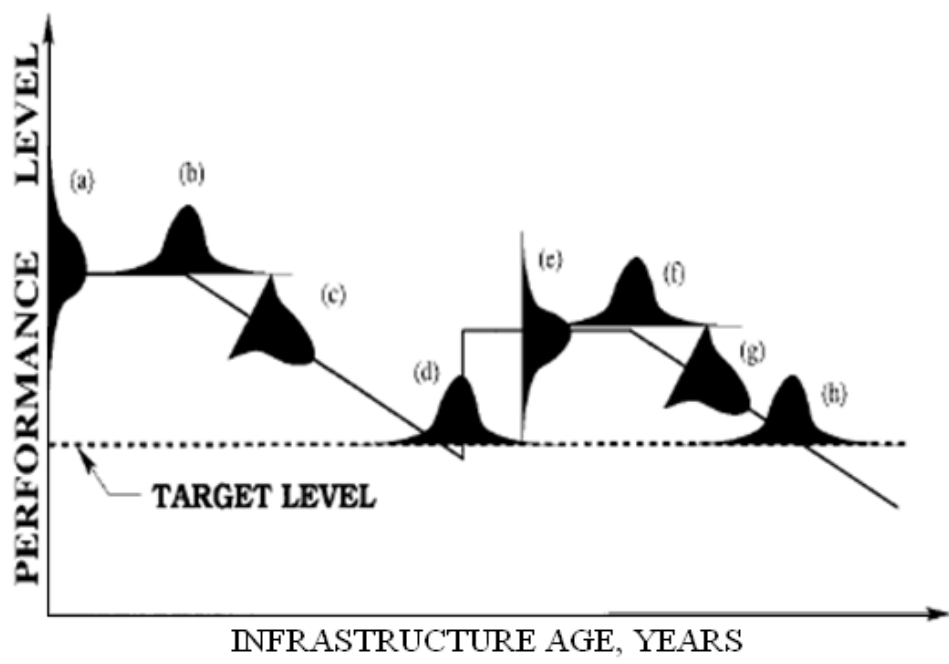

Figure 5. Reliability index profile of an infrastructure with M\&R (adapted from Frangopol et al. 2001).

A similar time-dependent reliability index profile can be developed for SSP structures. The target reliability index depends on various critical conditions of SSP structures. The corrective or preventive M\&R option depends on the current reliability index and expected lifetime of the structure. The uncertainties can be calculated from the statistical analysis from the SSP structure condition index inventory data and M\&R records. This study uses assumed approximate data to demonstrate the improved M\&R procedure for SSP structures. Further research is proposed in Appendix A to develop these uncertainties with real field inspection data and M\&R records. The M\&R strategies during the analysis period determined by the timedependent reliability profiles are used for the LCCA and environmental LCA. The optimal M\&R is the one with the least life-cycle cost and/ or least environmental impacts. 


\section{LCCA and Environmental LCA}

\subsection{Principles and methods of LCCA for SSP structures}

\subsubsection{Method of LCCA}

There are several basic considerations in selecting the most appropriate method for economic evaluation of M\&R alternatives. These considerations were reviewed in Chapter 2. The present-worth method is employed in this study; the method "involves the discounting of all future sums to the present, using an appropriate discount rate" (Hudson et al. 1997). The factor for discounting costs is:

$$
p w f_{i, n}=1 /(1+i)^{n}
$$

where:

$\mathrm{pwf}_{\mathrm{i}, \mathrm{n}}=$ present worth factor for a particular $\mathrm{i}$ and $\mathrm{n}$;

$\mathrm{i}=$ discount rate, and

$\mathrm{n}=$ number of years to when the sum will be expended or saved.

The following equation is used for the present-worth method:

$$
T P W C_{x 1, n}=(I C C)_{x 1}+\sum_{t=0}^{n}\left\{p w f_{i, t}\left[(C C)_{x 1, t}+(M O)_{x 1, t}+(U C)_{1, t}\right]\right\}-p w f_{i, n}(S V)_{x 1, n}
$$

where:

$\mathrm{TPWC}_{\mathrm{x} 1, \mathrm{n}}=$ total present worth of costs for alternative $\mathrm{x} 1$, for analysis period of $n$ years;

$(\mathrm{ICC})_{\mathrm{x} 1}=$ initial capital costs of construction, etc. for alternative $\mathrm{x} 1$;

$(C C)_{x 1, t}=$ capital costs of construction, etc., for alternative $\mathrm{x} 1$, in year $\mathrm{t}$, where $\mathrm{t}<\mathrm{n}$;

$\mathrm{pwf}_{\mathrm{i}, \mathrm{n}}=$ present worth factor for discount rate, $\mathrm{i}$, for t years;

$(\mathrm{MO})_{\mathrm{x} 1, \mathrm{t}}=$ maintenance plus operation costs for alternative $\mathrm{x} 1$ in year $\mathrm{t}$;

$(\mathrm{UC})_{\mathrm{x} 1, \mathrm{t}}=$ user cost, if applicable for alternative $\mathrm{x} 1$ in year $\mathrm{t}$; and

$(\mathrm{SV})_{\mathrm{x} 1, \mathrm{n}}=$ salvage value, if any, for alternative $\mathrm{x} 1$, at the end of the analysisperiod, $n$ years. 


\subsubsection{LCCA for SSP infrastructures}

In order to select the optimal M\&R solution for a SSP structure, an LCCA is needed. A cost and an effective life are assigned to each alternative included in the M\&R solutions. The cost and lifetime are estimated based on the engineering judgment, past experience of the engineer, and current market value of repair services. Some alternatives may need to be repeated at a regular frequency throughout the time period for the solution (e.g., protective coating). The time-dependent reliability index profile provides the information on how often the alternative should be completed. It also can be used to predict how many times the corrective maintenance (e.g., replacement of a wall) should be completed on a SSP structure to reach its expected lifetime.

The estimated costs over the lifetime of a SSP structure include: (1) initial professional and technical design services for SSP structures; (2) initial costs for a new SSP structure (materials, transportation, and construction); (3) professional and technical services for current condition evaluation and the in-depth field investigation to identify the causes of each distress; (4) maintenance and repair costs for all distresses including materials (steel, coating, etc.), transportation, and construction; and (5) salvage value.

A discount rate is also required to complete the LCCA, using the presentworth method mentioned in Section 6.1.1. The structure should be replaced if the total present worth of cost for the M\&R solution is larger than that for a new structure over the analysis period. The analysis period is from present to the expected lifetime of the structure. The present cost for a new structure includes initial costs and the $M \& R$ costs over the analysis period. Another criterion to tell if a structure fails is from the sustainability perspective. The structure should be replaced if the M\&R solution emits too much GHG and consumes too much energy over the analysis period.

\subsection{Environmental LCA}

Environmental LCA is another tool to determine if the structure should be replaced. An environmental LCA model is built to evaluate embodied energy and GHG emissions from a SSP structure under different M\&R scenarios over the analysis period. This modern sustainable addition to the traditional historic and classical analysis will help identify the carbon 
footprint impacts of different M\&R scenarios and help select the optimum M\&R solution with the lowest emissions.

\subsubsection{EIO-LCA method}

The LCA model developed for this study incorporates a modern Economic Input-Output model from Carnegie Mellon Green Design Institute (CMGDI). The EIO-LCA method was theorized and developed by economist Wassily Leontief in the 1970s based on his earlier Input-Output work from the 1930s (CMGDI 2010). Input into the EIO-LCA model is economic data only. The data is then linked to energy use and toxic releases associated with each industrial sector.

Results from using the CMGDI EIO-LCA tool provide guidance on the relative impacts of different types of products, materials, services, or industries with respect to resource use and emissions throughout the supply chain. Thus, the effect of producing a SSP retaining wall would include not only the impacts at the steel mills, but also from the mining metal ores, transportation from the ore yard to the steel mills, etc. that are needed to produce a SSP retaining wall.

The SSP structures can be recycled into new materials at the end of life. This type of developed LCA model is "cradle-to-cradle." An inventory analysis is completed and the emissions and energy consumptions of SSP structures with various M\&R scenarios over the analysis period can be compared using the LCA model.

\subsubsection{LCA methodology}

As reviewed in Chapter 3, there are four goals adhered to by the LCA methodology, which are repeated here along with explanations of how they were related to this study.

1. Goal and scope: Outline the purpose of the study and its breadth and depth; identify the functional unit for the study.

This study utilizes a cradle-to-cradle LCA model to evaluate the GHG emissions and energy consumption from SSP structures with various M\&R scenarios. The functional units used in this study were selected as GHG emission $\left(\mathrm{MTCO}_{2} \mathrm{E}\right)$ and energy consumption (MJ ) from $\$ 10,000$ of cost. 
2. Inventory analysis: Identify and quantify the environmental inputs and outputs associated with a product over its entire life cycle.

The entire life of an SSP structure includes initial design and construction (initial professional and technical design services for SSP structures; the material processing; manufacturing; transport; and initial construction), maintenance and repair (professional and technical services for SSP structure evaluation; the material processing; manufacturing; transport; and $M \& R$ ) and the end-of-life (recycling). The "SSP structure flow" in the LCA model is included in Table 6.

Table 6. SSP structure flow.

\begin{tabular}{|c|c|c|c|}
\hline Life Cycle & Process & Notes & Source \\
\hline \multirow{4}{*}{$\begin{array}{l}\text { Initial Design and } \\
\text { Construction }\end{array}$} & Professional and technical services & \multirow{4}{*}{ Economy-wide } & \multirow{4}{*}{ EIO-LCA } \\
\hline & Materials (steel, painting, etc.) & & \\
\hline & Transportation & & \\
\hline & Initial construction & & \\
\hline \multirow{4}{*}{$M \& R$} & Professional and technical services & \multirow{4}{*}{ Economy-wide } & \multirow{4}{*}{ EIO-LCA } \\
\hline & Materials (steel, painting, etc.) & & \\
\hline & Transportation & & \\
\hline & M\&R construction & & \\
\hline End-of-life & Landfill avoidance & Economy-wide & $\overline{\text { EIO-LCA }}$ \\
\hline
\end{tabular}

3. Impact assessment: Characterize inventory flows (inputs and outputs) in relation to a set of environmental and health impacts.

Based on the inventory, a customized LCA model for SSP structures is created using the EIO-LCA method. There are five steps to use the EIO-LCA method within the associated software (CMGDI 2010).

Step 1: Choose a model.

The first step in using the EIO-LCA method is to select the model year and country for industry data from the drop-down list of the online tool; U.S. models exist for the years 1992, 1997, and 2002. Data is also available for Germany, China, Spain, and Canada and can be selected from the model year drop down list. This study adopted the U.S. 2002 national producer price models. 
Step 2: Select industry and sector.

The second step is to select an industry sector to analyze. For the U.S. 2002 model, the economy is divided by industry sectors into 428 divisions which group businesses that produce similar goods or services (CMGDI 2010). The industry sector that produces the outputs (GHG emission and energy consumption) needs to be found. The industry sectors included in the life-cycle of a SSP structure and their sector numbers are summarized in Table 7.

Step 3: Select the amount of economic activity for this sector.

The third step is to determine the level of economic activity for the desired sector. Since the functional units used in this study were selected as GHG emission $\left(\mathrm{MTCO}_{2} \mathrm{E}\right)$ and energy consumption (MJ ) from $\$ 10,000$ of cost, the level of economic activity was determined to be $\$ 10,000$.

Step 4: Select the category of results to display.

The fourth step is to select the effects displayed in the results. The GHG emission and energy consumption were selected in this study. Now that a sector has been selected, a level of economic activity has been entered, and the effects to display have been determined, the EIO-LCA tool has all the information it needs to run the model.

Step 5: Run the model.

The cradle-to-cradle life cycle inventory accounts for the total GHG emission and embodied energy of SSP structures from the material processing, manufacturing, transport, initial construction, maintenance, repair and recycling. The customized LCA model is summarized in Table 7.

Table 7. Cradle-to-cradle LCA Model for SSP structures.

\begin{tabular}{|l|l|l|l|l|}
\hline \multirow{2}{*}{ Process } & Note & Sector No. & Total Energy & Total \\
\cline { 3 - 5 } & EIO-LCA & $\mathrm{MJ} / \$ 10,000$ & $\mathrm{MTCO2E} / \$ 10,000$ \\
\hline $\begin{array}{l}\text { Professional } \\
\text { and technical } \\
\text { services }\end{array}$ & $\begin{array}{l}\text { Initial design \& } \\
\text { condition } \\
\text { evaluation }\end{array}$ & 541300 & $0.64 \times 10^{4}$ & 0.36 \\
\hline \multirow{2}{*}{ Materials } & $\begin{array}{l}\text { Steel } \\
\text { manufacturing }\end{array}$ & 331110 & $30.1 \times 10^{4}$ & 25.9 \\
\cline { 2 - 5 } & Painting \& coating & 325510 & $1.02 \times 10^{4}$ & 0.31 \\
\hline
\end{tabular}




\begin{tabular}{|l|l|l|l|l|}
\hline \multirow{2}{*}{ Process } & Note & Sector No. & Total Energy & Total \\
\cline { 3 - 5 } & EIO-LCA & MJ $\$ 10,000$ & MTCO2E $\$ 10,000$ \\
\hline Transportation & $\begin{array}{l}\text { Truck } \\
\text { Transportation }\end{array}$ & 484000 & $13.4 \times 10^{4}$ & 9.86 \\
\hline \multirow{2}{*}{ Construction } & Initial construction & 230103 & $3.16 \times 10^{4}$ & 2.00 \\
\cline { 2 - 5 } & M\&R & 230301 & $3.80 \times 10^{4}$ & 2.43 \\
\hline $\begin{array}{l}\text { Landfill } \\
\text { avoidance }\end{array}$ & $\begin{array}{l}\text { Recycling, waste } \\
\text { management } \\
\text { avoidance }\end{array}$ & 562000 & $\left(1.42 \times 10^{4}\right)$ & $(22.9)$ \\
\hline
\end{tabular}

There are six gases listed below that contribute to GHG.

- carbon dioxide $\left(\mathrm{CO}_{2}\right)$

- methane $\left(\mathrm{CH}_{4}\right)$

- nitrous oxide $\left(\mathrm{N}_{2} \mathrm{O}\right)$

- hydrofluorocarbons (HFCs)

- sulfur hexafluoride $\left(\mathrm{SF}_{6}\right)$

- perfluorocarbons (PFCs)

These six different gases have varying impacts on global warming. For example, additional methane has approximately 23 times greater climate impact than the same incremental amount of $\mathrm{CO}_{2}$. Therefore, the impact of each gas is converted to the $\mathrm{CO}_{2} \mathrm{E}$ (the $\mathrm{CO}_{2}$ equivalent mass) that would have the same climate impact as the mass of the individual GHG released into the atmosphere.

The LCA model developed for this study is the industry benchmark, U.S. Department of Commerce EIO model from 2002, which is a produc$\mathrm{er}$ / price model. Therefore, to utilize this model, the input economic data should be converted to 2002 dollars. In the transportation process, only truck transportation was considered. The model can be updated with other transportation modes (rail transportation, sector no. 482000 and water transportation, sector no. 483000). At the end of life, SSP infrastructures will be recycled; thus waste management will be avoided. The energy consumption and GHG emission are negative in this cradle-to-cradle LCA model. But for infrastructures built with concrete, they will be landfilled at the end of their lives. The environmental impacts of the SSP structure can be compared with other concrete infrastructures by including the effects of landfill avoidance in the LCA model. The process of recycling steel will in- 
crease the GHG emission and energy consumption, but it is the beginning of another product's life-cycle. It is out of the boundary condition of the analysis for SSP structures in this study.

4. Interpretation: Combines the environmental impacts with the goals of the LCA study. The LCA results are combined with the LCCA results to select the optimum M\&R solution for a SSP structure.

The optimal M\&R solution is the one with the least life-cycle cost and minimum environmental impact. Two examples in Chapter 7 (an SSP wall and a cell) illustrate the modernized and improved inspection and analysis procedure. 


\section{Case Study Examples}

Two examples are included in this chapter to illustrate the proposed M\&R procedures for the SSP structures (Figure 2). The first example evaluates condition status and seeks the optimal M\&R alternative for a deteriorated cantilever wall in cohesive soil and backfilled with sand. The second example is for a corroded single cell on rock foundation filled with sand.

\subsection{Example SSP retaining wall (modified from Asker 1988; Greimann et al. 1990b)}

A cantilever wall in cohesive soil and backfilled with sand was evaluated for condition status. It was built in 1950. This structure has not experienced any prior M\&R activity. The expected lifetime is 100 years. The piles are PZ32 and A500 Grade $C$ steel $\left(F_{y}=50 \mathrm{ksi}\right)$. The cross section of the wall for the evaluated section is shown in Figure 6. After a detailed field inspection, the distresses in Table 8 were identified and the corresponding CIs were calculated. Mock inspection data was created for this example.

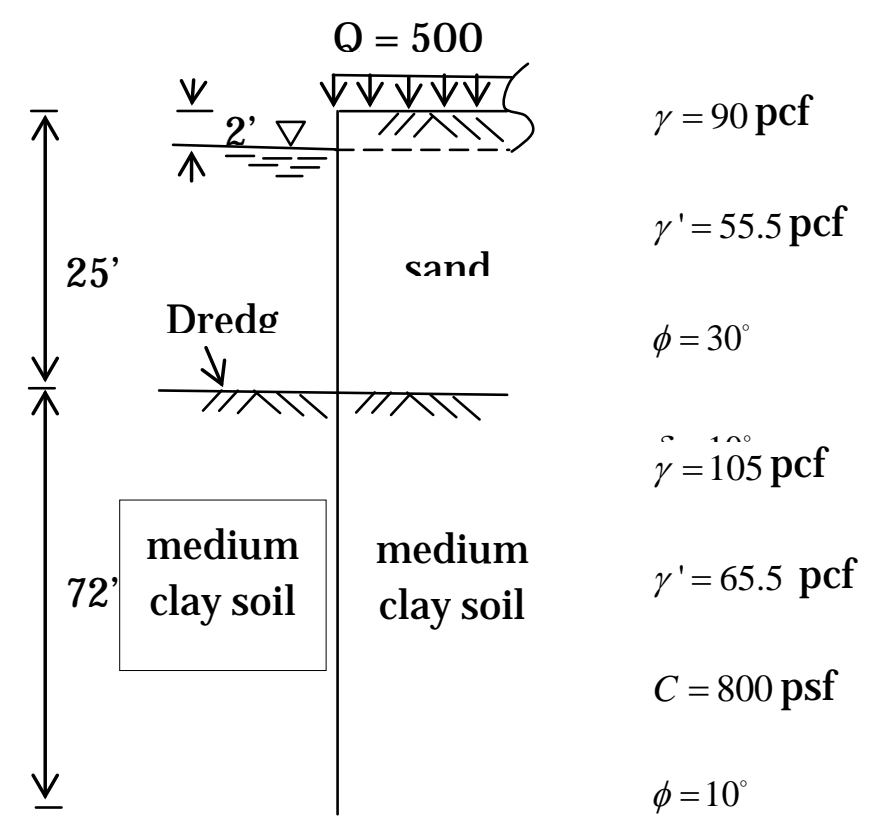

Figure 6. Cantilever wall in cohesive soil (adapted from Asker 1988). 
Table 8. Cl data example distresses for SSP wall example.

\begin{tabular}{|l|l|l|l|l|l|}
\hline Distresses & $\mathrm{Cl}$ & $\boldsymbol{w}_{\boldsymbol{i}}$ & $\begin{array}{l}\text { Adjustment } \\
\text { Factor }\end{array}$ & Revised $\boldsymbol{w}_{\boldsymbol{i}}$ & Revised $\boldsymbol{w}_{(\mathbf{\%})}$ \\
\hline Misalignment & 34 & 8 & 8 & 64 & 51.2 \\
\hline Corrosion & 40 & 5 & 8 & 40 & 32.0 \\
\hline Settlement & 86 & 4 & 1 & 4 & 3.2 \\
\hline Cavities & 100 & 4 & 1 & 4 & 3.2 \\
\hline $\begin{array}{l}\text { Interlock } \\
\text { Separation }\end{array}$ & 100 & 4 & 1 & 4 & 3.2 \\
\hline Holes & 100 & 3 & 1 & 3 & 2.4 \\
\hline Dents & 100 & 2 & 1 & 2 & 1.6 \\
\hline Cracks & 100 & 4 & 1 & 4 & 3.2 \\
\hline & - & - & - & 125 & 100 \\
\hline
\end{tabular}

\subsubsection{Condition index}

The functional condition index is:

Functional $\mathrm{Cl}=0.512(34)+0.32(40)+0.032(86)+0.032(100)+0.032(100)+$ $0.024(100)+0.016(100)+0.032(100)=47($ Zone 2$)$

To calculate the structural CI of the wall, bending factor of safety and soil factor of safety are calculated.

The maximum bending moment $\left(\mathrm{M}_{\max }\right.$, ) per foot of wall is (Asker 1988):

$$
M_{\max }=149.977 \text { kips } \cdot \mathrm{ft}
$$

The maximum moment occurs $5.4 \mathrm{ft}$ below the dredge line.

For PZ32 section designation, the section modulus, $\mathrm{S}_{\mathrm{x}}$, per foot of wall is:

$$
S_{x}=38.3 \mathrm{in}^{3}
$$

The maximum bending stress $\left(f_{b}\right)$ is:

$$
f_{b}=\frac{(149.977)(12)}{38.3}=46.99 \mathrm{ksi}
$$


The sheet bending factor of safety $\left(\mathrm{FS}_{1}\right)$ is:

$$
F S_{1}=\frac{50}{46.99}=1.06
$$

The soil factor of safety $\left(\mathrm{FS}_{2}\right)$ is determined by trial and error (Asker 1988). The penetration of the pile required for equilibrium, calculated by using $\mathrm{FS}_{2}$, equals the actual penetration of the pile. Finally, the soil factor of safety is determined to be $\mathrm{FS}_{2}=2.0$.

For sheet bending failure, the design factor of safety (2.0) is greater than the actual factor of safety (1.06). The safety condition index is:

$$
C I_{1}=40+60\left(\frac{1.06-1}{2-1}\right)=43.6 \quad(\text { Zone } 2)
$$

For soil failure, the design factor of safety (2.0) is equal to the actual factor of safety (2.0). The safety condition index is:

$$
C I_{2}=100
$$

The combined structural condition index is:

$$
\text { Structural CI }=\left(\frac{43.6}{100}\right)\left(\frac{100}{100}\right)(100)=43.6(\text { Zone } 2)
$$

The condition index of the cantilever wall is the minimum of functional and structural condition index. Thus the condition index for the cantilever wall is:

$$
\mathrm{Cl}=43.6(\text { Zone } 2)
$$

The CI is used to alert engineers with the current condition of structures (Greimann and Stecker 1990b). A CI below 70, as in this example, is a good indication that M\&R alternatives should be evaluated. The field inspection and CI calculation also provide the problem list and M\&R alternatives (Section 7.1.2). M\&R strategies over the analysis period should be determined through reliability assessment for structures with relatively low CI (structures in CI Zone 2 and 3) (Section 7.1.3). The maintenance 
alternatives are then assessed using the LCCA and environmental LCA methods (Section 7.1.4).

\subsubsection{Problem list and M\&R alternatives}

The condition index (43.6) of the structure falls in the lower part of Zone 2; therefore, the LCA of M\&R alternatives is recommended to determine the appropriate action. Note that one can go directly to the risk and reliability analysis from the field inspection; however, the CI is an established algorithm that automatically follows the field inspection. In addition, the $\mathrm{CI}$ analysis is an excellent tool to build the problem list and M\&R alternatives. The appropriate maintenance action could be a series of small relatively minor fixes or complete replacement. (The problem list generated from the field inspection and CI was shown in Table 8.) Misalignment and corrosion are two identified distresses. The appropriate M\&R action depends on the cause of the problem. To fix the misalignment problem, sections of wall could be replaced, the anchor system could be added, and the dredge line brought back to design levels and protected. The misalignment is determined to be caused by the change of the dredge line. To fix this problem, the dredge line should be brought back to design level and protected. To fix the corrosion distress, sections of wall could be replaced or the protective coating could be added.

Three possible M\&R alternatives are therefore determined and subsequently explored:

1. Bring the dredge line back to the design level to fix the misalignment problem; sandblast the areas affected by corrosion, weld thin steel sheets to these areas and paint;

2. Raise the dredge line $2 \mathrm{ft}$ higher than the current level and add anchor system to fix the misalignment problem; sandblast the areas affected by corrosion, weld thin steel sheets to these areas and paint;

3. Do nothing and replace later.

The third alternative is to do nothing. However, Section 7.1.3.4 shows that without any M\&R activity, the structure cannot reach the designed lifetime of 100 years.

If the structure fails by LCCA and environmental LCA, then alternative 3 will be implemented. The economic and environmental impacts of alternative 1 and 2 will now be compared with the alternative 3 . 
Which alternative is finally selected depends on the LCCA and environmental LCA. The structure should be replaced) if neither of the two alternatives has less life-cycle cost and environmental impacts than the replacement of the entire structure (Alternative 3) in the analysis period. The expected lifetime of the structure is 100 years. The analysis period is 40 years from present (2010) to the expected lifetime of the structure (2050). It should be noted that the optimal M\&R alternative can be selected just based on the life-cycle cost criteria alone. The environmental analysis is merely a sustainable option which can be completed once the economic analysis is finished. The combination of economic and environmental impacts, however, can help make an informed and sustainable maintenance and repair decision.

\subsubsection{Risk and reliability analysis}

\subsubsection{Failure limit state}

The misalignment and corrosion distresses are determined to be most likely related to the bending failure limit state. The current reliability index of the bending failure limit state is to be calculated.

The bending failure limit state function using Eq.5-11 (proposed in Section 5.2.1 and repeated here for convenience) is:

$$
g\left(F_{y}, k\right)=F_{y}-\frac{M_{\max } k}{S}
$$

where:

$\mathrm{F}_{\mathrm{y}}=$ the yield stress of the steel;

$\mathrm{M}_{\max }=$ the maximum moment in the pile;

$\mathrm{S}=$ section modulus; and

$\mathrm{k}=$ an uncertainty factor.

\subsubsection{Calculation of the reliability index}

Calculation without incorporating the steel corrosion model

The yield stress of the steel (Fy) is a random variable. It is assumed to be normally distributed with a mean value of $49.64 \mathrm{ksi}\left({ }_{F_{\mathrm{y}}}=49.64 \mathrm{ksi}\right)$ and a standard deviation of $4.62 \mathrm{ksi}\left({ }_{F_{y}}=4.62 \mathrm{ksi}\right)$. The random stress uncer- 
tainty factor $\mathrm{k}$ is assumed lognormally distributed with a mean value of $0.96\left(\mu_{k}=0.96\right)$ and a standard deviation of $0.12\left(\sigma_{k}=0.12\right)$. The maximum moment Mmax is a random variable depending on the water elevation, top of the pile to dredge distance, soil properties, boundary conditions, etc. The section modulus ( $\mathrm{S}$ ) is also a random variable that is dependent on the cross-sectional dimension properties. The bending failure limit state function becomes a non-linear function if all four random variables (Fy, Mmax, $k, S$ ) are considered. Then the reliability index of the non-linear limit state function can be determined by the simultaneous equation procedure described in Section 5.4.2. For the purposes of this example, the maximum moment (Mmax) and the section modulus (S) are assumed to be deterministic variables. The bending failure limit state function (Eq. 5-14) is then simplified to a linear function:

$$
g\left(F_{y}, k\right)=F_{y}-\frac{149.977(12) k}{38.3}=F_{y}-46.99 k
$$

The reliability index, $\beta$, of the cantilever wall is calculated using Eq. 5-27 (first proposed in Section 5.4.1 and repeated here for convenience) as follows:

$$
\beta=\frac{a_{0}+\sum_{i=1}^{n} a_{i} u_{x i}}{\sqrt{\sum_{i=1}^{n}\left(a_{i} \sigma_{x i}\right)^{2}}}=\frac{1(49.64)-46.99(0.96)}{\sqrt{[(1)(4.62)]^{2}+[(46.99)(0.12)]^{2}}}=0.62
$$

The probability of failure is $P_{f}=\Phi(-\beta)=0.268=26.8 \%$. It indicates a relatively high possibility for the structure to fail within the remaining 40 years of design life. The target threshold of reliability index in the timedependent reliability index profile is usually determined by engineering experts, upper level management, or similar. In this example, it is determined by letting the safety factor equal 1.0 (i.e., when the design strength at the maximum moment is equal to the yield strength, $50 \mathrm{ksi}$ ). The target reliability index is then calculated to be 0.22 , and the corresponding probability of failure is $41.3 \%$. 


\section{Calculation with incorporating the steel corrosion model}

The location where the maximum moment occurs is $5.40 \mathrm{ft}$ below the dredge line. If corrosion deterioration below the dredge line is considered, one can then utilize the assumed corrosion deterioration model (proposed in Section 5.2.1 as Eq. 5-17 and repeated here for convenience):

$$
\log 2 C=\log 23.4+0.65 \log t+\varepsilon_{c}
$$

where:

$\mathrm{C}=$ the thickness loss (micrometers) due to corrosion underground;

$\mathrm{t}=$ time (years); and

$\varepsilon_{c}=$ an uncertainty factor with a mean of 0 and standard deviations of

0.219 .

From Eq. 7-13, the mean value of the thickness loss $\mathrm{C}$ when $\mathrm{t}=60$ (i.e., 60 years after the structure was built) is $168 \mu \mathrm{m}\left(661.4 \times 10^{-5} \mathrm{in}\right.$. ). The original thickness of a PZ32 section is $12.7 \mathrm{~mm}$ (0.5 in.) (Asker 1988). The section thickness is then calculated to be $12.53 \mathrm{~mm}$ ( $0.4933 \mathrm{in}$.) with a standard deviation of $0.83 \mu \mathrm{m}\left(3.27 \times 10^{-5} \mathrm{in}\right.$.). The bending failure limit function and the reliability index are:

$$
\begin{gathered}
g\left(F_{y}, k\right)=F_{y}-\frac{149.977(12) k}{36.3}=F_{y}-49.6 k \\
\beta=\frac{a_{0}+\sum_{i=1}^{n} a_{i} u_{x i}}{\sqrt{\sum_{i=1}^{n}\left(a_{i} \sigma_{x i}\right)^{2}}}=\frac{1(49.64)-49.6(0.96)}{\sqrt{[(1)(4.62)]^{2}+[(49.6)(0.12)]^{2}}}=0.27
\end{gathered}
$$

The probability of failure is $P_{f}=\Phi(-\beta)=0.394=39.4 \%$. The probability of failure was predictably increased from $26.8 \%$ to $39.4 \%$ by incorporating the steel corrosion model.

\subsubsection{Updating the reliability index with inspection results}

The reliability index ( $\beta=0.27$ ) in Section 7.1.3.2 was determined by the maximum moment ( $\mathrm{M}_{\max }=149.977$ kips.ft) that occurs $5.4 \mathrm{ft}$ below the 
dredge line. The maximum tensile stress might occur at the splash zone, where the corrosion is most severe and can be determined by visual inspection. The reliability of the structure should also be checked at this most severe corrosion location. The corrosion deterioration models should and can be updated using the visual inspection results described in Section 5.5 in order to calculate the reliability index. The following calculation shows how to update the reliability of the structure by the Bayesian technique. In this example, the most severe corrosion location (splash zone) is not the critical location to determine the reliability index because the moment where the corrosion is most severe (splash zone) is only 0.345 kips·ft. Using Eq. 5-13 for steel corrosion model in splash zone (proposed in Section 5.2.1 and repeated here for convenience):

$$
\log C=\log 148.5+0.903 \log t+\varepsilon_{c}
$$

with $\mathrm{t}=60$, the mean and standard deviation of the thickness loss are then determined to be $6 \mathrm{~mm}$ (0.236 in.) and $0.594 \mathrm{~mm}$ (0.0234 in.) respectively. At the splash zone, it is determined that "obvious uniform thickness reduction" is observed. According to Table 9, the mean and standard deviation of the thickness loss are taken as $2000 \mu \mathrm{m}(0.079 \mathrm{in}$.) and $510 \mu \mathrm{m}$ (0.02 in.) based on the level 4 field inspection rating of corrosion. The functional CI due to corrosion equals 40 (Table 8), which was calculated based on the level 4 field inspection corrosion data.

Table 9. Conditions state definitions for corrosion levels (adapted from Estes et al. 2003)

\begin{tabular}{|l|l|l|l|l|}
\hline $\begin{array}{l}\text { Rating } \\
\text { level }\end{array}$ & Description & \multicolumn{1}{|c|}{ mils } & \multicolumn{2}{|c|}{ Thickness loss per side } \\
\hline 0 & New condition & 0 & 0 & - \\
\hline 1 & $\begin{array}{l}\text { Minor surface scale or widely scattered small } \\
\text { pits }\end{array}$ & $0-8$ & $0-200$ & LN[100,51] \\
\hline 2 & $\begin{array}{l}\text { Considerable surface scale and / or moderate } \\
\text { pitting }\end{array}$ & $0-20$ & $0-500$ & LN[250,128] \\
\hline 3 & $\begin{array}{l}\text { Severe pitting in dense pattern, thickness } \\
\text { reduction in local areas }\end{array}$ & $0-40$ & $0-1000$ & LN[500,255] \\
\hline 4 & Obvious uniform thickness reduction & $40-120$ & $1000-3000$ & $\mathrm{~N}[2000,510]$ \\
\hline 5 & $\begin{array}{l}\text { Holes due to thickness reduction and general } \\
\text { thickness reduction }\end{array}$ & $>120$ & $>3000$ & $\mathrm{~N}[4500,1531]$ \\
\hline
\end{tabular}

Note: LN represents the log-normal distribution; $\mathrm{N}$ represents the normal distribution.

Using the Bayesian updating (Eq. 5-32 and 5-33, proposed in Section 5.5.3 of Chapter 5 and repeated here for convenience): 


$$
\begin{gathered}
\mu^{\prime \prime}=\frac{\mu\left(\sigma^{\prime}\right)^{2}+\mu^{\prime}(\sigma)^{2}}{\left(\sigma^{\prime}\right)^{2}+(\sigma)^{2}} \\
\sigma^{\prime \prime}=\sqrt{\frac{\left(\sigma^{\prime}\right)^{2}(\sigma)^{2}}{\left(\sigma^{\prime}\right)^{2}+(\sigma)^{2}}}
\end{gathered}
$$

with $\mu=2 \mathrm{~mm}\left(0.079\right.$ in.), $\mu^{\prime}=6 \mathrm{~mm}$ (0.236 in.), $\sigma=0.51 \mathrm{~mm}$ (0.02 in.) and $\sigma^{\prime}=0.594 \mathrm{~mm}$ (0.0234 in.), the mean value ( $\left.\mu^{\prime \prime}\right)$ and standard deviation ( $\sigma^{\prime \prime}$ ) of thickness loss are updated to be $3.7 \mathrm{~mm}$ and $0.39 \mathrm{~mm}$. The section modulus is then calculated to be 9.1.in ${ }^{3}$ which is reduced from 36.3 $\mathrm{in}^{3}$. The tensile stress at the location where the corrosion is most severe is calculated to be $0.455 \mathrm{ksi}$, which is much less than the yield strength (50 $\mathrm{ksi}$ ) and indicates the location is not critical to yield. The reliability index is calculated to be 10.65 and hence the probability of failure is negligible $\left(<10^{-9}\right)$, which is far below the probability of failure limit recommended for a newly constructed structure of 1/ 100,000 (Nilson \&Winter 1991).

The reliability index ( $\beta=4.95$ ) at the splash zone is therefore not used to develop the time-dependent reliability index profile for the M\&R alternatives. But it should be noted that, in some cases, the maximum tensile stress can occur at the splash zone, and therefore, the reliability index has to be updated by using the visual inspection data to depict the reliable condition versus time curve.

\subsubsection{Time-dependent reliability index profile}

The current reliability index of the structure is calculated to be $\beta=0.27$, which is used to develop the time-dependent reliability index profile. For convenience, the three $M \& R$ alternatives are repeated here.

1. Bring the dredge line back to the design level to fix the misalignment problem; sandblast the areas affected by corrosion, weld thin steel sheets to these areas and paint.

2. Raise the dredge line 2- $\mathrm{tt}$ higher than the current level and add anchor system to fix the misalignment problem; sandblast the areas affected by corrosion; weld thin steel sheets to these areas and paint.

3. Do nothing and replace later.

In this example, bringing the dredge line back to the design level or raising the dredge line $2 \mathrm{ft}$ higher improves the reliability index of the structure. 
To depict the curve, some uncertainties are also needed (e.g., improvement of reliability due to one M\&R alternative and the deterioration rate used in this example). Those uncertainties are determined from a statistical analysis for SSP structures or similar hydraulic steel structure inspection data and M\&R records (as detailed in Section 5.6). To simplify the analysis, only the improvements of reliability and deterioration rates due to M\&R alternatives 1 and 2 are used. The assumed uncertainties are summarized in Table 10. Using the information in Table 10, the timedependent reliability index profiles of Alternatives 1 and 2 are depicted in Figure 7 and compared with the time-dependent reliability index profiles without any M\&R activities.

Table 10. Uncertainties for the time-dependent reliability index profile.

\begin{tabular}{|l|l|l|}
\hline M\&R & Improvement of Reliability Index & Deterioration Rate(per year) \\
\hline Alternative 1 & 0.715 & 0.014 \\
\hline Alternative 2 & 0.6 (0.07 subsequent coating) & 0.02 \\
\hline Without M\&R & 0 & 0.007 \\
\hline
\end{tabular}

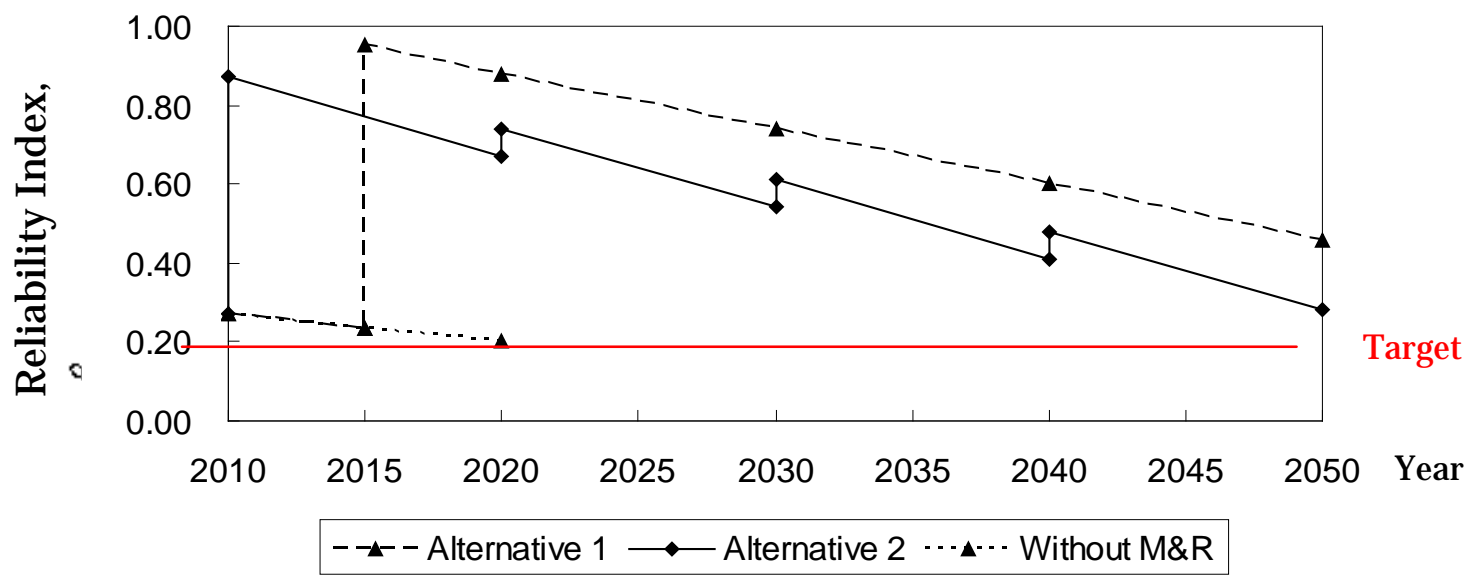

Figure 7. Time-dependent reliability index profiles.

The target reliability index is 0.22 (factor of safety equal to 1.0) and the corresponding probability of failure is $41.3 \%$. According to the timedependent reliability index profiles (Figure 7), without any M\&R activity, the structure cannot reach the designed lifetime of 100 years. This is because, by the year of 2020, the reliability index drops below the target reliability index (0.22). Alternative 1 needs to be implemented in 2015 when the reliability index is close to 0.22. By 2050, the reliability index of Alternative 1 remains well above the target value (0.22). Raising the dredge line 
$2 \mathrm{ft}$ higher (Alternative 2) has to be implemented every 10 years from present to 2050 to keep the structure safe (above 0.22 ) by 2050. The third alternative (structural replacement) needs to be implemented in 2015. Without any M\&R activity, if the structure is replaced in 2015 it is predicted to still be safe in 2050. The economic and environmental LCA impacts of the three alternatives are now compared for optimal selection.

\subsubsection{Impacts of LCCA and environmental LCA}

\subsubsection{Impacts of LCCA}

The relative costs of the three M\&R alternatives are summarized in Table 11. The analysis period is 40 years, from 2010-2050. The total present worth of costs (TPWC) for the three alternatives is calculated using Eq. 6-2 (shown again as Eq. 7-19 below). The discount rate is 5\%. The user cost is not applicable in this calculation. The TPWC for the three alternatives are shown in Table 11.

$T P W C_{x 1, n}=(I C C)_{x 1}+\sum_{t=0}^{n}\left\{p w f_{i, t}\left[(C C)_{x 1, t}+(M O)_{x 1, t}+(U C)_{1, t}\right]\right\}-p w f_{i, n}(S V)_{x 1, n}$

Table 11. Cost comparison of the three alternatives.

\begin{tabular}{|c|c|c|c|c|c|c|}
\hline \multirow{2}{*}{ Construction Time (Year) } & \multirow{2}{*}{$\begin{array}{l}\text { Alternative } 1 \\
2015\end{array}$} & \multicolumn{4}{|c|}{ Alternative 2} & \multirow{2}{*}{$\begin{array}{l}\text { Alternative } 3 \\
2015\end{array}$} \\
\hline & & 2010 & 2020 & 2030 & 2040 & \\
\hline $\begin{array}{l}\text { Professional and } \\
\text { technical services }(\$)\end{array}$ & 10,000 & 1,000 & 1,200 & 1,400 & 1,600 & 15,000 \\
\hline $\begin{array}{l}\text { Materials (steel, coating, } \\
\text { etc) }(\$)\end{array}$ & 8,000 & 2,400 & 2,800 & 3,200 & 3,600 & 20,000 \\
\hline Transportation (\$) & 3,500 & 800 & 900 & 1,000 & 1,100 & 5,000 \\
\hline $\begin{array}{l}\text { M\&R/Initial } \\
\text { Construction (\$) }\end{array}$ & 30,000 & 7,600 & 8,000 & 8,400 & 8,800 & 50,000 \\
\hline $\begin{array}{l}\text { Residual Value* at } \\
2050(\$)\end{array}$ & 15,000 & \multicolumn{4}{|l|}{12,000} & 55,000 \\
\hline TPWC (\$) & 38,221 & \multicolumn{4}{|l|}{26,785} & 70,114 \\
\hline
\end{tabular}

* Residual value is based on the remaining life.

Based on the LCCA results, Alternative 2 is the optimal M\&R strategy with the minimum cost. The economic impact of Alternative 3 is over twice that of Alternative 1, which is more costly than Alternative 2. 


\subsubsection{Environmental Impacts}

The cradle-to-cradle model (Table 12, first proposed in Chapter 6) is employed to calculate the GHG emission and energy consumption during the analysis period. The landfill costs of the three alternatives are assumed to be the same $(\$ 20,000)$. Environmental impacts are shown in Table 13.

Based on the environmental LCA results, Alternative 2 is still to be selected as the optimal M\&R strategy with the minimum impacts. The energy consumption of Alternative 3 is over 2.5 times greater and GHG emission is over 3 times greater than Alternative 1. Alternative 1 emits GHG over 11 times and consumes energy almost 4 times that of Alternative 2 respectively. If the three $M \& R$ alternatives are ranked according to the economic and environmental impacts, the ranking is summarized in Table 14. In Table 14, " 1 " and " 3 " represent the least and most severe impacts respectively. Table 14 clearly shows Alternative 2 is the optimal M\&R alternative with and without LCA environmental impacts. 
Table 12. Cradle-to-cradle LCA model for SSP structures.

\begin{tabular}{|l|l|l|l|l|}
\hline Process & Note & $\begin{array}{l}\text { Sector No. } \\
\text { EIO-LCA }\end{array}$ & $\begin{array}{l}\text { Total Energy } \\
\mathrm{MJ} / \mathbf{\$ 1 0 , 0 0 0}\end{array}$ & $\begin{array}{l}\text { Total } \\
\mathrm{MTCO}_{2} \mathrm{E} / \mathbf{\$ 1 0 , 0 0 0}\end{array}$ \\
\hline $\begin{array}{l}\text { Professional } \\
\text { and technical } \\
\text { services }\end{array}$ & $\begin{array}{l}\text { Initial design \& } \\
\text { condition } \\
\text { evaluation }\end{array}$ & 541300 & $0.64 \times 10^{4}$ & 0.36 \\
\hline \multirow{2}{*}{ Materials } & $\begin{array}{l}\text { Steel } \\
\text { manufacturing }\end{array}$ & 331110 & $30.1 \times 10^{4}$ & 25.9 \\
\cline { 2 - 5 } & Painting \& coating & 325510 & $1.02 \times 10^{4}$ & 0.31 \\
\hline Transportation & $\begin{array}{l}\text { Truck } \\
\text { transportation }\end{array}$ & 484000 & $13.4 \times 10^{4}$ & 9.86 \\
\hline \multirow{2}{*}{ Construction } & Initial construction & 230103 & $3.16 \times 10^{4}$ & 2.00 \\
\cline { 2 - 5 } & M\&R & 230301 & $3.80 \times 10^{4}$ & 2.43 \\
\hline \multirow{2}{*}{$\begin{array}{l}\text { Landfill } \\
\text { avoidance }\end{array}$} & $\begin{array}{l}\text { Recycling, waste } \\
\text { management } \\
\text { avoidance }\end{array}$ & 562000 & $\left(1.42 \times 10^{4}\right)$ & $(22.9)$ \\
\hline
\end{tabular}

Table 13. Environmental impacts of the three alternatives.

\begin{tabular}{|l|l|l|l|l|l|l|}
\hline \multirow{2}{*}{ Process } & \multicolumn{3}{|l|}{ Alternative 1 } & \multicolumn{2}{l|}{ Alternative 2 } & \multicolumn{2}{l|}{ Alternative 3 } \\
\cline { 2 - 7 } & $\begin{array}{l}\text { GHG } \\
\text { (MTCO2E) }\end{array}$ & $\begin{array}{l}\text { Energy } \\
\text { (MJ) }\end{array}$ & $\begin{array}{l}\text { GHG } \\
\text { (MTCO2E) }\end{array}$ & $\begin{array}{l}\text { Energy } \\
\text { (MJ) }\end{array}$ & $\begin{array}{l}\text { GHG } \\
\text { (MTCO2E) }\end{array}$ & $\begin{array}{l}\text { Energy } \\
\text { (MJ) }\end{array}$ \\
\hline $\begin{array}{l}\text { Professional and } \\
\text { technical services }\end{array}$ & 0.282 & 5015 & 0.095 & 1686 & 0.54 & 9600 \\
\hline $\begin{array}{l}\text { Materials (steel or } \\
\text { coating) }\end{array}$ & 16.235 & $\begin{array}{l}18867 \\
3\end{array}$ & 0.191 & 6281 & 51.8 & $\begin{array}{l}60200 \\
0\end{array}$ \\
\hline Transportation & 2.704 & 36747 & 1.956 & $\begin{array}{l}2658 \\
5\end{array}$ & 4.93 & 67000 \\
\hline $\begin{array}{l}\text { Construction (Initial or } \\
\text { M\&R) }\end{array}$ & 5.712 & 89322 & 4.304 & $\begin{array}{l}6731 \\
1\end{array}$ & 11 & $\begin{array}{l}15800 \\
0\end{array}$ \\
\hline Landfill avoidance & -4.86 & -28400 & -4.86 & $\begin{array}{l}-2840 \\
0\end{array}$ & -4.86 & -28400 \\
\hline Total & 20.073 & $\begin{array}{l}29135 \\
7\end{array}$ & 1.686 & $\begin{array}{l}7346 \\
2\end{array}$ & 63.41 & $\begin{array}{l}80820 \\
0\end{array}$ \\
\hline
\end{tabular}

Table 14.Ranking of the three wall alternatives.

\begin{tabular}{|l|l|l|l|}
\hline M\&R & Economic & Environmental & Average Ranking \\
\hline Alternative 1 & 2 & 2 & 2 \\
\hline Alternative 2 & 1 & 1 & 1 \\
\hline Alternative 3 & 3 & 3 & 3 \\
\hline
\end{tabular}




\subsection{Example SSP cell structure*}

In this example, a single cell on rock foundation filled with sand is to be rated for condition status. It was built in 1950. This structure has not experienced any prior M\&R activity. The expected lifetime is 100 years. The cell has an 8-in. thick concrete cap. The plan and cross-section of the cell are shown in

Figure 8. The concrete cap is considered as a surcharge load and is calculated by $Q=\left(\frac{8}{12}\right)(150)=100$ psf. After a detailed field inspection, the distresses in Table 15 are identified and the corresponding CIs are calculated. The inspection was completed in 2010.

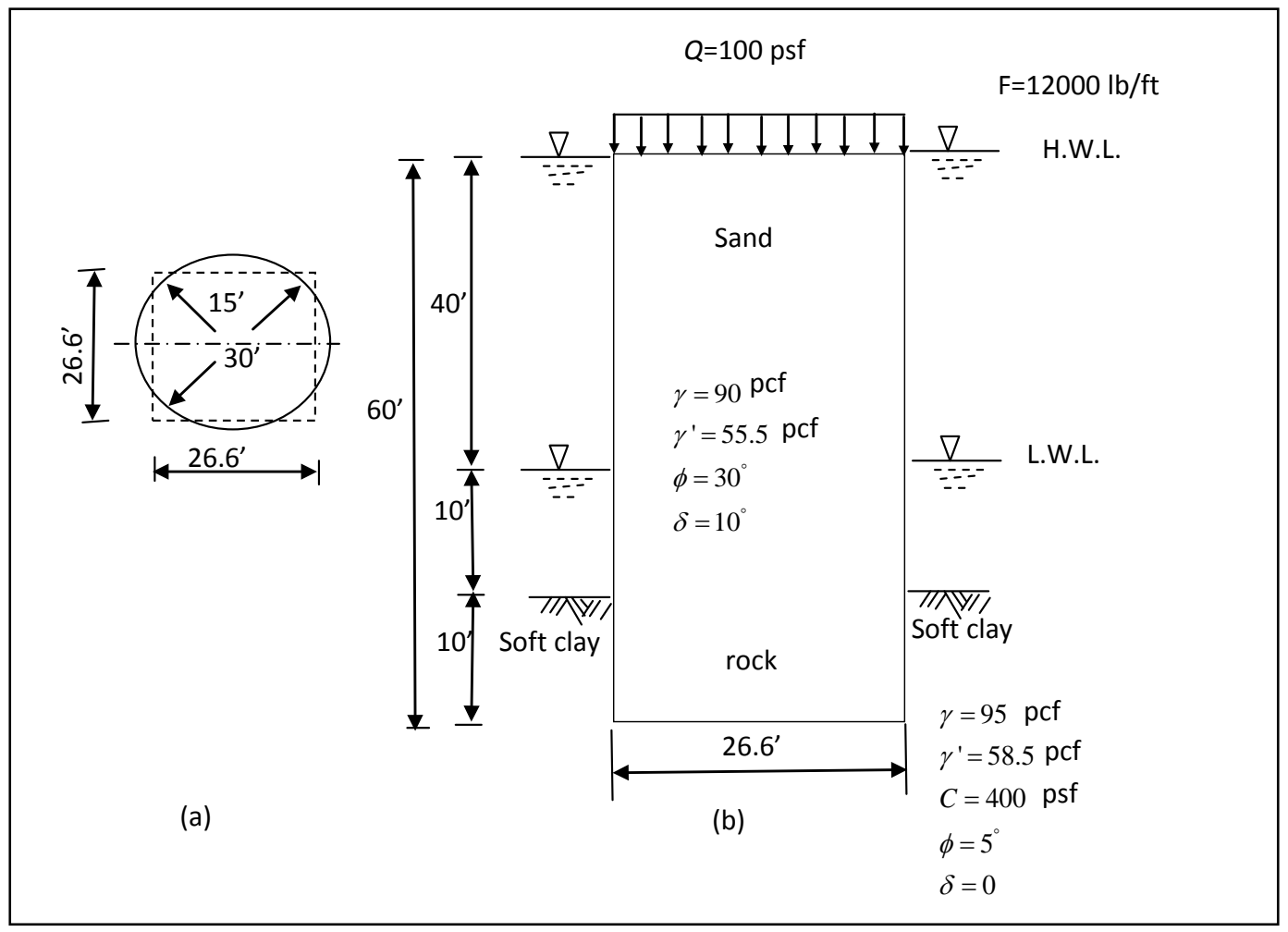

Figure 8. Single cell on rock foundation: (a) plan; (b) cross section. 
Table 15. Cl data example distresses for SSP cell example.

\begin{tabular}{|l|l|l|l|l|l|}
\hline Distresses & $\mathrm{Cl}$ & $\boldsymbol{w}_{\boldsymbol{i}}$ & Adjustment factor & Revised $\boldsymbol{w}_{\boldsymbol{i}}$ & Revised $\boldsymbol{W}_{\boldsymbol{i}}(\%)$ \\
\hline Misalignment & 30 & 8 & 8 & 64 & 51.2 \\
\hline Corrosion & 40 & 5 & 8 & 40 & 32 \\
\hline Settlement & 80 & 4 & 1 & 4 & 3.2 \\
\hline Cavities & 100 & 4 & 1 & 4 & 3.2 \\
\hline Interlock Separation & 100 & 4 & 1 & 4 & 3.2 \\
\hline Holes & 100 & 3 & 1 & 3 & 2.4 \\
\hline Dents & 100 & 2 & 1 & 2 & 1.6 \\
\hline Cracks & 100 & 4 & 1 & 4 & 3.2 \\
\hline Total & - & - & - & 125 & 100 \\
\hline
\end{tabular}

\subsubsection{Condition index}

Functional $\mathrm{Cl}=0.512(30)+0.32(40)+0.032(80)+0.032(100)+0.032(100)+0.024$

$(100)+0.016(100)+0.032(100)=44($ lower end of Zone 2$)$

To calculate the structural CI of the cell, the factors of safety against vertical shear, sliding on foundation, and bursting are calculated per Asker (1988).

\subsubsection{Vertical Shear}

The net overturning moment $\left(\mathrm{M}_{0}\right)$ is:

$$
M_{0}=12,000 \times 60=720,000 \mathrm{lb} \cdot \mathrm{ft} / \mathrm{ft}
$$

The resisting moment $\left(\mathrm{M}_{\mathrm{r}}\right)$ is:

For high water level

$$
M_{r}=\frac{2}{3}(44,105)(26.6)+55,265=837,394 \mathrm{lb} \cdot \mathrm{ft} / \mathrm{ft}
$$

For low water level

$$
M_{r}=\frac{2}{3}(67,378)(26.6)+55,265=1,250,102 \mathrm{lb} \cdot \mathrm{ft} / \mathrm{ft}
$$

The factor of safety against vertical shear is then calculated as: 
For high water level

$$
F S_{1}=\frac{837,394}{720,000}=1.16
$$

For low water level

$$
F S_{1}=\frac{1,250,102}{720,000}=1.73
$$

The design factor of safety should be greater than or equal to 1.5. Therefore, the CIs against vertical shear are:

For high water level

$$
C I_{1}=40+\frac{1.16-1}{1.5-1}(60)=59(\text { Zone } 2)
$$

For low water level

$$
C I_{1}=100
$$

\subsubsection{Sliding on foundation}

The passive force $\left(F_{p}\right)$ is calculated as $12,214 \mathrm{lb} / \mathrm{ft}$. The weight of the fill $\mathrm{W}$, the frictional resistance along the bottom of the cell $\left(\mathrm{F}_{\mathrm{f}}\right)$ and the sliding factors of safety $\left(\mathrm{FS}_{2}\right)$ are :

For high water lever

$$
\begin{gathered}
W=(100+55.5 \times 60)(26.6)=91,238 \mathrm{lb} / \mathrm{ft} . \\
F_{f}=(91,238)(0.5)=45,619 \mathrm{lb} / \mathrm{ft} \\
F S_{2}=\frac{12,214+45,619}{12,000}=4.82
\end{gathered}
$$

For low water level

$$
W=(100+90 \times 40+55.5 \times 20)(26.6)=127,946 \mathrm{lb} / \mathrm{ft}
$$




$$
\begin{gathered}
F_{f}=(127,946)(0.5)=63,973 \mathrm{lb} / \mathrm{ft} \\
F S_{2}=\frac{12,214+63,973}{12,000}=6.35
\end{gathered}
$$

The design factor of safety against sliding should be greater than or equal to 1.5. Therefore, the CI for both high and low water levels is:

$$
C I_{2}=100
$$

\subsubsection{Bursting}

The minimum ultimate interlock strength $\left(t_{u}\right)$ for a PSA28 SSP section, is $12,000 \mathrm{lb} / \mathrm{in}$. The radius of the cell $(\mathrm{R})$ is $15 \mathrm{ft}$.

For high water level

The maximum pressure $\left(\sigma_{t}\right)$ is calculated as $801 \mathrm{psf}$. The maximum interlock tension is.

$$
t_{\max }=(801)(15)\left(\frac{1}{12}\right)=1001 \mathrm{lb} / \text { in }
$$

The factor of safety against bursting is then:

$$
F S_{3}=\frac{12,000}{1,001}=11.99
$$

For low water level

The maximum pressure $\left(\sigma_{t}\right)$ is calculated as 1,227 psf. The maximum interlock tension is:

$$
t_{\max }=(1,227)(15)\left(\frac{1}{12}\right)=1,534 \mathrm{lb} / \mathrm{in}
$$

The factor of safety is then:

$$
F S_{3}=\frac{12,000}{1,534}=7.82
$$


The design factor of safety should be greater than or equal to 4 for a PSA28 SSP section. Therefore, the CI for both high and low water levels is $C I_{3}=100$.

\subsubsection{Combined structural condition index}

For high water level

$$
C I=\frac{59}{100}\left(\frac{100}{100}\right)\left(\frac{100}{100}\right)(100)=59
$$

For low water level

$$
C I=100
$$

The CI of the cantilever wall is the minimum of functional and structural condition index. Thus the CI for the cell is:

$$
\mathrm{Cl}=44 \text { (Zone 2) }
$$

The CI is below 70; thus the wall becomes a candidate forM\&R activity and therefore a candidate for rehabilitation. The field inspection and CI calculation provide a problem list and potential M\&R alternatives. M\&R strategies over the analysis period should be determined through reliability assessment for structures with relatively low CIs (structures in CI Zone 2 and Zone 3). The preferred maintenance activity is then determined by the LCCA and environmental LCA of M\&R alternatives.

\subsubsection{Problem list and M\&R alternatives}

The condition index (44) of the structure falls in the lower part of Zone 2; therefore, the LCA of M\&R alternatives is recommended to determine the appropriate maintenance action. Note that one can go directly to the risk and reliability analysis from the field inspection. However, the CI is an established algorithm that automatically follows from the field inspection. In addition, the CI analysis is an excellent tool to build the problem list and M\&R alternatives. The problem list generated from the field inspection and CI was shown in Table 8. Misalignment and corrosion are the identified distresses below 70. To fix the two problems, there are three possible $M \& R$ alternatives to be determined and subsequently explored, as listed here. 
1. Bring the dredge line back to the design level to fix the misalignment problem; replace sections of wall suffering from severe corrosion.

2. Bring the dredge line back to the design level to fix the misalignment problem; sandblast the areas affected by corrosion; weld thin steel sheets to these areas and paint.

3. Do nothing and replace later.

Which alternative is finally selected depends on the LCCA and environmental LCA impacts. It should be noted that the optimal M\&R alternative can be selected just based on the life-cycle cost criteria alone. However, this example will complete both. The expected lifetime of the structure is 100 years. The analysis period is 40 years from present (2010) to the expected lifetime of the structure (2050).

\subsubsection{Risk and reliability analysis}

\subsubsection{Failure limit state}

The misalignment distress is determined to be most likely related to the vertical shear failure mode as indicated in Figure 4 of Chapter 4 . As indicated by Table 8 , corrosion is an identified stress $(\mathrm{CI}=40)$. The factors of safety calculated for bursting failure mode were for structures which were assumed to behave as designed. The corrosion distress reduces the reliability of the structure for the bursting failure limit state. Therefore, the reliability of the deteriorated structure should be analyzed for both the vertical shear failure and the bursting failure limit states.

The vertical shear failure limit state function using Eq. 5-19 (proposed in Section 5.3.1 of Chapter 5 and repeated here for convenience) is:

$$
g\left(M_{r}, M_{0}\right)=M_{r}-M_{0}
$$

where:

$M_{0}=$ net overturning moment per unit length of cell;

$M_{r}=$ the resisting moment per unit length of cell. 
The bursting failure limit state function (using Eq. 5-24, initially proposed in Section 5.3.3 of Chapter 5 and reproduced here for convenience) is:

$$
g\left(t, \sigma_{t}\right)=\frac{T_{u} t}{t_{0}}-\sigma_{t} R
$$

where:

$\mathrm{T}_{\mathrm{u}}=$ the minimum ultimate interlock strength per unit length for straight web sections;

$\mathrm{t}=$ the thickness of the SSP cell;

$t_{0}=$ original thickness of the SSP cell;

$\sigma_{t}=$ the maximum interlock pressure in the main cell; and

$\mathrm{R}=$ the cell radius. The current reliability index is then the minimum value calculated from the vertical shear failure limit state and bursting failure limit state.

\subsubsection{Calculation of the reliability index}

Vertical shear failure limit state

The reliability index for the high water level is to be calculated because it governs the vertical shear failure limit state. The net overturning moment per unit length of cell $\left(\mathrm{M}_{0}\right)$ and the resisting moment per unit length of cell $\left(\mathrm{M}_{\mathrm{r}}\right)$ are random variables that were previously calculated. They are normally distributed. The mean values of the two variables are calculated to be $720,000 \mathrm{lb} \cdot \mathrm{ft} / \mathrm{ft}$ and 837,394 lb·ft/ft respectively, and standard deviations are calculated to be 103,450 lb·ft/ft and 95,030 lb·ft/ft respectively.

The reliability index ( $\beta$ ) of the single cell is calculated (using Eq. 4-27, previously introduced in Section 5.4.1 of Chapter 5 and reproduced here for convenience) as:

$$
\beta=\frac{a_{0}+\sum_{i=1}^{n} a_{i} u_{x i}}{\sqrt{\sum_{i=1}^{n}\left(a_{i} \sigma_{x i}\right)^{2}}}=\frac{1(837,394)-1(720,000)}{\sqrt{[(1)(103,450)]^{2}+[(1)(95,030)]^{2}}}=0.84
$$

The probability of failure is $P_{f}=\Phi(-\beta)=0.2005=20.05 \%$. The target threshold of reliability index in the time-dependent reliability index profile 
is usually determined by engineering experts, upper level management, or similar. In this example, it is determined by letting the safety factor equal 1.0 (i.e., when the resisting moment is equal to the net overturning moment). The target reliability index is then calculated to be 0 in this example because $\mathrm{M}_{\mathrm{r}}$ and $\mathrm{M}_{0}$ are assumed to have the same mean value, and the corresponding probability of failure is $50 \%$.

\section{Bursting failure limit state}

The factor of safety for the high water level (11.99) is higher than that for the low water lever (7.82). The reliability index for the low water level is to be calculated because it governs the bursting failure limit state. The location where the maximum interlock pressure occurs is given as $5 \mathrm{ft}$ below the low water level. The corrosion deterioration model (proposed in 5.2.3 as Eq. 5-17 and reproduced here for convenience) is used to calculate the thickness loss under the low water level line.

$$
\log 2 C=\log 23.4+0.65 \log t+\varepsilon_{c}
$$

where:

$\mathrm{C}=$ the thickness loss (micrometers) due to corrosion underground;

$\mathrm{t}=$ time (years); and

$\varepsilon_{c}=$ an uncertainty factor with a mean of 0 and standard deviations of 0.219 .

From Eq. 7-45, the mean value of the thickness loss $\mathrm{C}$ when $\mathrm{t}=60$ (i.e., 60 years after the structure was built) is $168 \mu \mathrm{m}\left(661.4 \times 10^{-5} \mathrm{in}\right.$.). The original thickness of a PSA28 section is $12.7 \mathrm{~mm}$ ( $0.5 \mathrm{in}$.) (Asker 1988). The section thickness is then calculated to be $12.53 \mathrm{~mm}(0.4933 \mathrm{in}$.) with a standard deviation of $0.83 \mu \mathrm{m}\left(3.27 \times 10^{-5} \mathrm{in}\right.$.). The maximum interlock pressure is calculated to be $1,227 \mathrm{psf}$, with a standard deviation of 214 psf. The bursting failure limit function and the reliability index are:

$$
g\left(t, \sigma_{t}\right)=\frac{12,000 t}{12.7}-\sigma_{t} \frac{15}{12}=944.9 t-1.25 \sigma_{t}
$$




$$
\beta=\frac{a_{0}+\sum_{i=1}^{n} a_{i} u_{x i}}{\sqrt{\sum_{i=1}^{n}\left(a_{i} \sigma_{x i}\right)^{2}}}=\frac{944.9(12.53)-1.25(1227)}{\sqrt{\left[(944.9)\left(0.83 \times 10^{-3}\right)\right]^{2}+[(1.25)(214)]^{2}}}=38
$$

The probability of failure is $P_{f}=\Phi(-\beta) \approx 0$.

The bursting might also occur at the location where the corrosion is most severe at the splash zone. The corrosion model given by Eq. 5-13 (first proposed in Chapter 5 and reproduced here for convenience) is used to calculate the thickness loss at the splash zone:

$$
\log C=\log 148.5+0.903 \log t+\varepsilon_{c}
$$

With $\mathrm{t}=60$, the mean and standard deviation of the thickness loss are then determined to be $6 \mathrm{~mm}$ ( $0.236 \mathrm{in})$ and $0.594 \mathrm{~mm}$ (0.0234 in) respectively. At the splash zone, obvious uniform thickness reduction is observed ( $\mathrm{CI}=40$ in Table 15). According to Table 16, the mean and standard deviation of the thickness loss are taken as $2000 \mu \mathrm{m}(0.079$ in) and $510 \mu \mathrm{m}$ (0.02 in.), based on the level 4 field inspection corrosion data ( $\mathrm{CI}=40$ in Table 15).

Table 16. Conditions state definitions for corrosion levels (adapted from Estes et al. 2003)

\begin{tabular}{|l|l|l|l|l|}
\hline \multirow{2}{*}{$\begin{array}{l}\text { Rating } \\
\text { level }\end{array}$} & Description & \multicolumn{3}{|l|}{ Thickness loss per side } \\
Mils & \multicolumn{2}{|c|}{ Lm } \\
\hline 0 & New condition & 0 & 0 & - \\
\hline 1 & $\begin{array}{l}\text { Minor surface scale or widely } \\
\text { scattered small pits }\end{array}$ & $0-8$ & $0-200$ & LN[100,51] $(\mu \mathrm{m})$ \\
\hline 2 & $\begin{array}{l}\text { Considerable surface scale and / } \\
\text { or moderate pitting }\end{array}$ & $0-20$ & $0-500$ & LN[250,128] \\
\hline 3 & $\begin{array}{l}\text { Severe pitting in dense pattern, } \\
\text { thickness reduction in local areas }\end{array}$ & $0-40$ & $0-1000$ & LN[500,255] \\
\hline 4 & $\begin{array}{l}\text { Obvious uniform thickness } \\
\text { reduction }\end{array}$ & $40-120$ & $1000-3000$ & $\mathrm{~N}[2000,510]$ \\
\hline 5 & $\begin{array}{l}\text { Holes due to thickness reduction } \\
\text { and general thickness reduction }\end{array}$ & $>120$ & $>3000$ & $\mathrm{~N}[4500,1531]$ \\
\hline
\end{tabular}

Using the Bayesian updating (first proposed in Section 5.5.3 of Chapter 5 as Eq. 5-32 and 5-33 and reproduced here for convenience) with $\mu=2$ 
$\mathrm{mm}(0.079 \mathrm{in}), \mu^{\prime}=6 \mathrm{~mm}$ (0.236 in.), $\sigma=0.51 \mathrm{~mm}(0.02 \mathrm{in}$.$) and$ $\sigma^{\prime}=0.594 \mathrm{~mm}(0.0234 \mathrm{in}$.):

$$
\begin{gathered}
\mu^{\prime \prime}=\frac{\mu\left(\sigma^{\prime}\right)^{2}+\mu^{\prime}(\sigma)^{2}}{\left(\sigma^{\prime}\right)^{2}+(\sigma)^{2}} \\
\sigma^{\prime \prime}=\sqrt{\frac{\left(\sigma^{\prime}\right)^{2}(\sigma)^{2}}{\left(\sigma^{\prime}\right)^{2}+(\sigma)^{2}}}
\end{gathered}
$$

The mean value ( $\mu^{\prime \prime}$ ) and standard deviation ( $\sigma^{\prime \prime}$ ) of thickness loss are updated to be $3.7 \mathrm{~mm}$ and $0.39 \mathrm{~mm}$. The cross section thickness is then calculated to be $9.00 \pm 0.39 \mathrm{~mm}$.

At that location, the interlock pressure is calculated to be $1,141 \mathrm{psf}$, with a standard deviation of 199 psf. The bursting failure limit function and the reliability index are:

$$
\begin{gathered}
g\left(t, \sigma_{t}\right)=\frac{12,000 t}{12.7}-\sigma_{t} \frac{15}{12}=944.9 t-1.25 \sigma_{t} \\
\beta=\frac{a_{0}+\sum_{i=1}^{n} a_{i} u_{x i}}{\sqrt{\sum_{i=1}^{n}\left(a_{i} \sigma_{x i}\right)^{2}}}=\frac{944.9(9.00)-1.25(1141)}{\sqrt{[(944.9)(0.39)]^{2}+[(1.25)(199)]^{2}}}=15.9
\end{gathered}
$$

The probability of failure is $P_{f}=\Phi(-\beta) \approx 0$.

The above calculation indicates the bursting failure does not govern the failure mode of the structure, but the vertical shear failure does. Therefore, the current reliability index ( $\beta=0.84$ ) is determined by the vertical shear failure limit state.

\subsubsection{Time-dependent reliability index profile}

The current reliability index of the structure was calculated to be $\beta=0.84$, which is used to develop the time-dependent reliability index profile. For convenience, the three $M \& R$ alternatives are repeated here.

1. Bring the dredge line back to the design level to fix the misalignment problem; replace sections of wall suffering from severe corrosion. 
2. Bring the dredge line back to the design level to fix the misalignment problem; sandblast the areas affected by corrosion; weld thin steel sheets to these areas and paint.

3. Do nothing and replace later.

To depict the curve, some uncertainties are needed (e.g., improvement of reliability due to one M\&R alternative and the deterioration rate used in this example). Those uncertainties are determined from a statistical analysis for SSP structures or similar hydraulic steel structure inspection data and M\&R records (as detailed in Section 5.6). To simplify the analysis, only the improvements of reliability and deterioration rates due to M\&R alternative 1 and 2 are used. The M\&R alternatives' uncertainties are summarized in Table 17. Using the information in Table 17, the timedependent reliability index profiles of Alternative 1 and Alternative 2 are depicted in Figure 9 and compared with the time-dependent reliability index profiles without any M\&R activities.

Table 17. Uncertainties for the time-dependent reliability index profile.

\begin{tabular}{|l|l|l|}
\hline M\&R & Improvement of Reliability Index & Deterioration Rate (per year) \\
\hline Alternative 1 & 0.6 & 0.02 \\
\hline Alternative 2 & 0.3 (0.2 subsequent compacting) & 0.04 \\
\hline Without M\&R & 0 & 0.08 \\
\hline
\end{tabular}

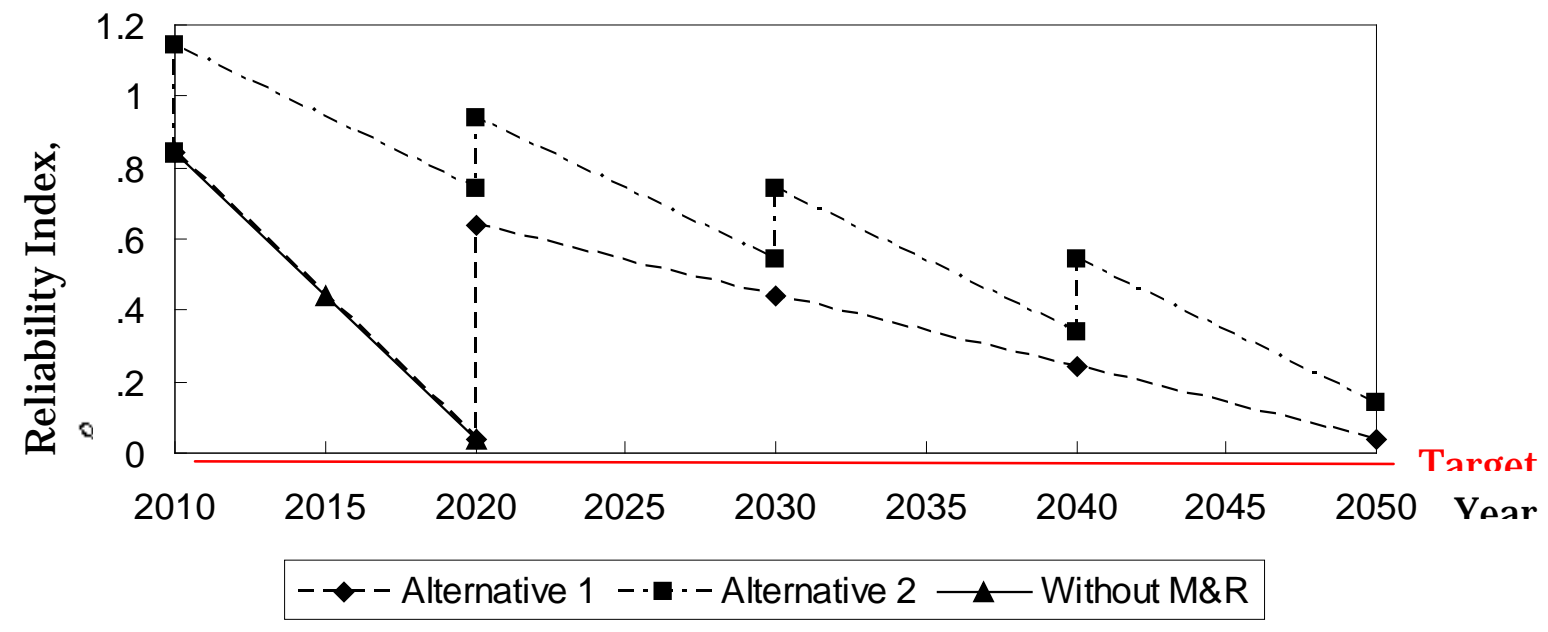

Figure 9. Time-dependent reliability index profiles.

The target reliability index is 0 (factor of safety equal to 1.0) and the corresponding probability of failure is $50 \%$. According to the time-dependent 
reliability index profiles (Figure 9), without any M\&R activity, the structure cannot reach the designed lifetime of 100 years as it reaches the target reliability index in 2020. Alternative 1 has to be implemented in 2020 when the reliability index is reduced to 0.04 . Alternative 2 has to be implemented every 10 years from present to 2050 to keep the structure safe by the year of 2050. The third alternative (structural replacement) has to be implemented in 2020 at the latest, but it was assumed to be implemented in 2015 in this example (just an assumption for LCCA). Without any M\&R activity, the structure replaced in 2015 will still be safe by 2050 . The economic and environmental LCA impacts of the three alternatives are now compared for optimal selection.

\subsubsection{Impacts of LCCA and environmental LCA}

\subsubsection{Impacts of LCCA}

The costs of the three M\&R alternatives are summarized in Table 18. The analysis period is 40 years, from 2010-2050. The TPWC for the three alternatives is calculated using Eq. 7-53 (first proposed as Eq. 6-2 in Chapter 6 and repeated below for convenience). The discount rate is $5 \%$. The user cost is not applicable in this calculation. The TPWC for the three alternatives are shown in Table 18.

$$
T P W C_{x 1, n}=(I C C)_{x 1}+\sum_{t=0}^{n}\left\{p w f_{i, t}\left[(C C)_{x 1, t}+(M O)_{x 1, t}+(U C)_{1, t}\right]\right\}-p w f_{i, n}(S V)_{x 1, n}
$$

Table 18. Cost comparison of the three alternatives.

\begin{tabular}{|c|c|c|c|c|c|c|}
\hline $\begin{array}{l}\text { Construction } \\
\text { Time (Year) }\end{array}$ & $\begin{array}{l}\text { Alternative } 1 \\
2015\end{array}$ & $\begin{array}{l}\text { Alternati } \\
2010\end{array}$ & $\begin{array}{l}\text { ve } 2 \\
2020\end{array}$ & 2030 & 2040 & $\begin{array}{l}\text { Alternative } 3 \\
2015\end{array}$ \\
\hline $\begin{array}{l}\text { Professional } \\
\text { and technical } \\
\text { services }(\$)\end{array}$ & 20,000 & 2,000 & 2,000 & 2,000 & 2,000 & 25,000 \\
\hline $\begin{array}{l}\text { Materials (steel, } \\
\text { coating etc) }\end{array}$ & 8,000 & 2,400 & 2,800 & 3,200 & 3,600 & 20,000 \\
\hline $\begin{array}{l}\text { Transportation } \\
(\$)\end{array}$ & 10,000 & 5,000 & 3,000 & 3,000 & 3,000 & 10,000 \\
\hline $\begin{array}{l}\text { M\&R/Initial } \\
\text { Construction (\$) }\end{array}$ & 20,000 & 8,000 & 2,500 & 2,500 & 2,500 & 20,000 \\
\hline $\begin{array}{l}\text { Residual Value } \\
\text { at } 2050(\$)\end{array}$ & 12,000 & \multicolumn{4}{|l|}{15,000} & 55,000 \\
\hline TPWC (\$) & 43,740 & \multicolumn{4}{|l|}{28,194} & 50,952 \\
\hline
\end{tabular}


Based on the LCCA results, Alternative 2 is the optimal M\&R strategy with the minimum cost.

\subsubsection{Environmental Impacts}

The cradle-to-cradle model first proposed in Chapter 6, is employed to calculate the GHG emission and energy consumption during the analysis period (Table 19). The landfill costs of the three alternatives are assumed to be the same $(\$ 2,000)$. The optional environmental impacts are shown in

Table 20.

Table 19 Cradle-to-cradle LCA Model for SSP structures.

\begin{tabular}{|l|l|l|l|l|}
\hline \multirow{2}{*}{ Process } & Note & Sector No. & Total Energy & Total \\
\cline { 2 - 5 } & ElO-LCA & $\mathrm{MJ} / \$ 10,000$ & $\mathrm{MTCO}_{2} \mathrm{E} / \$ 10,000$ \\
\hline $\begin{array}{l}\text { Professional } \\
\text { and technical } \\
\text { services }\end{array}$ & $\begin{array}{l}\text { Initial design \& } \\
\text { condition } \\
\text { evaluation }\end{array}$ & 541300 & $0.64 \times 10^{4}$ & 0.36 \\
\hline \multirow{2}{*}{ Materials } & $\begin{array}{l}\text { Steel } \\
\text { manufacturing }\end{array}$ & 331110 & $30.1 \times 10^{4}$ & 25.9 \\
\cline { 2 - 5 } & Painting \& coating & 325510 & $1.02 \times 10^{4}$ & 0.31 \\
\hline Transportation & $\begin{array}{l}\text { Truck } \\
\text { Transportation }\end{array}$ & 484000 & $13.4 \times 10^{4}$ & 9.86 \\
\hline \multirow{2}{*}{ Construction } & Initial construction & 230103 & $3.16 \times 10^{4}$ & 2.00 \\
\cline { 2 - 5 } & M\&R & 230301 & $3.80 \times 10^{4}$ & 2.43 \\
\hline \multirow{2}{*}{$\begin{array}{l}\text { Landfill } \\
\text { avoidance }\end{array}$} & $\begin{array}{l}\text { Recycling, waste } \\
\text { management } \\
\text { avoidance }\end{array}$ & 562000 & $\left(1.42 \times 10^{4}\right)$ & $(22.9)$ \\
\hline
\end{tabular}

Table 20. Environmental impacts of the three alternatives.

\begin{tabular}{|l|l|l|l|l|r|l|}
\hline \multirow{2}{*}{ Process } & \multicolumn{2}{|c|}{ Alternative 1 } & \multicolumn{2}{c|}{ Alternative 2 } & \multicolumn{2}{c|}{ Alternative 3 } \\
\cline { 2 - 7 } & $\begin{array}{l}\text { GHG } \\
\text { (MTCO2E) }\end{array}$ & $\begin{array}{l}\text { Energy } \\
\text { (MJ) }\end{array}$ & $\begin{array}{l}\text { GHG } \\
\text { (MTCO2E) }\end{array}$ & $\begin{array}{l}\text { Energy } \\
\text { (MJ) }\end{array}$ & $\begin{array}{l}\text { GHG } \\
\text { (MTCO2E) }\end{array}$ & $\begin{array}{l}\text { Energy( } \\
\text { MJ) }\end{array}$ \\
\hline $\begin{array}{l}\text { Professional and } \\
\text { technical services }\end{array}$ & 0.564 & 10029 & 0.160 & 2844 & 0.705 & 12536 \\
\hline Materials & 0.194 & 6394 & 0.257 & 8460 & 40.587 & 471683 \\
\hline Transportation & 7.726 & $\begin{array}{l}10499 \\
3\end{array}$ & 8.545 & 116132 & 7.726 & 104993 \\
\hline Construction & 3.808 & 59548 & 2.686 & 42011 & 3.808 & 59548 \\
\hline Landfill avoidance & -4.580 & -2840 & -4.580 & -2840 & -4.580 & -2840 \\
\hline Total & 7.712 & $\begin{array}{l}17812 \\
3\end{array}$ & 7.069 & 166606 & 48.245 & 645920 \\
\hline
\end{tabular}


Based on the environmental impacts, Alternative 2 is still the optimal $M \& R$ strategy. If the three $M \& R$ alternatives are ranked according to the economic and environmental impacts, the ranking is summarized in Table 21. In Table 21, Alternative 1 and Alternative 3 represent the least and most severe impacts respectively. Table 21 clearly shows Alternative 2 is the optimal M\&R alternative with and without LCA environmental impacts.

Table 21. Ranking of the three M\&R alternatives.

\begin{tabular}{|l|c|c|c|}
\hline $\begin{array}{l}\text { M\&R } \\
\text { Alternative }\end{array}$ & $\begin{array}{l}\text { Economic } \\
\text { Ranking }\end{array}$ & $\begin{array}{l}\text { Environmental } \\
\text { Ranking }\end{array}$ & Average Ranking \\
\hline Alternative 1 & 2 & 2 & 2 \\
\hline Alternative 2 & 1 & 1 & 1 \\
\hline Alternative 3 & 3 & 3 & 3 \\
\hline
\end{tabular}




\section{Conclusion and Recommendations for Further Study}

\subsection{Conclusion}

This study proposed a sustainable approach for optimal SSP structure maintenance and repair. This approach couples field inspections and CI methodology with risk and reliability assessments to quantify the life-cycle cost and environmental LCA impacts of various M\&R alternatives. Different failure limit states of SSP structures were analyzed to develop the timedependent reliability index profile. In this study, synthetic parameters were used to develop the profile. The time-dependent reliability index profile was used to determine the M\&R strategies over the lifetime of a SSP structure. The optimal M\&R solution can be selected by comparing the economic and environmental impacts of different M\&R scenarios through life cycle assessment. The present-worth method was adopted in the LCCA. An environmental cradle-to-cradle model was created to evaluate the GHG emission and energy consumption from the SSP structures under different M\&R strategies.

Whether the structure should be repaired or replaced will then be determined by the economic and environmental impacts of M\&R alternatives. In other words, if it is too costly to repair, or if the M\&R alternative is emitting too much GHG, or if it is consuming too much energy over the analysis period, the structure would need to be replaced.

The analysis described in this report should be looked at as an example of what is involved in evaluating the M\&R alternatives for relatively simple (such as SSP) structures. It provides an opportunity to look at a detailed example and assess whether the level of effort is too great. Likewise, it also provides an opportunity to look at whether it provides sufficient information for decision making or an excessive level of information on the merits of the M\&R alternatives, or even the right information.

\subsection{Recommendations}

Using the CI, reliability, preliminary LCCA, environmental LCA, and individual judgment, an engineer can make a preliminary selection of a 
maintenance plan for the sheet pile structure. However, there are some limitations to this analysis. Recommendations are made here for the future study.

- The reliability index or the probability of failure is utilized to indicate the condition of the SSP structure. The examples in Chapter 6 calculate the probability of failure at a particular point in time. It is understood that USACE determines its Civil Works repair and rehabilitation priorities based on the annual probability of failure of its infrastructure. One way to determine this annual probability is using the annual mean value and standard deviation of the loads and resistances to calculate the annual reliability index or probability of failure. For example, in Section 6.1, $\mathrm{M}_{\max }$ is assumed to be a deterministic variable to simplify the calculation. Therefore, the probability of failure was calculated at a particular point (when it was inspected). However, it is a random variable depending on the water elevation, top to dredge distance, soil properties, and surcharge load at the section of a SSP retaining wall being evaluated. Based on the annual inventory data, the distribution of $\mathrm{M}_{\text {max }}$ can be determined, which can be used to calculate the annual reliability of index or the probability of failure.

- The uncertainties should be developed for the construction of accurate time-dependent reliability index profile through the analysis of actual inventory and maintenance data. This is proposed in the Appendix A. For SSP structures, these uncertainties include (a) improvement in reliability resulting from M\&R; (b) correlation of condition and reliability for different distresses; (c) improvement in reliability resulting from $M \& R ;(d)$ duration of maintenance effect on structural reliability; (e) reliability deterioration rate without $M \& R$; ( $f$ ) reliability deterioration rate during maintenance effect; and ( $\mathrm{g}$ ) time of re-application of maintenance.

- A field inspection should be completed periodically to build the structural health inventory including the random variables data used in the reliability analysis (e.g., water elevation, top-to-dredge distance, soil properties, surcharge load, dents, cracks, corrosion levels, etc.). USACE districts generally have 5-yr periodic inspection reports with general descriptions, photographs, and maybe more details on some issues of particular concern. But the CI inspection method is recommended to be employed. The CI field inspection records all the random variables data needed for the reliability analysis, and the CI method provides the problem list and $M \& R$ alternative list. 
- The life-cycle analysis should consider as many feasible alternatives as possible, within the constraints of time and other resources.

- The environmental LCA model requires a benchmark analysis to check its accuracy; the EIO-LCA method was used to create the LCA model for the SSP structures. Models developed by other methods might be different but should be comparable to the EIO-LCA model developed in this study.

- The analysis provides support for a management decision but alone, it does not represent a decision.

- Based on the results of this project, development of a corresponding computer algorithm should be considered, with the updated life-cycle analysis module for the economic and environmental analysis.

In the last 10 years, there has been much progress in how risk-based approaches are used to assess deficiencies and risk-mitigation actions within the USACE Civil Works community. The most notable application has been within dam safety.* This particular USACE dam safety application, applications such as those presented in this report, and other risk-based approaches all have different levels of technical rigor; therefore, it is important to also consider the availability and quality of the performance (failure) data on which each of these approaches are based, the effort required to collect more data, and the extent to which the needed data can be collected.

While the technical rigor of the method is important, it should not be judged in isolation. It is also important to consider the quality of associated data that can be reasonably expected to be used both today as well as in the future when more data is collected. The quality of an analysis is dependent on both the risk analysis method and the adequacy of the associated data. An inferior method can produce superior results if the data is better. Far more effort and thought has gone into developing the methodologies than the collection of the data. More thought needs to go into how this data is obtained and practices set up to collect this data. Once data is being collected, the data and practices need to be reviewed and evaluated.

\footnotetext{
* While not publicly available, risk assessment information and more is available to some readers at the following USACE Knowledge Management Environment website:

https://kme.usace.army.mil/Centers/IWR/RMC/External/Method/default.aspx?RootFolder=\%2fCenter s\%2fIWR\%2fRMC\%2fExternal\%2fMethod\%2fBPM\%2fVersion\%202\%2e0\%2fManual\%28pdf\%29\&Folde $\underline{\text { rCTID }=\& V i e w=\% 7 b 16208 C 33 \% 2 d 9 E F 9 \% 2 d 47 D 0 \% 2 d 98 E 9 \% 2 d 4 D 372 E 7 F 9745 \% 7 d . ~}$
} 


\section{References}

AIJ (Architectural Institute of J apan). 1993. The English Edition of Principal Guide for Service Life Planning of Buildings, J apan.

Albrecht, P. and Naeemi, A.H. 1984. Performance of Weathering Steel in Bridges. NCHRP report. Washington D.C.: Transportation Research Board.

ASCE (American Society of Civil Engineers). 2009. Report Card for America's Infrastructure. Available at http://www.infrastructurereportcard.org/sites/default/files/RC2009_full_report.pdf.

Asker, Y. I. 1988. "Safety Rating of Steel Sheet Pile Structures.” M.S. thesis. Ames, IA: Iowa State University.

ASTM. 1990. Building Maintenance, Repair, and Replacement Database for Life-cycle Cost Analysis: A User's Guide to the Computer Program. Philadelphia, PA: American Society for Testing and Materials

British Standards Institution (BSI). 1992. Guide to Durability of Buildings and Building Elements, Products and Components. BS 7543:1992. London, U.K..

Canadian Standards Association (CSA). 1994. "Guideline on Durability in Buildings.” CSA S478, Draft 9.

Carr, R. 2000. “Construction Congestion Cost (CO3) Basic Model.” J ournal of Construction Engineering and Management 126(2): 105-113.

Chan A., G.Keoleian, and E.Gabler. 2008. "Evaluation of Life-cycle Cost Analysis Practices Used by the Michigan Department of Transportation," J ournal of Transportation Engineering, ASCE. 134(6): 236- 245.

Choate, P., and S.Walter. 1981. America in Ruins: The Decaying Infrastructure. Durham, NC: Duke Press.

CMDGI (Carnegie Mellon University Green Design Institute). 2010. Economic InputOutput Life Cycle Assessment (EIO-LCA), US 2002 Industry Benchmark model [Internet], Available from: <http:// www.eiolca.net

Das, P.C. 2000. "Reliability Based Bridge Management Procedures.” In Bridge Management Four, edited by M.J . Ryall, G.A. R. Parke, and J .FE. Hardings.

Delatte, N. J . 2009. Beyond Failure: Forensic Case Studies for Civil Engineers. Reston, VA: ASCE Press.

Delucchi, M., and D.McCubbin. 1996. "The Social Cost of the Health Effects of Motor Vehicle Air Pollution: Report \#11 in the series The Annualized Social Cost of Motor Vehicle Use in the United States, Based on 1990-1991 Data. Rep. No. UCD-ITS-RR-96-3(11). Davis, CA: Institute of Transportation Studies, University of California. 
DOI (US Department of the Interior). 1983. "Economican Environmental Principles and Guidelines for Water and Related Land Resources Implementation Studies." Report PB 84-199405. Washington, DC: U.S. Water Resources, Department of the Interior.

ERES Consultants. 2003. "Neutral third party Ohio pavement selection process analysis." Report Prepared for Ohio DOT Pavement Selection Advisory Council, Champaign.

Estes A.C. and Frangopol, D.M. 1996. "Life-Cycle Reliability-Based Optimal Repair Planning for Highway Bridges: A Case Study.” In Structural Reliability in Bridge Engineering, edited by D.M. Frangopol and G. Hearn. New York: McGraw-Hill, 54-59.

Estes A.C., D.M. Frangopol, and S. D. Foltz. 2003. “Updating Reliability of Steel Miter Gates On Locks and Dams Using Visual Inspection Results". J ournal of Engineering Structures 26: 319-333.

Federal Highway Administration (FHWA). 1998. "Life-cycle Cost Analysis in Pavement Design.” HNG-42/ 9-98(5M)QE. Washington, DC: FHWA. . 2002. “Life-cycle Cost Analysis Primer.” FHWA-IF-02-047. Washington, DC: FHWA . 2003a. "Economic Analysis Primer." FHWA IF-03-032. Washington, DC: FHWA.

Feld, J ., and K.L. Carper. 1997. Construction Failure (2nd ed.). New York, NY: J ohn Wiley \&Sons.

Foltz, S., P. Howdyshell, , and D. McKay. 2001. Understanding Condition Indexes: Current Status and Future Opportunities. ERDC/ CERL SR-01-12. Champaign, IL: U.S. Army Engineer Research and Development Center.

Foltz, S. and D. McKay. 2008. Condition Assessment Aspects of an AssetManagement Program. ERDC/ CERL SR-08-1. Champaign, IL: U.S. Army Engineer Research and Development Center.

Frangopol, D.M., K. Lin, and A.C. Estes. 1997. "Life Cycle Cost Design of Deteriorating Structures.” J ournal of Structural Engineering ASCE, 123 (10): 1390-1401.

Frangopol, D.M., and P.C. Das. 1999. “Management of Bridge Stocks Based on Future Reliability and Maintenance Costs." In Current and Future Trends in Bridge Design, Construction, and Maintenance, edited by P.C. Das, D. M. Frangopol, and A.S. Nowak. London: The Institution of Civil Engineers, Thomas Telford, 4558.

Frangopol, D.M., and H. Furuta. 2001. "Life Cycle Cost Analysis and Design of Civil Infrastructure Systems." American Society of Civil Engineers.

Frangopol, D.M., J .S. Kong, and E.S.Gharaibeh. 2001. "Reliability-based Life-cycle Management of Highway Bridges." J ournal of Computing in Civil Engineering ASCE. 15(1): 27-34.

Frohnsdorff, G. 1996. “Predicting the Service Lives of Materials of Construction.” In Proceedings of Fourth Materials Engineering Congress, Washington, DC. 38-53. 
Gerke, R., R. Dewald, and R. Gerbrandt. 1998. "Use of Highway Network Level Data for a Project Level Life Cycle Analysis". In Proceedings of the 1998 Transportation Conference. Ames, Iowa: Iowa State Univ., 135-138.

Golabi, K., P. Thompson, and W.A. Hyman. 1992. Pontis Technical Manual, prepared for the Federal Highway Administration.

Greimann, L.F., and J.H. Stecker. 1989. User's Manual: Inspection and Rating of Steel Sheet Pile Structures. Technical Report REMR-OM-3. Springfield, VA: NTIS U.S. Army Corps of Engineers.

Greimann, L.F., and J.H. Stecker. 1990a. "Inspection and Rating of Steel Sheet Pile.” J ournal of Performance of Constructed Facilities, ASCE: 4(3), August.

Greimann, L.F., and J.H. Stecker. 1990b. "Maintenance and Repair of Steel Sheet Pile Structures." Technical Report REMR-OM-09. Washington, DC: U.S. Army Corps of Engineers.

Greimann, L.F., J.H. Stecker, and K.L. Rens. 1990a. Inspection and Rating of Miter Lock Gates. Technical Report REMR-OM-07. Washington, DC: U.S. Army Corps of Engineers.

. 1990b. REMR Management Systems-navigation Structures, Management System for Miter Lock Gates. Technical Report REMR-OM-08. Washington, DC: U.S. Army Corps of Engineers.

Greimann, L.F., J .H. Stecker, A.M. Kao, and K.L. Rens. 1991. “Inspection and Rating of Miter Lock Gates.” J ournal of Performance of Constructed Facilities ASCE , 5(4): 226-238.

Greimann, L.F., J.H. Stecker, and K.L. Rens. 1993. REMR Management Systems, Condition Rating Procedures for Sector Gates. REMR-OM-13. Champaign, IL: U.S. Army Construction Engineering Research Laboratory.

Greimann, L.F., J.H. Stecker, K.L. Rens, and M. Nop. 1994. REMR Management Systems Navigation Structures, User's Manual Version 2.0. REMR-OM-15. Champaign, IL: U.S. Army Construction Engineering Research Laboratory.

Greimann, L.F., J .H. Stecker, and K.L.Rens. 1996. “Condition Assessment of Navigation Lock and Dam Structures." Presentation at the Semisesquicentennial Transportation Conference, Ames, Iowa.

Greimann, L.F., J .H. Stecker, K.L. Rens, and D. McKay. 1997. “Condition Assessment of Navigation Lock and Dam Structures." In Proceedings, Infrastructure Condition Assessment: Art, Science, and Practice. Boston, MA, 385-394.

Grigg, N. S. 1988. Infrastructure Engineering and Management. New York: J ohn Wiley and Sons.

Haas R., Hudson, W.R., and Zaniewski, J .P. 1994. Modern Pavement Management. Malabar, Fla: Krieger Publishing Company.

Hasofer, A.M., and N.C. Lind. 1974. "Exact and Invariant Second-Moment Code Format." J ournal of the Engineering Mechanics Division ASCE. 100(1): 111-121. 
Highway Research Board. 1962. "The AASHO Road Test: Report 5-Pavement Report." HRB Special Report 61-E. Washington DC: National Research Council.

Hudson, S. W., Carmichael III, R.F., Moser, L.O., Hudson, W.R., and Wilkes, W.J . (1987). "Bridge Management Systems." NCHRP Report 3000. National Cooperative Highway Research Program, Transportation Research Board, National Research Council. Washington D.C.

Hudson, W.R., R. Haas, and W.Uddin. 1997. Infrastructure Management - Integrating Design, Construction, Maintenance, Rehabilitation, and Renovation. New York: MoGraw-Hill.

HR Wallingford. 2011. "Carbon Accounting of Engineering Projects.” Innovation \& Research Focus. August, Issue \#86. Also available online at http:// www.innovationandresearchfocus.org.uk/articles/html/issue 86/carbo n accounting of engineering projects.asp.

ISO (International Organization for Standardization) 2006. ISO 14044: 2006. Environmental management -- Life cycle assessment -- Requirements and guidelines. Geneva, Switzerland: ISO.

Jiang, X., and K.L. Rens. 2010a. "Bridge Health Index for the City and County of Denver, Colorado I: Current Methodology." J ournal of Performance of Constructed Facilities, ASCE, 24 (580). doi:10.1061/(ASCE)CF.1943-5509.0000128.

. 2010b. "Bridge Health Index for the City and County of Denver, Colorado II: Denver Bridge Health Index." J ournal of Performance of Constructed Facilities, ASCE, 24 (580); doi:10.1061/(ASCE)CF.1943-5509.0000128.

Kong, J .S., and Frangopol, D.M. (2004). “Cost-Reliability Interaction in Life-cycle Cost Optimization of Deteriorating Structures." J ournal of Structural Engineering ASCE, 130 (11): 1704-1712.

Leonards, G. 1982. “Investigation of Failures.” J ournal of Geotechnical Engineering Division, American Society of Civil Engineers.

Liu, M., and D.M. Frangopol. 2006. “Optimizing Bridge Network Maintenance Management under Uncertainty with Conflicting Criteria: Life-cycle Maintenance, Failure, and User Costs." J ournal of Structural Engineering, ASCE, 132 (11): 1835-1845.

Liu, R. 2010. "Examining into the Influence of Post-Mercury-Control on Fly Ash Concrete." Doctoral dissertation. Denver, CO: University of Colorado.

Lounis, Z., and M.S. Mirza. 2001. “Reliability-Based Service Life Prediction of Deteriorating Concrete Structures.” In Vol.1, Proceedings of $3^{\text {rd }}$ Int. Conf. on Concrete under Severe Conditions held in Vancouver, BC. p 965-972.

McAllister, T. P., and B.R. Ellingwood. 2000. "Reliability-Based Condition Assessment of Welded Steel Miter Gate Structures." In Proceedings of the 8th ASCE J oint Specialty Conference on Probabilistic Mechanics and Structural Reliability held in Notre Dame, IN. 
McAllister, T.P., and B. R. Ellingwood. 2002. "Reliability-Based Condition Assessment of Welded Steel Miter Gates with Fatigue Damage." ICOSSAR 01. In Proceedings of the $8^{\text {th }}$ International Conference on Structural Safety and Reliability, Newport Beach, CA: Sweets \& Zeitlinger Publishers.

McKay, D.T., K.L. Rens, L.F. Greimann, and J.H. Stecker. 1999. “Condition Index Assessment for U.S. Army Corps of Engineers Civil Works." J ournal of Infrastructure Systems, 5(2): 52-60.

Mencken , H.L 1949. A Mencken Chrestomathy: His Own Selection of His Choicest Writing. New York: Vintage Books

Mori, Y., and B. Ellingwood. 1993. "Reliability-Based Service Life Assessment of Aging Concrete Structures." ASCE J ournal of Structural Engineering 119(5): 16001621.

National Science Foundation. 1994. Civil Infrastructure Systems Research. Washington, DC.

NCHRP (National Cooperative Highway Research Program). 2003. "Bridge Life-Cycle Cost Analysis." NCHRP Report 483, Washington, DC: Transportation Research Board.

NJ DOT (New J ersey Dept. of Transportation). 1999. Road User Cost Manual. Trenton, NJ : NJ DOT.

Nilson, A.H, and G. Winter. 1991. Design of Concrete Structures. New York: McGrawHill.

Nowak, A.S., and K.R. Collins. 2000. Reliability of Structures. NewYork: McGraw-Hill.

O’Day, D. K. 1984. “Aging Water Supply Systems: Repair or Replace.” In InfrastructureMaintenance and Repair of Public Works Annals of the New York Academy of Science, 431: 241-258.

Ozbay, K., D. J awad, N. A. Parker, , and S. Hussain. 2004. Life Cycle Cost Analysis: State-of-the-Practice vs. State-of-the-Art. Rutgers University and the City College of the City University. New York: New York Press.

Padula, J., C. Chasten, R. Mosher, P. Mlaker, J. Brokaw, and W. Stough. 1994. “Reliability Analysis of Hydraulic Steel Structures with Fatigue and Corrosion Degradation." Technical Report ITL-94-3. Washington, DC: U.S. Army Corps of Engineers.

Paterson, W. D. O., and B. Attoh-Okine. 1992. "Simplified Models of Paved Road Deterioration Based on HDM-III.” Transportation Research Record 1344. Washington, DC:Transportation Research Board.

Petcherdchoo, A., L.A.C. Neves, , and D.M. Frangopol. 2008. "Optimizing Lifetime Condition and Reliability of Deteriorating Structures with Emphasis on Bridges." J ournal of Structural Engineering, ASCE, 134(4): 544-552.

REMR Research Program. http:// www.wes.army.mil/ REMR/ remr.html 
Rens, K.L. 1989. “Maintenance Management System for Miter Lock Gates.” M.S. thesis. Ames, IA: Iowa State University.

Rens, K.L., L.F. Greimann, J .H. and Stecker. 1993. "Condition Assessment Procedures for Sector Gates." In Fifth International Conference on Structural Faults and Repair held in Scotland, UK. p 3-9.

Rens, K.L., L.G. Greimann, J.H. Stecker, and A.D. Bondoc. 1994. "Sector Gate Case Study: Condition Assessment of Chicago Harbor Lock." In Proceedings of 48 th Mechanical Failures Prevention Meeting held in Wakefield, MA. p. 347-358.

Reiner, Mark B. 2007. “Technology, Environment, Resource and Policy Assessment of Sustainable Concrete in Urban Infrastructure." Doctoral dissertation. University of Colorado at Denver and Health Sciences Center.

Shahin, M.Y., D.M. Bailey,and D.E. Brotherson. 1987. Membrane and Flashing Condition Indexes for Built-up Roofs. Vol. II, Inspection and Distress Manual. Technical Report M87/ 13, Vol II/ADA190368. Champaign, IL: U.S. Army Construction Engineering Research Laboratories.

Shahin, M.Y., and S.D. Kohn. 1981. Pavement Maintenance Management for Roads and Parking Lots. Tech. Rep. M294/ 13, Vol II/ADA1120296. Champaign, IL: U.S. Army Construction Engineering Research Laboratories.

Stecker, J .H., L.F. Greimann, and K.L. Rens. 1993. Chicago Harbor Lock Inspection. Technical Report submitted to U.S. Army Corps of Engineers, Chicago District.

Stecker, J .H., L.F. Greimann, S. Mellema, , and K.L. Rens. 1997. REMR Management Systems: Navigation and Flood Control Structures, Condition Rating Procedures for Lock and Dam Operating Equipment. REMR-OM-19. Champaign, IL: U.S. Army Construction Engineering Research Laboratory.

Steinthal, B. G. 1984. "Infrastructure Maintenance Strategies-Governmental Choices and Decision Methodologies." In Infrastructure-Maintenance and Repair of Public Works, Annals of the New York Academy of Sciences, Vol. 431: 139-154.

TRB (Transportation Research Board). 1985. Life Cycle Cost Analysis for Pavements. Synthesis of Highway Practice No. 122. Washington, DC: National Cooperative Highway Research Program, National Research Council.

Thoft-Christensen, P. and J ensen, F.M. and Middleton, C.R. and Blackmore, A. (1996) Assessment of the Reliability of Concrete Slab Bridges. In: The 7th Reliability and Optimization of Structural Systems, presented at the seventh Working Conference on Reliability and Optimization of Structural Systems held at Boulder, Colorado, USA, on April 2-4, 1996. The Working Conference was organized by the IFIP (International Federation for Information Processing) Working Group 7.5 of Technical Committee 7.

Thomasson, R.O. 1982. "In-Place Sewer Reconstruction Proves Cost-Effective.” American City and County . 97 (2): 31-32

Uddin, W. 1993. “Application of User Cost and Benefit Analysis for Pavement Management and Transportation Planning." In Proceedings, 4R Conference and Road Show, Philadelphia, PA, pp. 24-27. 
Uddin, W., R.F. Carmichael III, and W.R.Hudson. 1987. "A Methodology for Life-cycle Cost Analysis of Pavements Using Microcomputer." In Proceedings, 6 ${ }^{\text {th }}$ International Conference, Structural Design of Asphalt Pavements, Ann Arbor, MI, Vol. 1.

USACE. 1939. US Engineer Office. "Report on Corrosion Test of Metals in the Mississippi River." Washington, DC: War Department, Corps of Engineers, US Army.

USACE. 1997. "Reliability Analysis of Miter Gates Lock and Dam 12.” Rock Island, IL: USACE Rock Island District.

USACE. 2002. “Lock 27 Major Rehabilitation Report, Main Chamber Miter Gate Reliability Analysis." St. Louis, MO: USACE St. Louis District.

U.S. Army. 1986. Economic Studies for Military Construction Design-Applications. TM 5-802-1. Washington, DC: Department of the Army.

U.S. Government. 2001. Code of Federal Regulations: Title 23, Chapter I, Part 627-Value Engineering. Washington, DC: U.S. Government Printing Office.

U.S. Steel Corporation. 1979. USS Steel Sheet Piling Handbook. Pittsburgh, PA: United States Steel Corporation.

Watantada, Harral, Paterson, Bhandan, and Tsunkawa. 1987. The Highway Design and Maintenance Standards Model, Vols. 1 and 2. Baltimore, MD: J ohns Hopkins University Press.

Wikipedia. 2010. “Failure.” Retrieved on J une 25, 2010. http:// en.wikipedia.org/ wiki/ Failure

Wikipedia. 2010. “Infrastructure" Retrieved on J uly 8, 2010. http:// en.wikipedia.org/ wiki/Infrastructure

Wilde, W., S. Waalkes, and R.Harrison. 2001. Life Cycle Cost Analysis of Portland Cement Concrete Pavements. SWUTC/ 01/ 167205-1. Austin, TX: Center for Transportation Research. Univ. of Texas at Austin.

Zaniewski, J . P., B. C. Butler, G. Cunningham, G. E. Elkins, M. S. Paggi, and R. Machemehl. 1982. Vehicle Operating Costs, Field Consumption and Pavement Type and Condition Factors. Final Report. Washington, DC: Federal Highway Administration. 


\title{
Appendix A: Proposal for Uncertainties Development for Time-Dependent Reliability Index Profiles
}

\author{
A Sustainable Approach for Optimal Steel Sheet Pipe Structure \\ Assessment, Maintenance, and Rehabilitation (Phase II)
}

\section{Research Objective}

The proposed M\&R procedure for SSP structures is able to estimate the condition of a deteriorated structure. The selection of the optimal M\&R alternative depends on the time-dependent reliability index profile. To construct the reliable curve depicting condition levels versus time, the statistical uncertainties need to be developed. For SSP structures, these uncertainties include:

- constructed and current reliability,

- correlation of condition and reliability for different distresses,

- improvement in reliability resulting from M\&R,

- duration of maintenance effect on structural reliability,

- reliability deterioration rate without M\&R,

- reliability of deterioration rate during maintenance effect, and

- time of re-application of maintenance.

All these uncertainties can be determined from a statistical analysis for SSP structures or similar hydraulic steel structure inspection data and $M \& R$ records. The overall goal of this project is to develop these uncertainties for time-dependent reliability index profiles and to apply the improved M\&R procedure to identify the optimal alternative for real deteriorated SSP structures. In other words, the goal is to develop accurate timedependent reliability index profile of a SSP structure with M\&R.

\section{Research Plan}

The proposed research includes four tasks: 
- Task I: Field inspection data and M\&R records review;

- Task II: Statistical analysis for the uncertainties;

- Task III: Evaluating example SSP structures using the improved M\&R procedure with real data;

- Task IV: Determine the repair and rehabilitation priority among the example SSP structures; and

- Task V: Final Technical Report writing with ultimate dissemination into ASCE J ournals such as: Performance of Constructed Facilities, Infrastructure Systems, and the like.

In Task I, several USACE Districts (e.g., Detroit District, Chicago District, Rock Island District, etc.) will be contacted to obtain historical records for SSP structures. These data will be organized and used for the calculation of the reliability index, statistical analyses, and evaluations of deteriorated structures. The data needed include:

- Original structural design documents

- Initial construction date

- Expected lifetime

- SSP structure field inspection data

- Construction and M\&R records:

$>$ M\&R options

$\checkmark$ Corrective (e.g., replace a wall, replace a single sheet etc.)

$\checkmark$ Preventive (e.g., add protective coating, fix holes, etc.)

M\&R date

$>$ Costs

Initial Design and Construction Costs:

$\checkmark$ Professional and technical services; 
$\checkmark$ Materials (steel, painting etc);

$\checkmark$ Transportation; and

$\checkmark \quad$ Initial construction

M\&R Costs:

$\checkmark$ Professional and technical services;

$\checkmark$ Materials;

$\checkmark$ Transportation; and

$\checkmark$ M\&R construction.

If the field inspection associated with the CI methodology has never been completed in some USACE districts, their own similar field inspection data will be requested. Those data will be used as much as possible to calculate the reliability index of the structure at the time when it was inspected, which will be used in Task III to identify the optimal M\&R alternatives for those deteriorated structures.

In Task II, the statistical analyses of acquired data will be completed to calculate the uncertainties for the time-dependent reliability index profile. The distribution, mean value, and standard deviation of said parameters will be derived in Task II. The accuracy of these parameters depends on the quality of the data obtained from Task I. After calculating the uncertainties, the optimal maintenance and repair intervals can be determined and the time-dependent reliability index profiles of various M\&R alternatives can be developed.

Task III will evaluate actual SSP structures with real field data provided by USACE districts (or collected from the field inspection trip; however, any field trip would add substantial expense) by using the improved M\&R procedure for SSP structures. The optimal M\&R action will be identified for those deteriorated structures that are inspected. 
Task IV will provide an approach to determine the repair and rehabilitation priorities for SSP structures. The annual probability of failure of the example SSP structures will be analyzed in Task III. The failure consequence (e.g., failure cost) will be determined for those structures in this task. The current expected failure cost is the product of the annual probability of failure and the structural failure cost. While structures with the highest current failure probabilities and expected failure costs typically receive closer analysis, the goal is to prioritize repair and rehabilitation based on the cost-benefit ratio.

Task $\mathbf{V}$ is final report writing and preparation of dissemination into refereed journals.

The draft report for each task will be submitted to HQUSACE upon completion. The final report will address all of the comments from the draft reports and will be submitted in both digital and hardcopy format to USACE at the conclusion of the study.

\section{Work-time schedule}

The proposed schedule for this study is presented in Table A-1. This chart provides information regarding when each phase is to begin and to be completed. The proposed research is estimated to require approximately 9 months to complete.

Table A-1. Work-time schedule.

\begin{tabular}{|c|c|c|c|c|c|c|c|c|c|c|c|c|}
\hline Month & 1 & 2 & 3 & 4 & 5 & 6 & 7 & 8 & 9 & 10 & 11 & 12 \\
\hline Task I & & & & & & & & & & & & \\
\hline Task II & & & & & & & & & & & & \\
\hline Task III & & & & & & & & & & & & \\
\hline Task IV & & & & & & & & & & & & \\
\hline Task V & & & & & & & & & & & & \\
\hline
\end{tabular}

\section{Anticipated benefits and research outcomes}

This study will provide necessary information to complete the improved $M \& R$ procedure for SSP infrastructure. Using the guideline, specific USACE districts will gain improved capabilities to monitor the current conditions of SSP infrastructure and to identify the prioritized structures that will require sustainable M\&R. In addition, this will help decision 
makers to take the correct actions to reduce the cost and carbon footprint based on the proposed rehabilitation strategy for the deteriorated SSP structures. Furthermore, the methodology developed for this relatively simple type of structure can be extended to more complex and critical structural systems such as gates, valves, concrete walls, operating equipment, and other components making up locks, dams, and related navigation facilities. It can also be expanded to include pavements, buildings, and other type of infrastructure. 


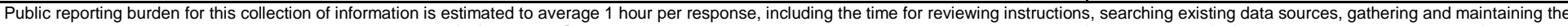

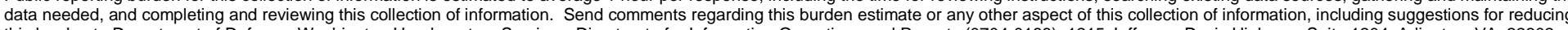

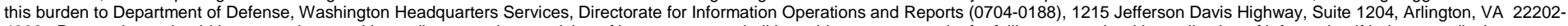

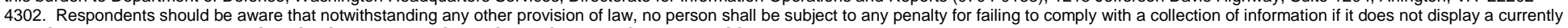
valid OMB control number. PLEASE DO NOT RETURN YOUR FORM TO THE ABOVE ADDRESS.

\begin{tabular}{|l|l|l|l} 
1. REPORT DATE (DD-MM-YYYY) & 2. REPORT TYPE & 3. DATES COVERED (FrOm - To)
\end{tabular}

\section{TITLE AND SUBTITLE}

Final Technical Report

A Sustainable Approach for Optimal Steel Sheet Pile Structure Assessment, Maintenance, and Rehabilitation

\section{5a. CONTRACT NUMBER}

5b. GRANT NUMBER

\section{AUTHOR(S)}

Kevin L. Rens, Rui Liu, and Stuart Foltz

5d. PROJECT NUMBER

W9132T-10-P-0082

5e. TASK NUMBER

5f. WORK UNIT NUMBER

8. PERFORMING ORGANIZATION REPORT NUMBER

ERDC/CERL TR-11-34

\section{Construction Engineering Research Laboratory (CERL)}

U.S. Army Engineer Research and Development Center (ERDC)

PO Box 9005

Champaign, IL 61826-9005

\section{SPONSORING I MONITORING AGENCY NAME(S) AND ADDRESS(ES)}

Headquarters

US Army Corps of Engineers

441 G Street NW

Washington DC 20314-1000

10. SPONSOR/MONITOR'S ACRONYM(S)

USACE

11. SPONSOR/MONITOR'S REPORT NUM$\operatorname{BER}(\mathrm{S})$

\section{DISTRIBUTION / AVAILABILITY STATEMENT}

Approved for public release; distribution is unlimited.

\section{SUPPLEMENTARY NOTES}

\section{ABSTRACT}

The U.S. Army Corps of Engineers (USACE) has constructed a wide variety of civil works structures. Due to age and other factors, many of these structures have deteriorated to a point that they need varying levels of maintenance and repair (M\&R). Steel sheet pile (SSP) structures are part of the USACE civilian projects such as lock and dam and other navigation facilities. Failure of a SSP wall or cell can significantly affect the operations of a lock and dam or general river navigation. An improved SSP inspection procedure is proposed, to couple previously developed field inspection condition index (CI) methodology with reliability assessments and to quantify the life-cycle costs and environmental impacts associated with various M\&R scenarios. M\&R strategies over the analysis period are determined through reliability assessment for structures with relatively low CI (structures in CI Zone 2 and Zone 3). The level of failure would then be determined by the life cycle cost analysis (LCCA) and environmental life cycle assessment (LCA) of M\&R alternatives. Using these methodologies, specific USACE districts will gain improved capabilities to monitor the current conditions of SSP infrastructure and to identify the prioritized structures requiring sustainable M\&R.

\section{SUBJECT TERMS}

Civil Works; maintenance and repair; steel sheet pile structures; inspections; condition indexes

\begin{tabular}{l} 
16. SECURITY CLASSIFICATION OF: \\
\hline \begin{tabular}{c|c|c|}
\hline $\begin{array}{c}\text { a. REPORT } \\
\text { Unclassified }\end{array}$ & $\begin{array}{c}\text { b. ABSTRACT } \\
\text { Unclassified }\end{array}$ & $\begin{array}{c}\text { c. THIS PAGE } \\
\text { Unclassified }\end{array}$ \\
\hline
\end{tabular}
\end{tabular}

\begin{tabular}{|c|c|c|} 
17. LIMITATION & $\begin{array}{c}\text { 18. NUMBER } \\
\text { OF ABSTRACT }\end{array}$ & 19 \\
OF PAGES & & \\
\cline { 3 - 3 } & 105 &
\end{tabular}

19a. NAME OF RESPONSIBLE PERSON

19b. TELEPHONE NUMBER (include area code) 